\title{
REVISIÓN DE LAS ESPECIES SUDAMERICANAS DE Gutierrezia (Asteraceae, Astereae, Solidagininae)
}

\author{
Revision of the South American species of GutierRezia \\ (Asteraceae, Astereae, Solidagininae)
}

Francisco Ratto ${ }^{1 *}$ (D) y Adriana Bartoli ${ }^{1}$ (D)

1. Cátedra de Botánica Sistemática, Facultad de Agronomía, Universidad de Buenos Aires, Av. San Martín 4453, C1417DSE Buenos Aires, Argentina.

*ratto@agro.uba.ar

\section{Citar este artículo}

RATTO, F. y A. BARTOLI. 2020. Revisión de las especies sudamericanas de Gutierrezia (Asteraceae, Astereae, Solidagininae). Bol. Soc. Argent. Bot. 55: 411-470.

DOI: https://doi. org/10.31055/1851.2372.v55. n3.28227
Recibido: 17 Abril 2020

Aceptado: 11 Agosto 2020

Publicado: 30 Septiembre 2020

Editor: Franco E. Chiarini (D)

ISSN versión impresa 0373-580X ISSN versión on-line 1851-2372

\section{SUMMARY}

Background and aims: Gutierrezia is an American genus of Asteraceae, tribe Astereae, subtribe Solidagininae. A taxonomic revision of South American species of the genus was carried out, based on morphological data.

M\&M: To pursue our aim, an exhaustive bibliographic review was carried out, materials deposited in the main Herbaria were studied, the type specimens were consulted for nomenclatural purposes and collection trips were made.

Results: In the framework of the revision of the genus Gutierrezia, 3 species and 2 varieties new to the science were described and 2 species were rehabilitated. Eight names were lectotypified and one neotype was designated. We concluded that genus Gutierrezia is composed of 34 species, 17 of which inhabit North America, and 17 species with 2 varieties, here described, in South America.

\section{KEY WORDS}

Asteraceae, Astereae, South America, taxonomy.

\section{RESUMEN}

Introducción y objetivo: Gutierrezia es un género americano de Asteraceae perteneciente a la tribu Astereae y a la subtribu Solidagininae. En el presente trabajo se realizó un estudio taxonómico de las especies del hemisferio sur considerando datos morfológicos.

Materiales y métodos: Para realizarlo se llevó a cabo una exhaustiva revisión bibliográfica, se estudiaron materiales depositados en los principales Herbarios, se consultaron los ejemplares tipo con fines nomenclaturales y se realizaron viajes de colección.

Resultados: En el marco de la revisión del género Gutierrezia, se describieron 3 especies y 2 variedades nuevas para la ciencia., y se rehabilitaron 2 especies. Se lectotipificaron 8 nombres y se designó un neotipo. Se concluye que el género Gutierrezia está compuesto por 34 especies, 17 de las cuales habitan en Norteamérica, y 17 especies con 2 variedades, aquí descriptas, en Sudamérica.

Palabras clave

Asteraceae, Astereae, Sudamérica, taxonomía.

\section{INTRODUCCIÓN}

Lagasca, en 1816, describió el género Gutierrezia, con una sola especie, G. linearifolia. Dos años más tarde, Nuttal (1818), desconociendo el trabajo de Lagasca, describió el género monotípico Brachyris, con la especie B. euthamiae. Fue De Candolle, en 1836, quien realizó el primer estudio integral del género Gutierrezia (como Brachyris Nutt.) con cinco nuevas especies de su autoría (B. californica DC., B. dracunculoides DC., B. microcephala DC., B. neaeana DC. у B. ovatifolia DC.). En 1841 Hooker \& Arnott reconocieron que los géneros Gutierrezia y Brachyris era sinónimos. Varios años más tarde, Shinners (1950, 1951), basándose en caracteres morfológicos como longitud del 
pappus, tamaño de los capítulos y número de flores liguladas transfirió el género Gutierrezia a la sinonimia del género Xanthocephalum Willd. Desde este tratamiento las especies de Gutierrezia recibieron nombres fluctuantes entre ambos géneros. En 1960, Solbrig rehabilitó el género y unos años más tarde el mismo autor realizó una revisión de las especies de California. En 1966, Solbrig efectuó el primer estudio monográfico para las especies de Sudamérica y reconoció 11 especies: G. ameghinoi Speg., G. baccharoides Sch. Bip., G. espinosae Acevedo, G. gayana (Remy) Reiche, G. mandonii (Sch. Bip.) Solbrig, G. neaeana (DC.) Blake, G. repens Griseb., G. resinosa (H. \& A.) Blake, G. ruizlealii Solbrig, G. spathulata (Phil.) Kurtz y $G$. taltalensis Phil. Años más tarde Ruffin (1974) nuevamente consideró a Gutierrezia sinónimo de Xanthocephalum hasta que finalmente Lane (1982), basándose en caracteres tales como forma, longitud y pubescencia de las filarias, presencia de pelos glandulares en el receptáculo, longitud y ancho de las flores liguladas, forma de las anteras, tipo de polen, forma de las ramas del estilo, forma del pappus y de los aquenios, lo rehabilitó y estableció los límites entre ambos géneros. Posteriormente, en 1985, la misma autora publicó la revisión de las especies norteamericanas de Gutierrezia y reconoció 16 especies: G. alamanii A. Gray, G. argyrocarpa Greenman, G. arizonica (A. Gray) M. A. Lane, G. californica (DC.) Torr. \& A. Gray, G. conoidea (Hemsl.) M. A. Lane, G. grandis S. F. Blake, G. microcephala (DC.) A. Gray, G. petradoria (S. L. Welsh \& Goodrich) S. L. Welsh, G. ramulosa (Greene) M. A. Lane, G. sarothrae (Pursh) Britton \& Rusby, G. sericocarpa (A. Gray) M. A. Lane, G. serotina Greene, G. sphaerocephala A. Gray, G. texana (DC.) Torr. \& A. Gray, G. triflora (Rose) M. A. Lane y G. wrightii A. Gray.

Nesom (2006), en su contribución para la Flora de Norteamérica, incluyó una nueva especie para América del Norte, G. pomariensis (S. L. Welsh) S. L. Welsh, la que había sido considerada una variedad de G. sarothrae.

Suh \& Simpson (1990), mediante estudios filogenéticos moleculares con sitios de restricción, demostraron que todas las especies norteamericanas de Gutierrezia (G. alamanii, $G$. bracteata G. californica, G. conoidea, G. grandis,
G. microcephala G. ramulosa, G. sarothrae, $G$. serotina, G. sericocarpa, G. sphaerocephala, $G$. texana, G. triflora, G. wrightii) constituyen un grupo monofilético distante de Xanthocephalum. Dichos autores señalaron además que Gutierrezia, con número básico de cromosomas 4 , era afín a los géneros Amphiachyris (DC.) Nutt. y Thurovia Rose, que constituían su grupo hermano, mientras que Xanthocephalum, con $\mathrm{x}=6$ cromosomas, estaría más próximo a los géneros Grindelia Willd. y Olivaea Sch. Bip.

El objetivo del presente trabajo es resolver la taxonomía del género para Sudamérica basado en el estudio de material tipo, colecciones generales, observaciones a campo para poder realizar descripciones de cada una de las especies y variedades propuestas, confeccionar mapas de distribución y proporcionar iconografía en los casos necesarios.

Actualmente el género se encuentra representado por ca. 28 especies (Fig. 1), de las cuales 17 viven en América del Norte, en Estados Unidos y México (Nesom, 2006) y ca. 11 en América del Sur, con 6 especies endémicas en Argentina (Zuloaga et al., 2008).

\section{Materiales y métodos}

Para poder llevar a cabo este trabajo se realizaron viajes de colección en Argentina y Chile con el objetivo de observar las poblaciones a campo y obtener ejemplares de herbario para estudios posteriores. Se estudiaron ejemplares de herbario, imágenes digitales y fotografías depositados en las siguientes instituciones: Herbario Museo Argentino de Ciencias Naturales Bernardino Rivadavia, Buenos Aires, Argentina (BA); Herbario Gaspar Xuarez, Facultad de Agronomía, Universidad de Buenos Aires, Argentina (BAA); Herbario del Instituto de Recursos Biológicos, I.N.T.A., Castelar, Argentina (BAB); Herbario del Departamento de Biología, Universidad Nacional del Sur, Bahía Blanca, Argentina (BBB); Herbario del Departamento de Botánica, Universidad de Concepción, Concepción, Chile (CONC); Herbario del Museo de Ciencias Naturales, Universidad Nacional de Salta, Salta, Argentina (MCNS); Herbario Ruiz Leal, Unidad Botánica y Fitosociología, 


\section{F. Ratto y A. Bartoli - Revisión de Gutierrezia}

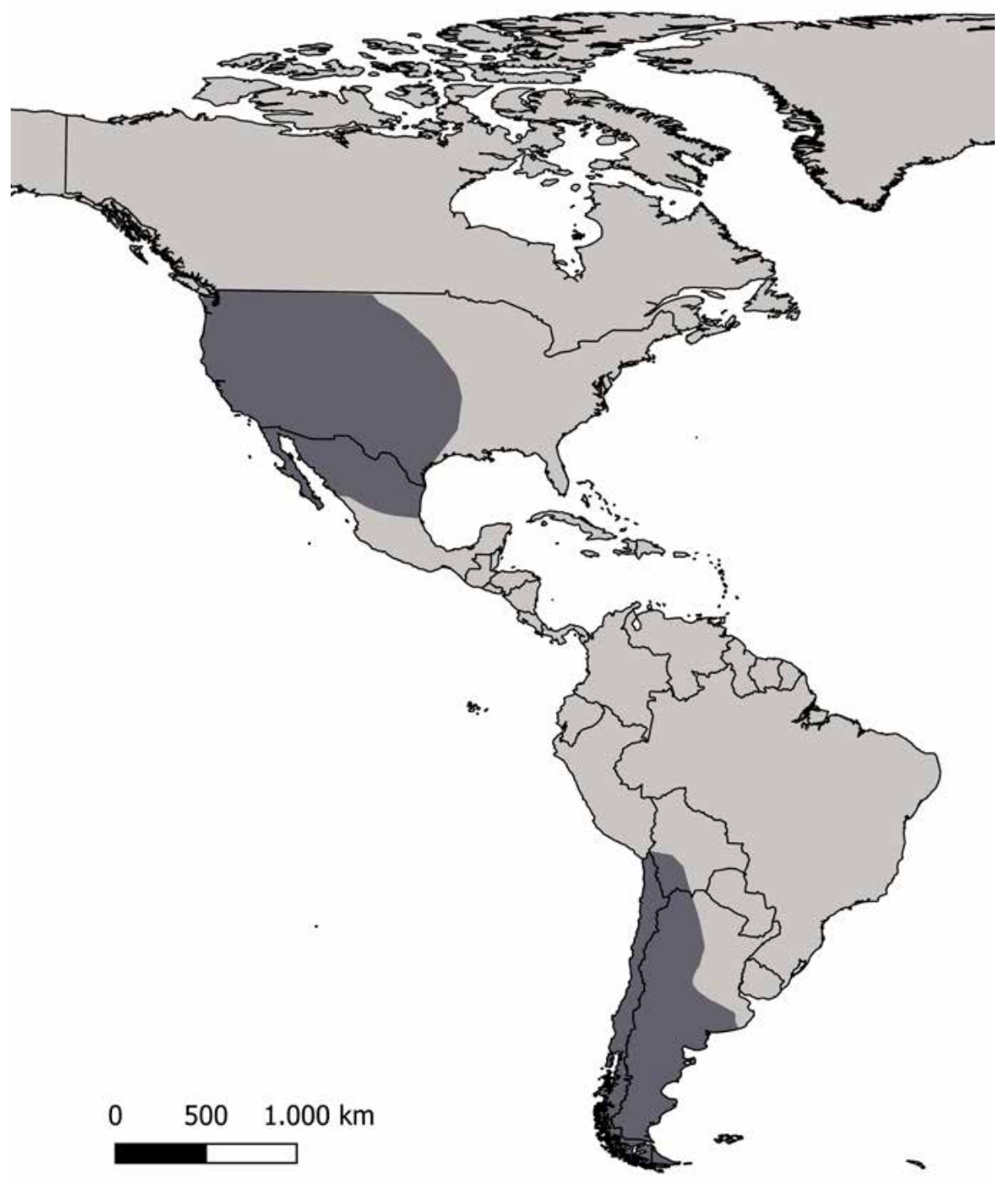

Fig. 1. Distribución geográfica del género Gutierrezia.

Mendoza, Argentina (MERL); Herbario Miguel Lillo, Tucumán, Argentina (LIL); Herbario del Museo de La Plata, Argentina (LP); Herbarium, Academy of Natural Sciences, Philadelphia, USA (PH); Herbarium Rancho Santa Ana Botanic Garden, Claremont, USA (RSA); Herbario del Instituto de Botánica Darwinion, San Isidro, Argentina (SI); Herbarium, Botany Department, University of Texas, Austin, USA (TEX).

Se transcribieron las etiquetas de los ejemplares; la información correspondiente al material adicional examinado se encuentra ordenada por país y subdivisión política ordenados por fecha de colección. Se cita ubicación geográfica, fecha, colector, número e institución en que se encuentra depositado el material. Se accedió a colecciones digitales de ejemplares tipo depositados en las siguientes instituciones: Herbario Gaspar Xuarez, Facultad de Agronomía, Universidad de Buenos Aires, Argentina (BAA); Herbarium Nationale Plantetuin van België, Jardin Botanique National de Belguique, Meise, 
Belgium (BR); Herbario Nacional Colombiano, Instituto de Ciencias Naturales, Museo de Historia Natural, Universidad Nacional de Colombia, Bogotá, Colombia (COL); Herbario Museo Botánico, Facultad de Ciencias Exactas, Fisicas y Naturales, Universidad Nacional de Córdoba, Argentina (CORD); Herbarium Royal Botanic Garden, Edinburgh, Scotland, U. K. (E); Herbarium , Botany Departament, Field Museum of Natural History, Chicago, U.S.A. (F); Herbarium, Conservatoireet jardín botaniques de la Ville de Genève, Genève, Switzerland (G); Harvard University Herbaria, Cambridge, U.S.A. (GH); Herbarium, Systematisch-Geobotanisches Institut, Göttingen, Germany (GOET); Herbarium, Royal Botanic Gardens, Kew, U.K. (K); Herbario, División Plantas Vasculares, Facultad de Ciencias Naturales y Museo, Universidad Nacional de La Plata, Argentina (LP); Herbario, Instituto de Botánica Carlos Spegazzini, La Plata, Argentina (LPS); Herbario Ruiz Leal, Unidad Botánica y Fitosociología, Mendoza, Argentina (MERL); Herbier, Institut de Botanique, Montpellier, France (MPU); Herbarium, New York Botanical Garden, Bronx, U.S.A. (NY); Herbier, Laboratoire de Phanérogamie, Muséum National d'HistoireNaturelle, Paris, France (P); Herbarium, Botany Dapartments, Swedish Museum of Natural History, Stockholm, Sweden (S); Herbario, Sección Botánica, Museo Nacional de Historia Natural, Santiago, Chile (SGO); United States National Herbarium, Botany Department, Washington, U.S.A. (US). Para realizar las observaciones y mediciones de los materiales, las partes vegetativas y reproductivas se trataron con agua caliente para hidratarlas. Las observaciones se realizaron con microscopio óptico Olympus. Los caracteres macroscópicos se observaron utilizando una lupa Zeitz. La descripción de las formas se realizó siguiendo la terminología propuesta por "The Comité for Systematics Association Descriptive Biological Terminology” (Anónimo, 1962).

\section{Resultados}

\section{Morfología del género}

Hábito: Plantas anuales o perennes, herbáceas, subleñosas o leñosas, de porte erecto, ascendente, decumbente o postrado. Las especies perennes pueden presentar rizomas, estolones o xilopodio.

Tallo: Simple en la base y ramificado en la parte superior o ramificado desde la base. En todas las especies es macizo; estriado, con tricomas glandulares estipitados.

Hojas: Alternas y sésiles, en algunas especies envainadoras, existen especies anuales de Norteamérica que presentan una roseta basal que en algunos casos puede ser persistente. Pueden ser lineares, elípticas, oblongas, angostamente oblongas, oblongo-elípticas, oblongo-espatuladas, espatuladas, ovadas o angostamente-ovadas. El margen generalmente es irregularmente dentado. El ápice varía desde agudo a obtuso.

El tamaño es muy variable entre las especies. Las caulinares pueden estar reducidas a bracteolas. La textura de las hojas es coriácea en la mayoría de las especies; en otras, como G. baccharoides y G. ameghinoi son casi suculentas. En cuanto al indumento, ambas epidermis presentan tricomas glandulares inmersos en depresiones en ambas superficies.

Capítulos: Son siempre terminales, pueden ser solitarios o agrupados en inflorescencias mayores. Pueden ser sésiles o brevemente pedunculados. Son siempre radiados, formados por flores liguladas en los márgenes y flores tubulosas en el centro. El involucro es hemisférico, acampanado, cilíndrico, turbinado u obcónico. Los filarios se disponen en 2-4 series, desiguales, gradualmente más largos, herbáceos, glandulosos, hialinos en la margen, con el ápice subulado en muchas especies (G. gayana) o acuminado, cuando acuminado el acumen puede ser plano, subterete o terete. El acumen es recto. El receptáculo es piloso y sin páleas, y puede ser plano a ligeramente convexo, algunas veces cónico y alveolado.

Flores: Las flores con corola liguladas se encuentran presentes en la zona marginal de los capítulos radiados. Pueden ser amarillas, blancas o excepcionalmente rosadas y presentan un tubo basal que se expande de manera gradual en forma de limbo elíptico a angostamente elíptico. El ápice del limbo puede ser entero o tridentado.

Las flores tubulosas se encuentran presentes en el centro de los capítulos y tienen forma de un tubo que se ensancha en forma gradual en algunas 


\section{F. Ratto y A. Bartoli - Revisión de Gutierrezia}

especies y abrupta en otras. El ápice de la corola presenta 5 lóbulos triangulares de no más de 2 $\mathrm{mm}$ long.

En el gineceo las ramas del estilo son libres entre sí, aplanadas en la cara adaxial, convexas en la abaxial, linear-elípticos a ovado-oblongos y están cubiertas en la cara abaxial por pelos colectores papilosos notablemente desarrollados. Las líneas estigmáticas son prominentes. Los estambres poseen apéndice conectival ovadoelíptico o triangular. La base de las tecas es levemente sagitada o redondeada.

Aquenios: Ovoides, cilíndricos o prismáticos, de color gris, a veces blanquecinos o marrón claro. El ápice es truncado y la superficie puede ser lisa, estriada o con costillas. El pappus es persistente y está formado por numerosas páleas desiguales persistentes, enteras o laciniadas, en algunas especies de Norteamérica se encuentra reducido a una coronita de escamas, erectas, algo divergentes.

\section{Tratamiento taxonómico}

Gutierrezia Lagasca, Genera et species plantarum 30. 1816. Tipo: Gutierrezia linearifolia Lagasca [= Gutierrezia sarothrae (Pursh) Britton \& Rusby].

Brachyris Nuttal, The Genera of North American Plants 2: 163. 1818. Tipo: Brachyris euthamiae Nutt., nom. ilegít. -Brachyachyris Sprengel, Syst. Veg. 3: 574. 1826, orthogr. var. -Gutierrezia Lagasca sect. Brachyris (Nutt.) Walp., Repert. Bot. Syst. 2: 989, 1843.

Brachyris euthamiae fue descripta por Nuttall (1818), quien menciona en el protólogo a Solidago sarothrae Pursh como sinónimo. Según los artículos 52.1 y 52.2 del Código de Melbourne (2012), B. euthamiae es un nombre ilegítimo, ya que se está dando un nuevo nombre para una entidad nombrada previamente.

Sprengel (1826) nombra en su trabajo a Brachyris como "Brachyachyris", dando así un nombre a una entidad ya descripta previamente por Nuttall. Por tal motivo, debe considerarse al nombre Brachyachyris como un error ortográfico.

Odontocarpha DC., Prodr. 5: 71. 1836. Tipo: Odonthocarpa poeppigii DC. (= Gutierrezia resinosa (Hook. \& Arn.) S. F. Blake.).

Hemiachyris DC., Prodr. 5: 313. 1836. Tipo: Hemiachyris texana DC. (= Gutierrezia texana
(DC.) Torrey \& A. Gray.) - Gutierrezia Lagasca $\mathrm{p}$ Hemiachyris (DC). Torrey \& A. Gray, Fl. N. Amer. 2: 194. - Gutierrezia Lagasca sect. Hemiachyris (DC.) Walp., Repert. Bot. Syst. 2:989. 1843. Greenella A. Gray, Proc. Amer. Acad. Arts 16:81. 1880. Tipo: Greenella arizonica A. Gray (= Gutierrezia arizonica (A. Gray) M. A. Lane).

Plantas terrestres, anuales, o perennes, herbáceas, sufruticosas o arbustivas de 3 a $200 \mathrm{~cm}$; a veces con rizomas; frecuentemente resinosas por la presencia de tricomas glandulares sésiles y estipitados. Hojas alternas, sésiles, glabras, resinosas, a veces con la lámina estrechándose en un pseudopecíolo, en algunas especies semiabrazadoras o envainadoras, lineares, elípticas, oblongas, angostamente oblongas, oblongo-elípticas u oblongo-espatuladas, enteras, algunas veces con pequeños dientes en el margen; en algunas especies norteamericanas formando una roseta basal que puede ser persistente, ambas epidermis presentan tricomas glandulares inmersos en depresiones en ambas superficies. Capítulos solitarios en el ápice de las ramas o agrupados en inflorescencias corimbiformes laxas o densas, radiados, heterógamos; involucro campanulado, cilíndrico o turbinado, sésiles o brevemente pedunculados, filarios en 2-4 series, desiguales, glandulosos, generalmente apiculados, con márgenes hialinos. Receptáculo plano, semiconvexo a cónico, desnudo, alveolado, piloso. Flores del margen 1-30, liguladas, femeninas, fértiles, blancas, blanco-amarillentas, amarillas o excepcionalmente rosadas, tubo glabro. Flores del disco 1-150, perfectas, fértiles, con corola tubulosa pentalobulada, a veces abruptamente ampliada, con los lóbulos triangulares, blancas, amarillentas o amarillas, excepcionalmente rosadas; tubo glabro en su interior. Anteras con apéndice conectival elíptico-triangular; base de las tecas redondeadas a levemente sagitadas. Estilo con ramas estigmáticas aplanadas, agudas u obtusas, linear-elípticas, cubiertas en la cara abaxial de pelos colectores papilosos; líneas estigmáticas bien definidas. Aquenios pilosos, algunas veces subglabros, con la superficie lisa o estriada, cilíndricos, prismáticos u ovoides, con el ápice truncado. Pappus con 8 a 30 páleas desiguales, enteras o laciniadas perennes, erectas, en algunas especies norteamericanas reducidas a pequeñas escamas. Número básico de cromosomas, $x=4$. 


\section{Clave para la identificación de las especies de Gutierrezia}

1- Arbustos o subarbustos decumbentes o postrados, algunas veces formando cojines. ............................ 2

- Arbustos o subarbustos erectos, nunca formando cojines. ...................................................................... 9

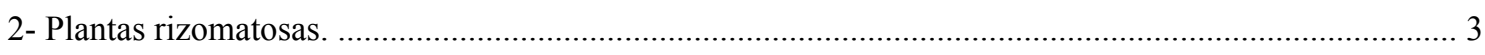

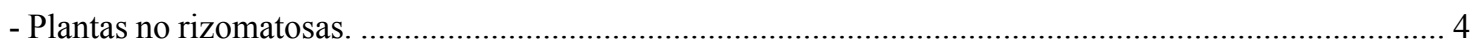

3- Hojas con pseudopecíolo envainador, espatuladas o elíptico-espatuladas, 8-15 x 3-5 mm. .. G. baccharoides

- Hojas sin pseudopecíolo envainador, elípticas o elíptico-espatuladas, 15-30 x 2-5 mm. G. repens

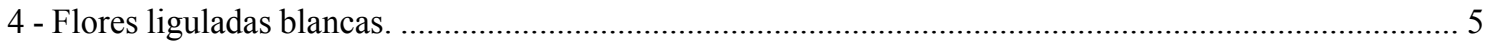

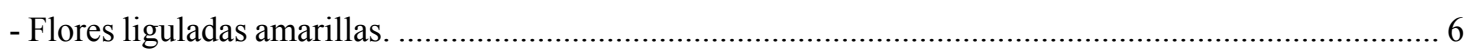

5- Hojas basales elíptico-espatuladas. Hojas caulinares linear-elípticas, 15-22 x 3-4 mm, tallos radicantes

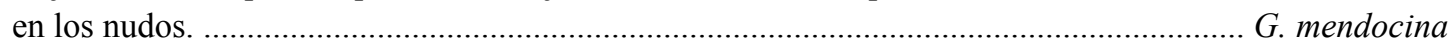

-Todas las hojas linear-elípticas, 20-60 x 2-5 mm, tallos no radicantes en los nudos. ............ G. taltalensis

6- Hojas linear-elípticas. ........................................................................................................ G. mandonii

-- Capítulos con todas las flores amarillas. .................................................... G. mandonii var. mandonii

-- Capítulos con todas las flores amarillentas, blancas o raramente rosadas. .... G. mandonii var. anomala

- Hojas elíptico-espatuladas o espatuladas. ........................................................................................... 7

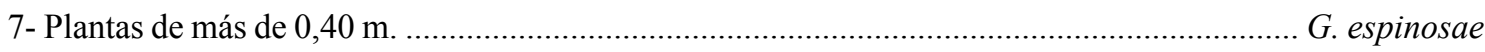

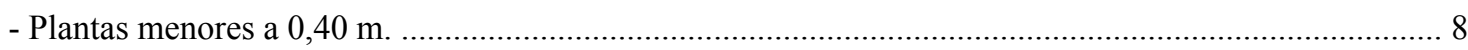

8- Hojas anchamente espatuladas, 10-25 x 2,5-6 mm. Involucro ovoide u ovoide- acampanado. ... G. spathulata

- Hojas elípticas, 15-35 x 2-5 mm. Involucro cilíndrico o cilíndrico-turbinado. .................... G. ameghinoi

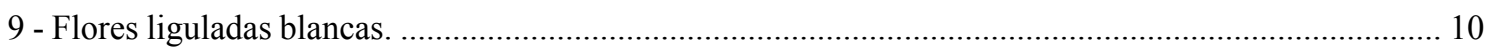

- Flores liguladas amarillas (excepcionalmente blancas en G. isernii var. nivea)................................... 13

10- Hojas lineares, 30-60 x 1-2 mm, involucro acampanado, 10-12 x 10-12 mm. ................... G. gayana

- Hojas linear-elípticas, involucro acampanado, cilíndrico o turbinado, menores a 10-12 x 10-12 mm... 11

11- Hojas elípticas, capítulos numerosos, agrupados en inflorescencias corimbiformes densas. ... G. solbrigii

- Hojas lineares o linear-elípticas, capítulos solitarios o agrupados de a 3-4 en inflorescencias laxas. .. 12

12- Hojas de 35-40 x 3-5 mm. Plantas de más de $100 \mathrm{~cm}$ de alto. .......................................... G. leucantha

- Hojas de 10-30 x 0,5-3 mm. Plantas menores a $100 \mathrm{~cm}$ de alto. .......................................... G. gilliesii

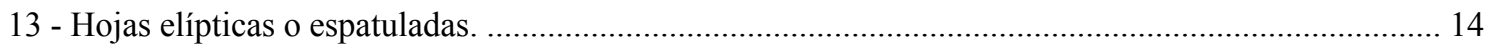

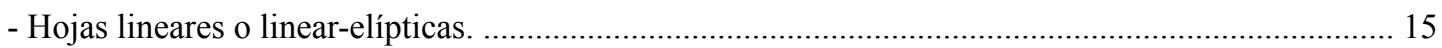

14 - Involucro cilíndrico. ..................................................................................................... G. chubutensis

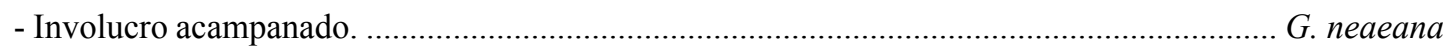

15 - Capítulos con involucro cilíndrico o cilíndrico-turbinado. ...................................................... G. isernii

-- Flores liguladas blancas. ................................................................................... G. isernii var. nivea

-- Flores liguladas amarillas. ............................................................................... G. isernii var. isernii

- Capítulos con el involucro turbinado o acampanado. ..................................................................... 16

16 - Plantas de más de $100 \mathrm{~cm}$ de alto. Hojas elípticas, 30-50 x 2-4 mm, pocos capítulos. ........ G. resinosa

- Plantas de más de $30 \mathrm{~cm}$ de alto. Hojas lineares, 5-15 x 1-1,5 mm, capítulos numerosos. .. G. tortosae 


\section{F. Ratto y A. Bartoli - Revisión de Gutierrezia}

1. Gutierrezia ameghinoi Speg., Revista Fac. Agron. Univ. Nac. La Plata. 3: 527. 1897. (Figs. 2, 3)

Tipo: Argentina. Prov. Santa Cruz, Río Deseado, 1894, C. Ameghino 94 (Holotipo LP 000075!).

$=$ Gutierrezia paniculata (DC) Phil. var. patagonica Speg. Revista Fac. Agron. Univ. Nac. La Plata 3:608. 1897. Gutierrezia brachyris Macloskie var. patagonica (Speg.) Macloskie. Rep Princeton Univ. Exp. Patag, 8: 780. 1905. Tipo: Argentina. Prov. Chubut "Hab. in collinis sterilibus prope Tecka-choique", 1897, C. Moyano s.n. (Holotipo: LP000076!).

Iconografia. Ratto F. \& Bartoli, A. 2015. The resurrection of Gutierrezia ameghinoi Speg. (Asteraceae, Astereae, Solidagininae), a species from Patagonia, Argentina. Phytotaxa 220 (3): 295-300.

Subarbustos de 10-20 (-25) cm de altura, muy ramificados desde la base. Tallos erectos, costados, glandulares, foliosos, hojas subcoriáceas, sésiles, irregularmente dentadas en el margen, elípticoespatuladas, atenuadas en un pseudopecíolo de 15-35 × 2-5 mm, obtusas. Capítulos numerosos, radiados, heterógamos, sésiles, de $12-16 \mathrm{~mm}$ de diámetro, dispuestos en cimas corimbiformes, con 1 o 2 brácteas elípticas de 2-3 $\mathrm{mm}$ de largo. Involucro cilíndrico, resinoso, de $6 \mathrm{~mm} \times 4 \mathrm{~mm}$. Receptáculo plano o ligeramente convexo, desnudo, alveolado, piloso. Filarios en 3 series, los exteriores oblongos, glandulares, los interiores estrechamente obovados. Flores liguladas 6-9, pistiladas, con lámina amarilla, elípticas a elíptico-espatuladas, de 4-7 mm de largo x 2-4 mm de ancho; estilo con ramas lineal elíptica, ápice agudo, papilosas. Flores del disco 8-10, perfectas, amarillas, de $4 \mathrm{~mm}$, tubulosas, con una garganta bruscamente ampliada. Anteras redondeadas en la base; ápice con el tejido conectivo ovado a ovado-elíptico, ramas del estilo linear-elípticas, agudas, con tricomas papilosos colectores en el lado exterior. Aquenios gris claro, cilíndricos a obovado-cilíndricos, costados, densamente seríceos; de 2-3 mm. Pappus compuesto por 8-12 paleas, con los márgenes laciniados, ca. $1-1,5 \mathrm{~mm}$ de largo en las flores liguladas y $2-3 \mathrm{~mm}$ de largo en las flores del disco.

Distribución geográfica y hábitat. Se la encuentra en las provincias argentinas de Río Negro y Santa
Cruz. Habita el dominio Andino-Patagónico en la provincia fitogeográfica Patagónica, creciendo en planicies con suelos muy arenosos desde el nivel del mar hasta los $250 \mathrm{msnm}$.

\section{Nombre vulgar. No se conoce.}

Material estudiado. ARGENTINA. Prov. Río Negro: Dpto. San Antonio, Sierra Grande, 16-I2016, F. Ratto, D. Sbarra y M. Sorondo 6/2016 (BAA). Prov. Santa Cruz: Dpto. Deseado, 35 $\mathrm{km}$ de Jaramillo, camino al bosque petrificado, 10-I-1967, O. Boelcke et al. 12167 (BAB); Puerto Deseado, 24-I-2015, F. Ratto 88 (BAA); Puerto Deseado, 24-I-2015, F. Ratto 89 (BAA); Puerto Deseado, 25-I-2015, F. Ratto 90 (BAA); Puerto Deseado, 25-I-2015, F. Ratto 91 (BAA).

Observaciones. 1) Especie fundada por Carlos Spegazzini (1897) basada en un ejemplar coleccionado por Carlos Ameghino. Luego fue sinonimizada con G. spathulata por Cabrera (1971) y rehabilitada recientemente por Ratto \& Bartoli (2015).

2) Especie ampliamente distribuida en el departamento de Deseado, provincia de Santa Cruz donde forma grandes poblaciones. También se la encuentra en Río Negro en el departamento de San Antonio, aunque es poco frecuente. Muchos ejemplares depositados en los herbarios aparecen generalmente determinados bajo el nombre de G. spathulata, de la cual se diferencia por formar cojines compactos y poseer capítulos cilíndricos.

3) Los ejemplares juveniles de G. chubutensis pueden confundirse con esta especie, pero los mismos luego toman un porte arbustivo.

2. Gutierrezia baccharoides Sch. Bip., Flora 38: 115. 1855. (Figs. 4, 5). Tipo: Chile. Ad sinum Oazy Harbour, ad terminum accessus maris, W. Lechler 1241. Feb 1853. (Holotipo P00742773!; Isotipos, K000221364!, BR0000005318278!, NY00169697!, P00742778!, P00742775!, P00742776!,? S E-2657!).

$=$ Gutierrezia hoffmanii Kuntze. Revis. Gen. Pl. 3(3): 156. 1898. Gutierrezia baccharoides Sch. Bip. var. hoffmanii (Kuntze) Hauman. Anales Soc. Ci. Argent. 86: 321, 1918. Tipo: Patagonia, Abr. 1882, F. P. Moreno \& J. Tonini 523 (Holotipo NY 00163638; Isotipo: B [destruido, fotografía de Serie Field Museum 14816]). 
Bol. Soc. Argent. Bot. 55 (3) 2020
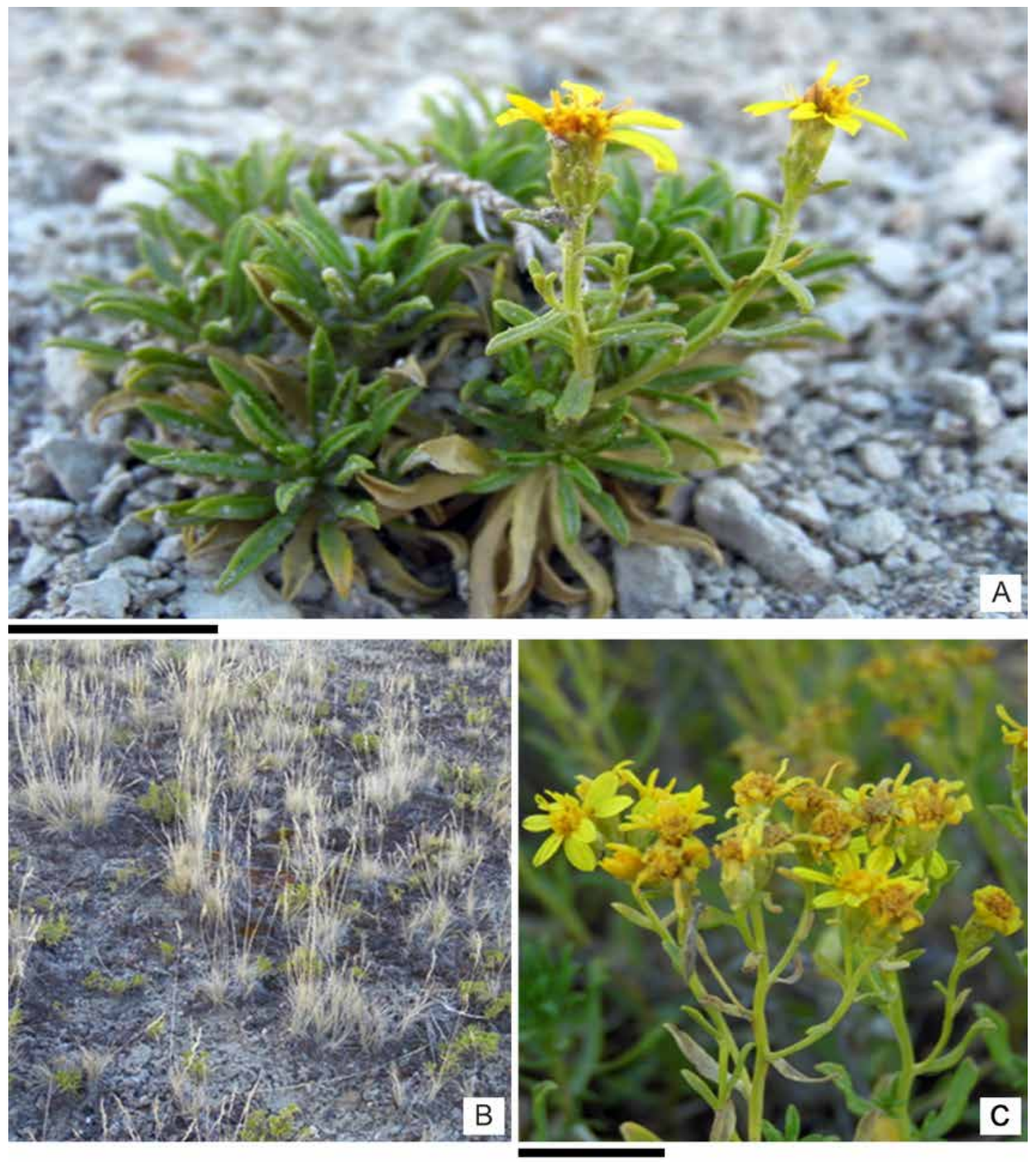

Fig. 2. Gutierrezia ameghinoi. A: Planta. B: Hábitat. C: Capítulos. Fotografías por F. Ratto. Escalas= A: 1,5 $\mathrm{cm} ; \mathrm{C}: 1,5 \mathrm{~cm}$.

Iconografía. Cabrera, A. L. 1971. En M. N Correa (Ed.). Fl. Patagónica. Compositae. Parte VII: 32, fig. 17. Colección científica del INTA.

Subarbustos de 3-20 cm, rizomatosos, tallos postrados, notablemente costados en sus partes jóvenes, glandulares, frondosos desde la base, hojas subcoriáceas, sésiles, espatuladas o elípticoespatuladas, atenuadas en un pseudopecíolo envainador, con el ápice obtuso, escotado, trinervadas, irregularmente dentadas, de 8-15 (-20) x 3-5 mm. Capítulos radiados, solitarios, 


\section{F. Ratto y A. Bartoli - Revisión de Gutierrezia}

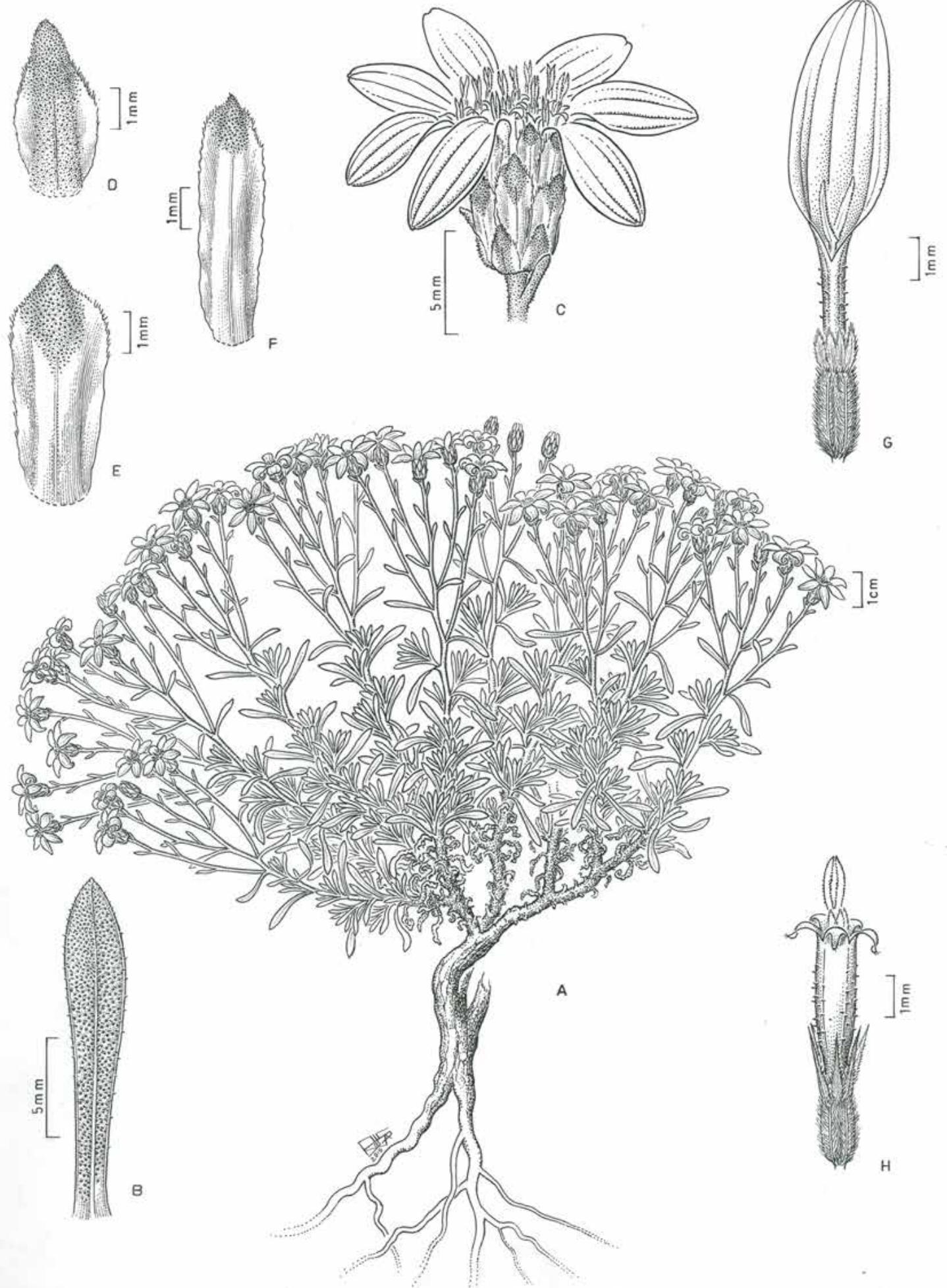

Fig. 3. Gutierrezia ameghinoi. A: Planta. B: Hoja. C: Capítulo. D-F: Filarias. G: Flor liguladas. H: Flor tubulosa. 
sésiles, de 15-20 $\mathrm{mm}$ de diámetro acompañados de 1-2 brácteas lineares o linear-elípticas de 1-3 mm, involucro acampanado, resinoso, 5-8 $\mathrm{mm} \times 4-10 \mathrm{~mm}$, Filarios en 3 series, oblongos, con bordes hialinos, la serie externa con ápice obtuso, glandular, la serie interna triangular, acuminados. Receptáculo plano o ligeramente convexo, alveolado, piloso. Flores liguladas 6 a 12, femeninas, color amarillo, lígula elíptica, de 6-8 $\mathrm{mm}$ de largo por 2-3 mm de ancho. Flores del disco 10 a 20, hermafroditas, con la corola amarilla, de 3-4 mm con garganta bruscamente ampliada. Anteras redondeadas en la base con tejido conectivo triangular de $0,5 \mathrm{~mm}$, ramas del estilo agudas a subagudas. Aquenios grisáceos, cilíndrico-ovoides, costados, densamente seríceos, de $2 \mathrm{~mm}$. Pappus o vilano compuesto de 12-25 páleas lineares a linearelípticas, laciniadas de 1-4 $\mathrm{mm}$ de largo en flores liguladas y de 2-4 mm en las flores del disco.

Distribución geográfica y hábitat. En Argentina se la encuentra desde Mendoza hasta Tierra del Fuego. En Chile vive en la Región XI, Magallanes. Vegeta entre los 400 y los $3800 \mathrm{msnm}$. Habita el dominio Andino-Patagónico en las provincias Patagónica y Subantártica en suelos rocosos y arenosos creciendo entre las piedras.

\section{Nombre vulgar. No se conoce.}

Material estudiado. ARGENTINA. Prov. Chubut: Dpto. Biedma, Golfo San Jorge, Sin colector, LP 16818 (LP); Golfo San Jorge, LP 16815 (LP). Dpto. Cushamen, 24-II-1924, BAB 55011 (BAB); Entre El Maitén y Esquel por Nahuel Pan ca. Amarillo, 14-I-1941, R. A. Pérez Moreau s.n. (BA). Dpto. Florentino Ameghino, LP 16814 (LP). Dpto. Futaleufú, Pasando El Maitén hacia Esquel, empalme R40, 28-II-1998, A. Bartoli \& R. Tortosa 18 (BAA). Dpto. Languiñeo, Lago Paz (Lago Vintter), 9-III-1954, A. Soriano 4618 (BAA); Río Chubut superior, Piedra Parada, 25-XII-1941, E. Petersen s.n. (BA); Dpto. Río Senguerr, Al sud del Senguer, 14-I-2013, L. Kraglievich s.n. (BA). Dpto. Tehuelches, Camino Lago Vintter-Lago Los Niños, 23-I-1992, E. G. Nicora 9634 (SI); Entre Río Pico y Lago Vintter, 16-I-1948, A. Soriano 3075 (SI, BAB, LP). Dpto. Telsen, De Telsen a Gan Gan, a 85 km de Gan Gan, 15-XII-2002, A. Bartoli \&
R. Tortosa 45/02-2 (BAA). Prov. Mendoza: Dpto. Luján de Cuyo, Pampa de La Polcura, 1IV-1961, A. Ruiz Leal 21671 (MERL); Pampa de la Polcura, 10-II-1062, O. T. Solbrig 3399 (LP); Vallecitos, centro de sky, 11-I-2011, F. Ratto et al. 90, 91 y 92 (BAA); Vallecitos, 15II-2016, F. Ratto, D. Sbarra \& D. Schiavinato 116/2016 (BAA). Dpto. San Carlos, Estancias Llaucha, portezuelo de Las Osamentas, 18-I1941, A. Ruiz Leal 7192 (MERL); Portezuelo de las osamentas (Ea. Llaucha), 18-I-1941, Sin colector 7192 (LP). Dpto. Tunuyán, En la cumbre de los cerros, 21-III-1935, A. Ruiz Leal 3128 (MERL); Playas de Vicente, 20-III-1935, A. Ruiz Leal 3086 (MERL). Dpto. Tupungato: Portezuelo Morado, 28-II-1949, Sin colector 11844, (MERL); Portezuelo Morado, 28-II-1949, G. Samper 11844 (LP). Prov. Neuquén: Dpto. Aluminé, PN Lanín, $\mathrm{C}^{\circ}$ Colo Huincul, 23II-1983, L. Cusato 2934 (BAA). Dpto. Añelo, Rincón Grande, 29-XII-1940, J. J. Naumeyer 384 (LP). Dpto. Huiliches, Cerro Lolog, 10-II1963, S. Schajovoskoy 5836 (BA). Dpto. Lácar, Cerro Repollo, Estancia Meliquina, 12-II-1965, Z. Rúgolo \& E. Agrasar 543 (BAA). Dpto. Los Lagos, Ea. Fortín Chacabuco, Nancucheo, 17-I-1960, O. Boelcke 8448 (BAA). Prov. Río Negro: Dpto. 9 de Julio, Meseta Somuncurá, cerro Corona, 10-I-2002, H. Troiani \& P. Steibel 15179 (BAA, SI); Desde Los Menucos hacía Comi-Co, 10-XII-2003, A. Bartoli \& R. Tortosa 21/03 (BAA, SI). Dpto. 25 de Mayo, Clemente Onelli, 01-I-1968, A. Ruiz Leal 25825 (LP). Dpto. Valcheta, Ladera N del cerro Corona, 13-II-1981, R. Rossow 161 (BAB); Somuncurá, 27 km N de Lag. Raimunda, 25-XI-1975, M. N. Correa et al. 6375 (BAB). Prov. Santa Cruz, Dpto. Güer Aike, Ea. La Angelina, Cabo Buen Tiempo, 29-I-1976, E. Méndez 1094 (BAB); Ea. Cabo Buen Tiempo, 29-I-1976, M. C. Latour et al. s.n. (BAB). CHILE. Laguna Flamea, I-2000, Sin colector, s.n. (SGO).

Observaciones. 1) Especie fundada por el botánico alemán Schultz Bipontinus (1855) basado en un ejemplar coleccionado por W. Lechler. Kuntze (1898) describió la especie Gutierrezia hoffmanii basándose en un ejemplar de F. P. Moreno \& J. Tonini. Posteriormente Hauman (1918) transfirió la especie como variedad de 


\section{F. Ratto y A. Bartoli - Revisión de Gutierrezia}
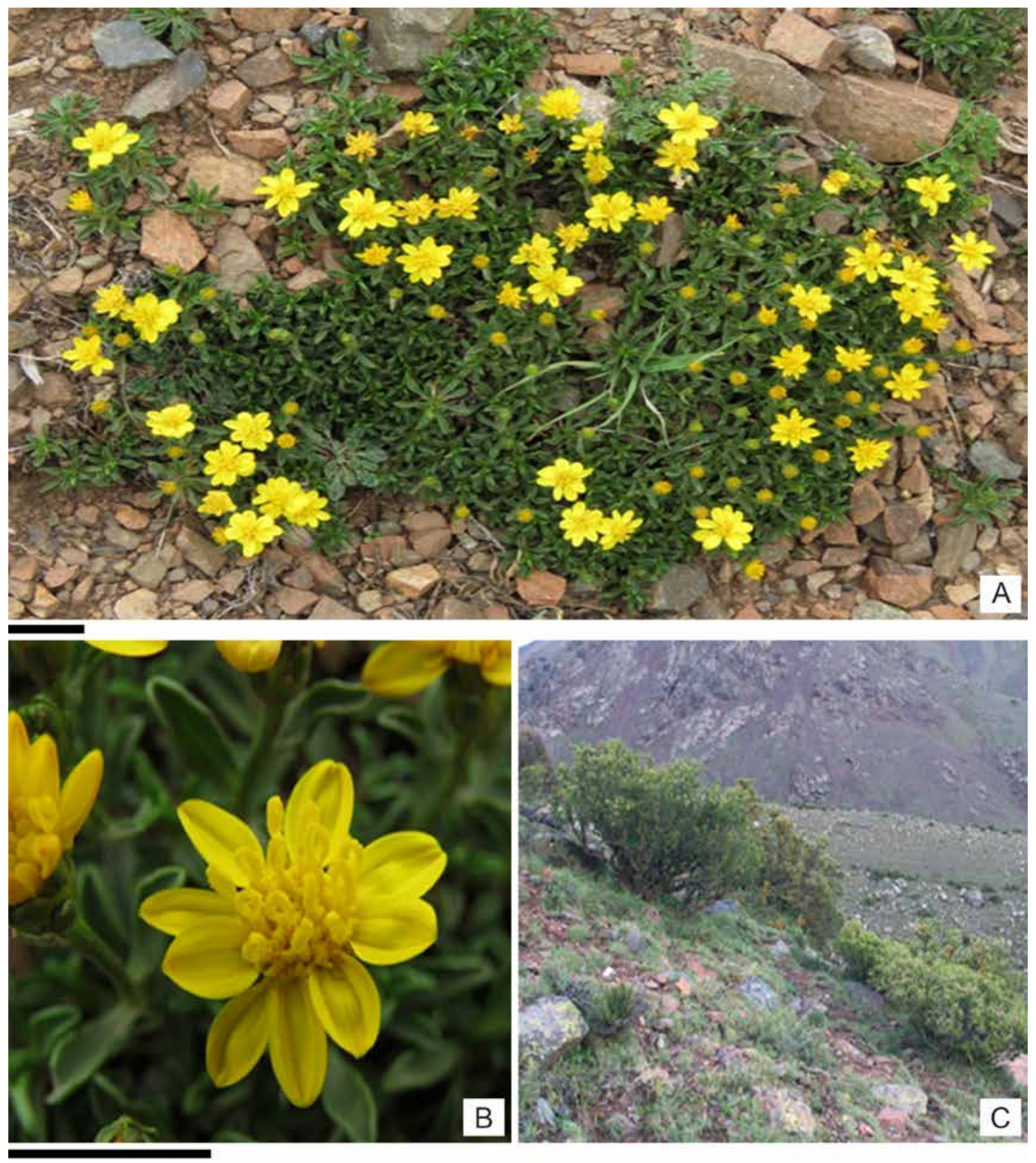

Fig. 4. Gutierrezia baccharoides. A: Planta. B: Detalle del capítulo. C: Hábitat. Escalas=A: $2 \mathrm{~cm} ; B=0,5 \mathrm{~cm}$.

G. baccharoides, Gutierrezia baccharoides Sch. Bip. var. hoffmanii basada en el mismo ejemplar. Finalmente, la especie fundada por Kuntze y la variedad fundada por Hauman fueron incluidas por Solbrig (1966) en la sinonimia de la especie de Schultz Bipontinus.
2) La especie generalmente se encuentra en la cordillera de Los Andes en las provincias de Mendoza y Neuquén, pero a partir de la provincia de Río Negro se la puede encontrar en elevaciones menores en toda la Patagonia.

3) Frecuentemente aparece formando cojines 


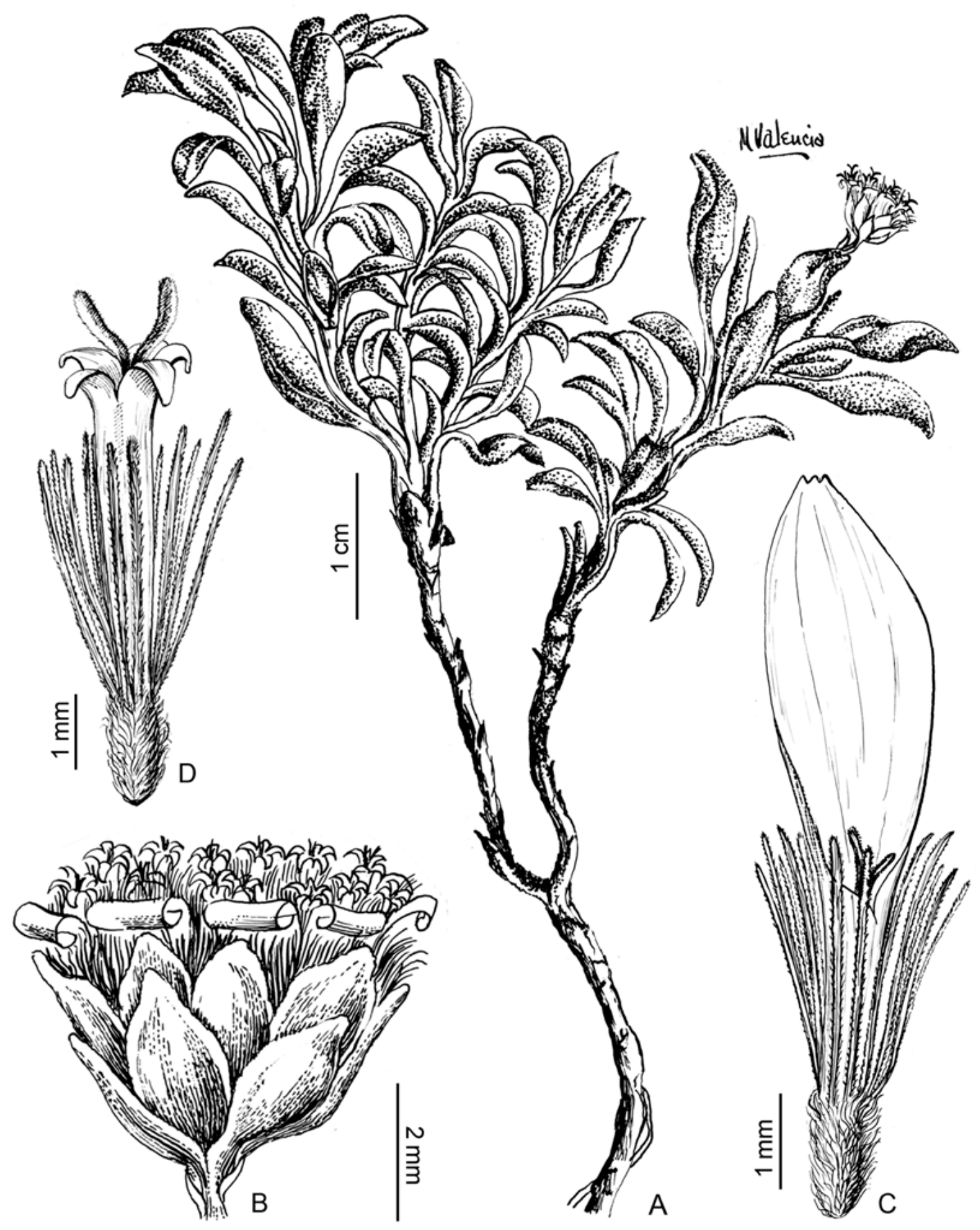

Fig. 5. Gutierrezia baccharoides. A: Planta. B: Capítulo. C: Flor ligulada. D: Flor tubulosa.

más o menos densos, entre las rocas o en suelos arenoso-rocosos. Es similar a $G$. spathulata de la cual se diferencia por tener hojas con pseudopecíolo envainador y capítulos mayores.

4) Es la única especie compartida entre la Argentina y Chile (Fig. 6). 


\section{F. Ratto y A. Bartoli - Revisión de Gutierrezia}

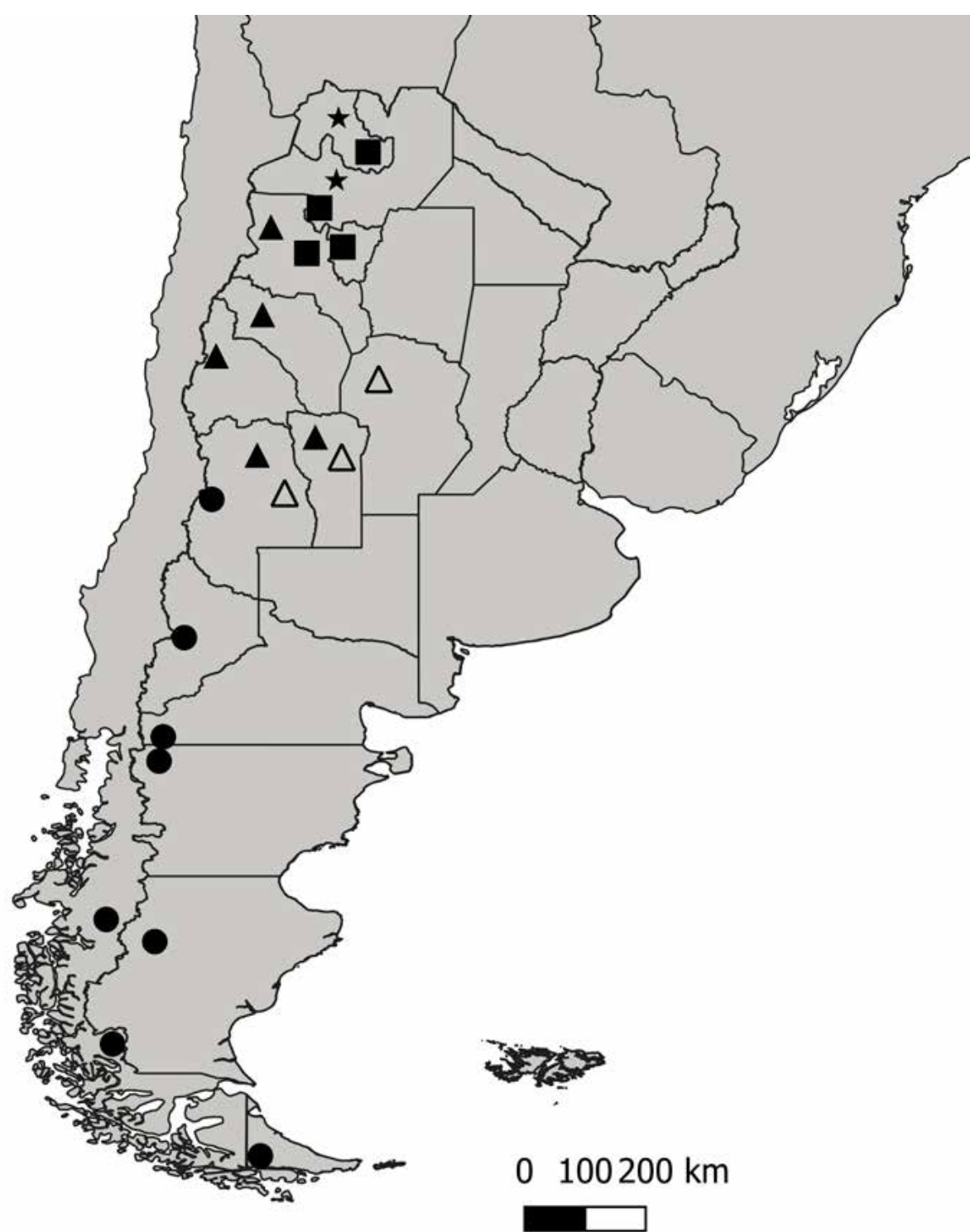

Fig. 6. Distribución geográfica de: G.baccharoides

G. isernii var. isernii $\boldsymbol{\Lambda}, G$. isernii var. nivea $\Delta, G$. repens $\mathbf{\square}, \mathrm{G}$. tortosae $\star$.

3. Gutierrezia chubutensis Ratto \& A. Bartoli., Phytotaxa 266 (2): 157-160. 2016. (Figs. 7, 8). Tipo: Argentina. Chubut. Gaiman. Dique Florentino Ameghino, S43 ${ }^{\circ} 42,061^{\prime}, \mathrm{O}^{\circ} 6^{\circ} 29,062^{\prime}, 147$ m, F. Ratto, D. Sbarra \& M. Sorondo 14/2016, 17-I-2016 (Holotipo BAA; Isotipos BC, SI).

Iconografia. Ratto, F. \& Bartoli, A. 2016. A new species of Gutierrezia (Asteraceae, Astereae,
Solidagininae) from Argentinian Patagonia. Phytotaxa 266 (2): 157-160. 2016.

Arbustos resinosos 30-55 (60) $\mathrm{cm}$. Tallos numerosos, erectos, rígidos, costados, glandulares, ramificados, hojosos desde la base hasta el ápice. Hojas subcoriáceas, erectas o en ángulo agudo, sésiles, elípticas, 25-50 x 3-6 mm, agudas. Capítulos radiados, heterógamos, sésiles, $1-1.5 \mathrm{~cm}$ diam., 

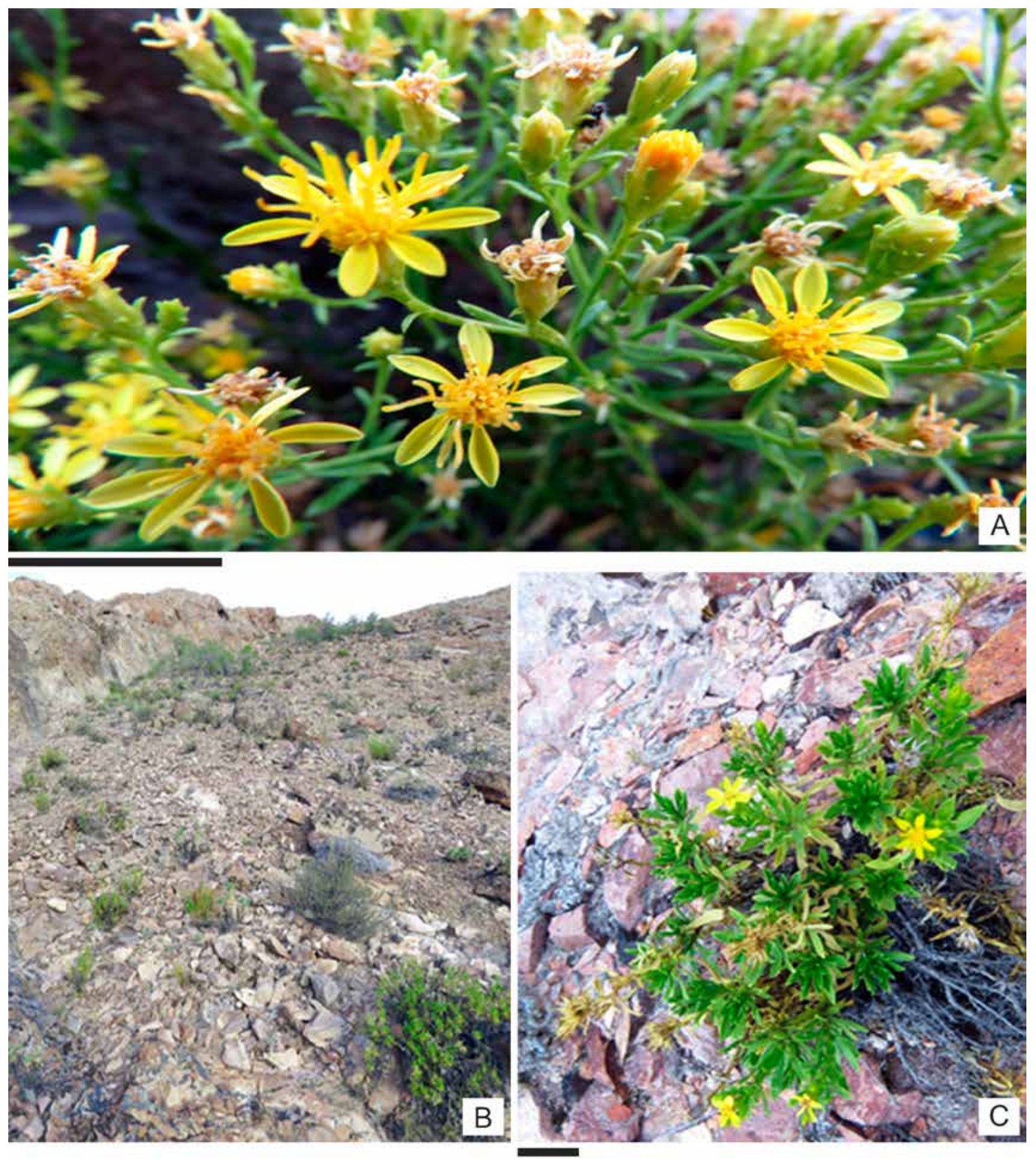

Fig. 7. Gutierrezia chubutensis. A: Inflorescencia. B: Hábitat. C: Planta. Fotografías por F. Ratto. Escalas= A: $1.5 \mathrm{~cm}$; C: $1,5 \mathrm{~cm}$.

agrupados en cimas corimbiformes en el ápice de los tallos; con 1-3 brácteas linear o linearelípticas retrorsas de 3-7 $\mathrm{mm}$ long. Involucro cilíndrico o cilíndrico-turbinado, resinoso, 7-9 $\mathrm{mm}$ x 2-4 mm. Receptáculo plano o levemente convexo, desnudo, alveolado, piloso. Filarios en tres series graduales, los de la serie externa ovados, glandulares, acuminados, los de la serie interna angostamente ovados y acuminados. Flores liguladas 8 a 9, pistiladas, con corola amarilla, 


\section{F. Ratto y A. Bartoli - Revisión de Gutierrezia}

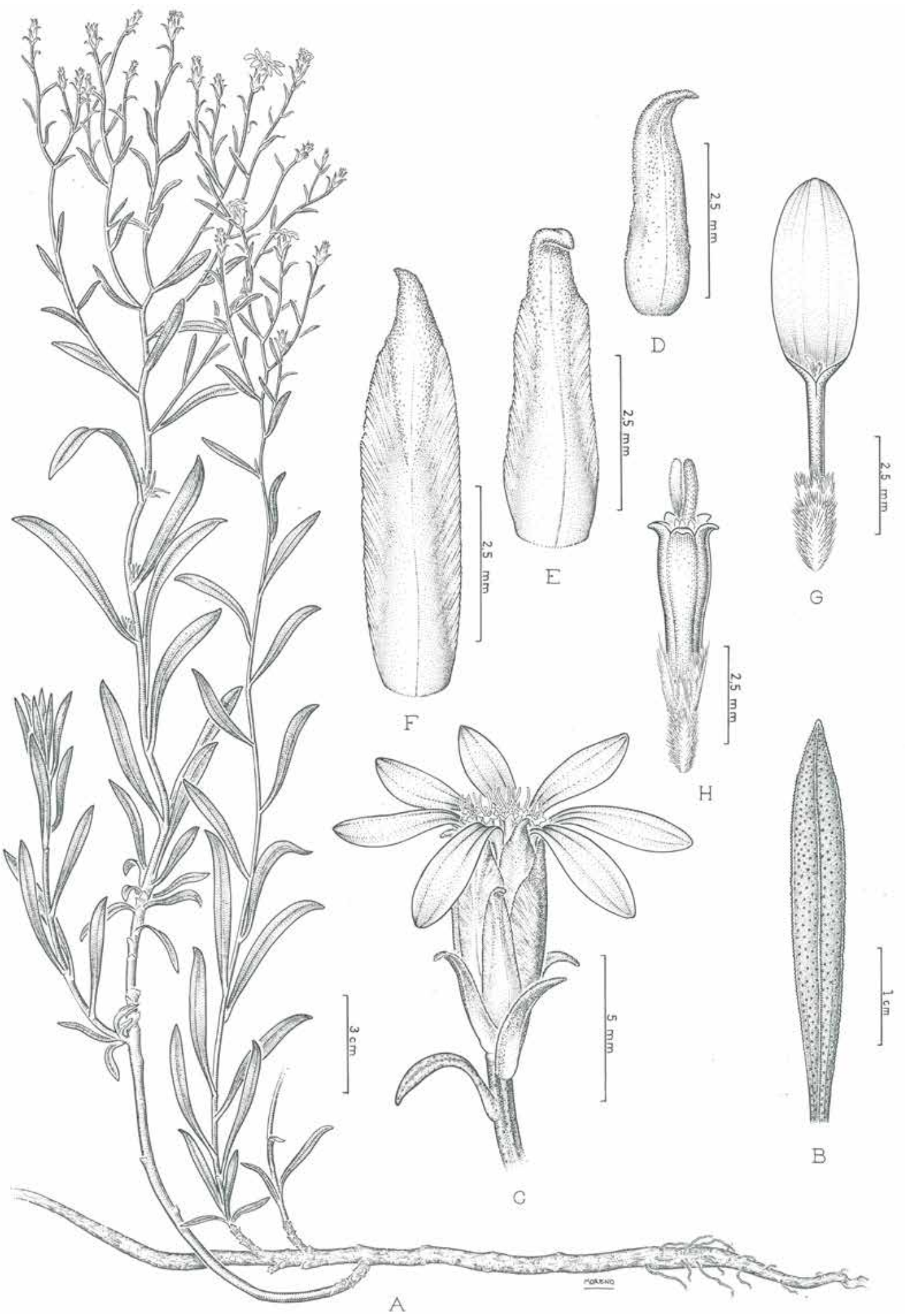

Fig. 8. Gutierrezia chubutensis. A: Planta. B: Hoja. C: Capítulo. D-F: Filarias. G: Flor ligulada. H: Flor tubulosa. 
angostamente obovada, 6-7 mm long.; estilos con las ramas linear-elípticas y ápice agudo, papilosas. Flores del disco 7-9, perfectas, con corola amarilla de $4 \mathrm{~mm}$, tubulosas con una garganta bruscamente ampliada. Anteras redondeadas en la base, apéndice conectival ovado-triangular de $0,5 \mathrm{~mm}$; ramas del estilo elípticas, obtusas con pelos colectores papilosos en la cara externa. Aquenios grises, cilíndricoturbinados, densamente seríceos. Pappus compuesto por 8 a 14 páleas linear o linear-elípticas, levemente laciniadas en la margen de $2 \mathrm{~mm}$ long. en las flores liguladas, y $2-3 \mathrm{~mm}$ long. en las tubulosas.

Distribución geográfica y hábitat. Se la ha encontrado en la provincia de Chubut, Argentina. Habita la provincia fitogeográfica de la Patagonia, en el distrito Patagonia Central. Crece en laderas rocosas a $200 \mathrm{msnm}$, asociada a vegetación xerofítica arbustiva.

\section{Nombre vulgar. No se conoce.}

Material estudiado. ARGENTINA. Prov. Chubut: Dpto Florentino Ameghino, RP 25, $130 \mathrm{~km}$ W Trelew, 25-11-1978, H. Cordo \& Ferrer 79-A-34 (SI). Dpto. Gaiman, Dique Florentino Ameghino, 17-I-2016, F. Ratto, D. Sbarra \& M. Sorondo 13/2016 (BAA).

Observaciones. 1) Especie endémica muy restringida, se la encuentra sólo en las cercanías del Dique Florentino Ameghino.

2) Los ejemplares juveniles de esta especie suelen confundirse con $G$. ameghinoi, pero claramente difieren de la especie mencionada ya que en el estado adulto son arbustos leñosos mientras que $G$. ameghinoi forma cojines subarbustivos.

4. Gutierrezia espinosae Acevedo., Bol. Mus. Nac. Hist. Nat. Santiago de Chile 24: 82. 1949. (Figs. 9, 10). Tipo: Chile. Antofagasta. Quebrada de La Chimba, 1-XII-1941, M. R. Espinosa Burgos s.n. (Holotipo GH00008515 [foto]!; Isotipos, SGO 000005596 [70854]!, SGO 000005597 [70857]!, SGO 000005598 [70455]!, SGO 000005599 [70456]!, SGO 000005600 [70454]!).

Iconografía. Acevedo de Vargas, R. 1949. Contribución a la Flora Cordillerana del Norte de Chile. Bol. Mus. Nac. Hist. Nat. Santiago de Chile 24: $82(1-2)$.
Arbustos pequeños de $40-60 \mathrm{~cm}$, ramificados en la base. Tallos decumbentes y erectos, acanalados, glandulares, con abundantes restos de hojas muertas en la base y corteza gris, notablemente foliáceos en el ápice. Hojas muy variables, espatuladas, oblanceoladas o elípticas, subcoriáceas, sésiles, reflejas en algunos ejemplares, semiabrazadoras, nervadura central muy marcada en la cara abaxial, de $12-40$ x 2-8 mm, subagudas a obtusas. Capítulos radiados, sésiles, de 10-12 $\mathrm{mm}$ de diámetro, formando cimas corimbiformes densas en el ápice de los tallos, con 1-2 o en algunos casos, numerosas brácteas oblongas de 2-3 mm. Involucro acampanado, resinoso, 7-10 mm x 5-7 mm. Receptáculo plano o ligeramente convexo, alveolado, piloso. Filarios en 3 series, oblongos, apiculados, glandular. Flores liguladas 7 a 12, femeninas, color amarillo, lígula ovado-espatuladas, de 6-8 $\mathrm{mm}$ de largo. Flores del disco 8 a 16, hermafroditas, con la corola amarilla, de 4-5 mm con una garganta bruscamente ampliada hacia el ápice. Anteras redondeadas en la base con tejido conectivo triangular de $0,5 \mathrm{~mm}$. Ramas del estilo obtusas. Aquenios grisáceos, ovoideturbinados, costados, densamente seríceos, de 1,5-2 mm. Pappus compuesto por ca. 14 páleas elípticas, laciniadas de $1-2 \mathrm{~mm}$ en las flores liguladas y 2-3 $\mathrm{mm}$ en las tubulosas.

Distribución geográfica y hábitat. Se la encuentra en Chile, Región I, Arica y Parinacota y Tarapacá; II, Antofagasta y III, Atacama y Coquimbo. Habita el Dominio fitogeográfico Andino-Patagónico en la provincia del Desierto entre los 0 y los $1000 \mathrm{msnm}$.

Nombre vulgar. No se conoce.

Material estudiado. CHILE. I Región: Tarapacá, Prov. Iquique: Alto Punta Lobos, 14-I-1998, R. Pinto s.n. (SGO). II Región: Antofagasta, Prov. Antofagasta, Antofagasta, 1-XII-1941, M. Espinosa s.n. (SGO); Quebrada de La Chimba, XII-1941, M. Espinosa s.n. (SGO); Quebrada Salar del Carmen, 9-XII-1941, M. R. Espinosa s.n. (SGO); La Chimba, 02-II-1941, E. Barros 70 (LP); Cerro Moreno, 28-IX-1941, E. Barros 1319 (LP). III Región: Atacama, Prov. Copiapó, Cerro Negro, 18-X-2006, N. Schulz 15 (SGO). IV Región: Coquimbo, Prov. Elqui, La Serena, X-1984, L. Faúndez s.n. (SGO); Choros Bajos, 28-IX-1947, B. Sparre 2798 (SGO). 


\section{F. Ratto y A. Bartoli - Revisión de Gutierrezia}
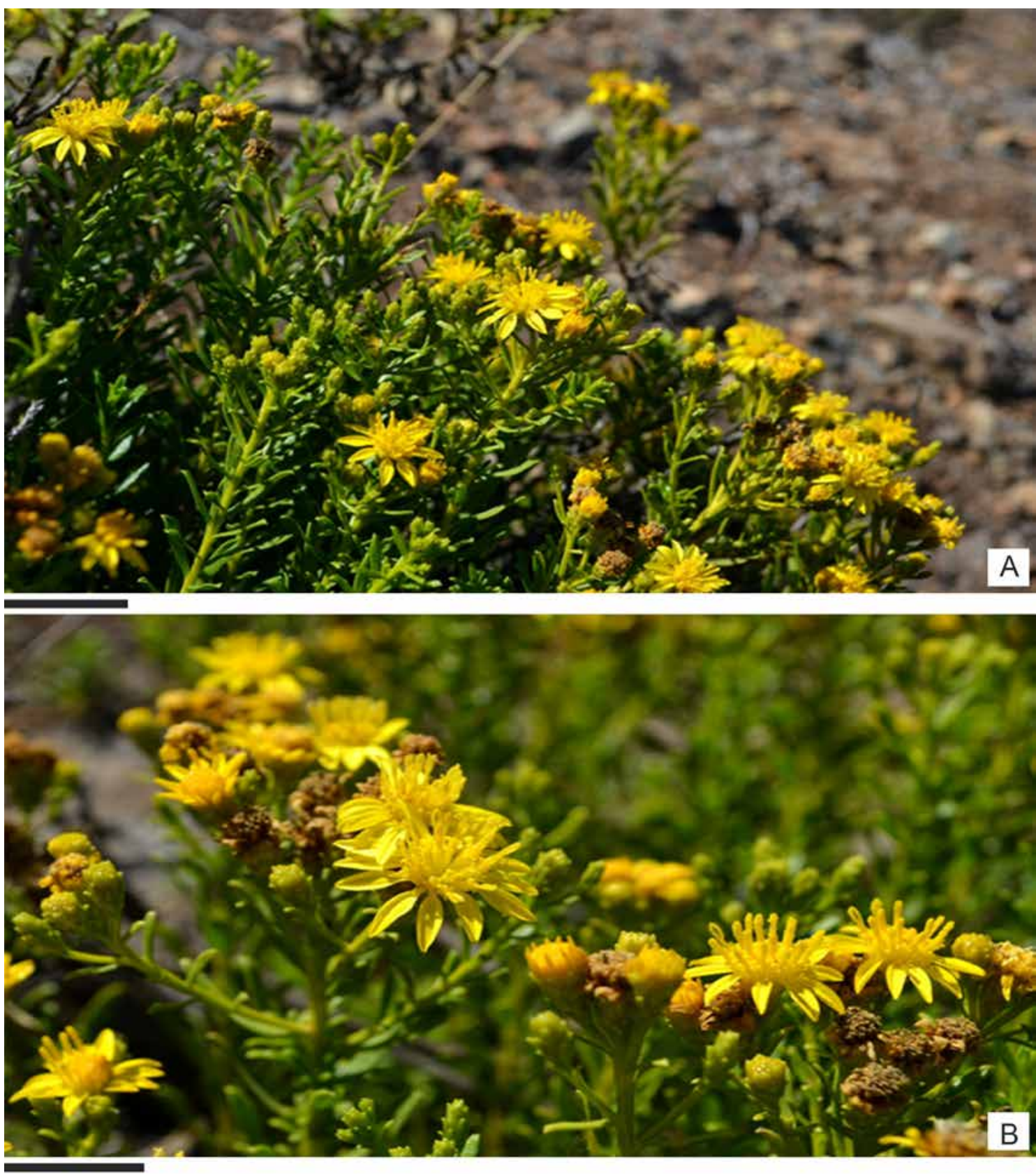

Fig. 9. Gutierrezia espinosae. A: Planta. B: Detalle de los capítulos. Fotografías por Marcelo Rosas. Escalas $=\mathrm{A}-\mathrm{B}: 1 \mathrm{~cm}$.

Observaciones. 1) Especie fundada por R. Acevedo de Vargas (1949) basada en un ejemplar del botánico chileno Marcial Ramón Espinosa Bustos (1874-1959) quién fue el colector del ejemplar tipo y realizó la diagnosis en latín de la especie.

2) Especie con hojas de morfología y tamaño muy variables desde anchamente elípticas a 


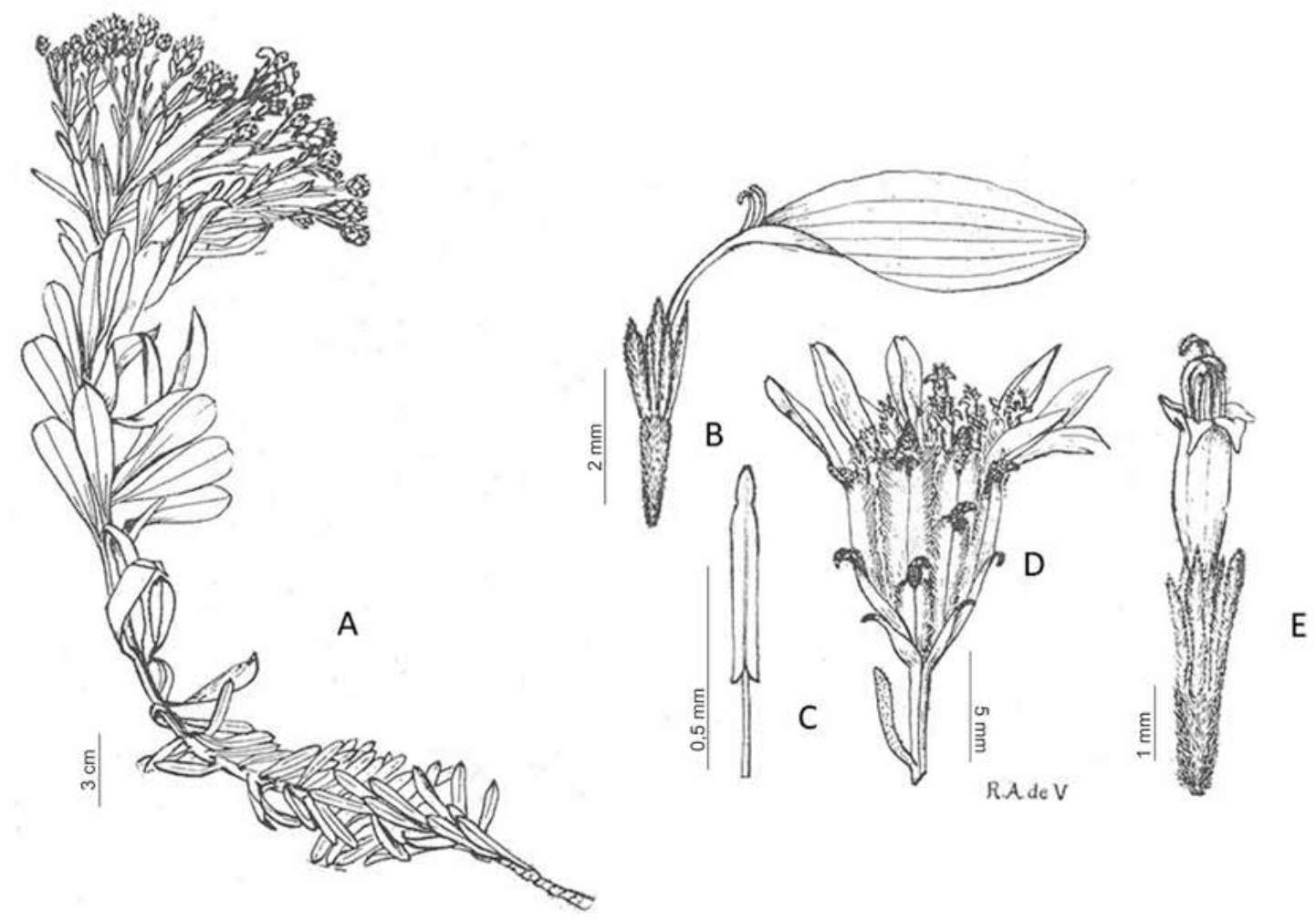

Fig. 10. Gutierrezia espinosae. A: Planta. B: Flor ligulada C: Antera. D: Capítulo. E: Flor tubulosa.

linear-elípticas. Similar a G. taltalensis, con quien comparte área de distribución.

3) Especie endémica muy restringida, se la encuentra solo en Morro Moreno y la quebrada de la Chimba. Poco coleccionada.

5. Gutierrezia gayana (J. Remy) Reiche., Anales Univ. Chile, 109: 22. 1901. (Figs. 11, 12). Odonthocarpa gayana J. Remy., En Gay, Fl. Chil. 1: 44. 1854. Brachyris gayana (J. Remy) J. Remy., En Gay, Fl. Chil. 4: 36. 1849. Tipo: Chile. Coquimbo, M. Cl. Gay. 206, 1838 (Lectotipo, designado por Ratto et al. 2019, P 00742779!; Isolectotipos, B destruido [fotografía de Serie Field Museum 14814], GH 00004314!, K 000221366!, K 000221367!, P 00742781!, P 00742782!).

Iconografía. Gay, C. 1854. Historia física y política de Chile, Botánica, Fl. Chil. 1: 44.

Arbustos de $30-80 \mathrm{~cm}$. ramificados en la base. Tallos erectos, acanalados, glandulares, frondosos en la base y ligeramente foliáceos hasta el ápice, erectos, hojas subcoriáceas, sésiles, irregularmente dentadas, hojas estrechamente lineares, de 30-60 × 1-2 mm, convolutas, agudas, hojas caulinares gradualmente menores. Capítulos radiados, sésiles, de $10-15 \mathrm{~mm}$ de diámetro, formando cimas corimbiformes en el ápice de los tallos, con 1 o 2 brácteas elípticas 4-6 mm de largo, notablemente acuminadas, glandulosas. Involucro acampanado, resinoso, 10-12 x 10-12 $\mathrm{mm}$. Receptáculo plano, alveolado, notablemente piloso. Filarios en 3 series, oblongos, glandulares, notablemente acuminados. Flores liguladas 13 a 16, color blanco, lígula estrechamente elíptica, de $10-12 \mathrm{~mm}$ de largo. Flores del disco 28 a 40, femeninas, con la corola de color blanco, de 4-5 $\mathrm{mm}$ con garganta bruscamente ampliada hacia el ápice. Anteras subagudas en la base con tejido conectivo triangular de $0,3-0,5 \mathrm{~mm}$. Ramas del estilo subagudas. Aquenios grisáceos, poliédricoturbinados, costados, densamente seríceos, 2-3 de $\mathrm{mm}$. Vilano de 15-20 páleas elípticas y laciniadas 

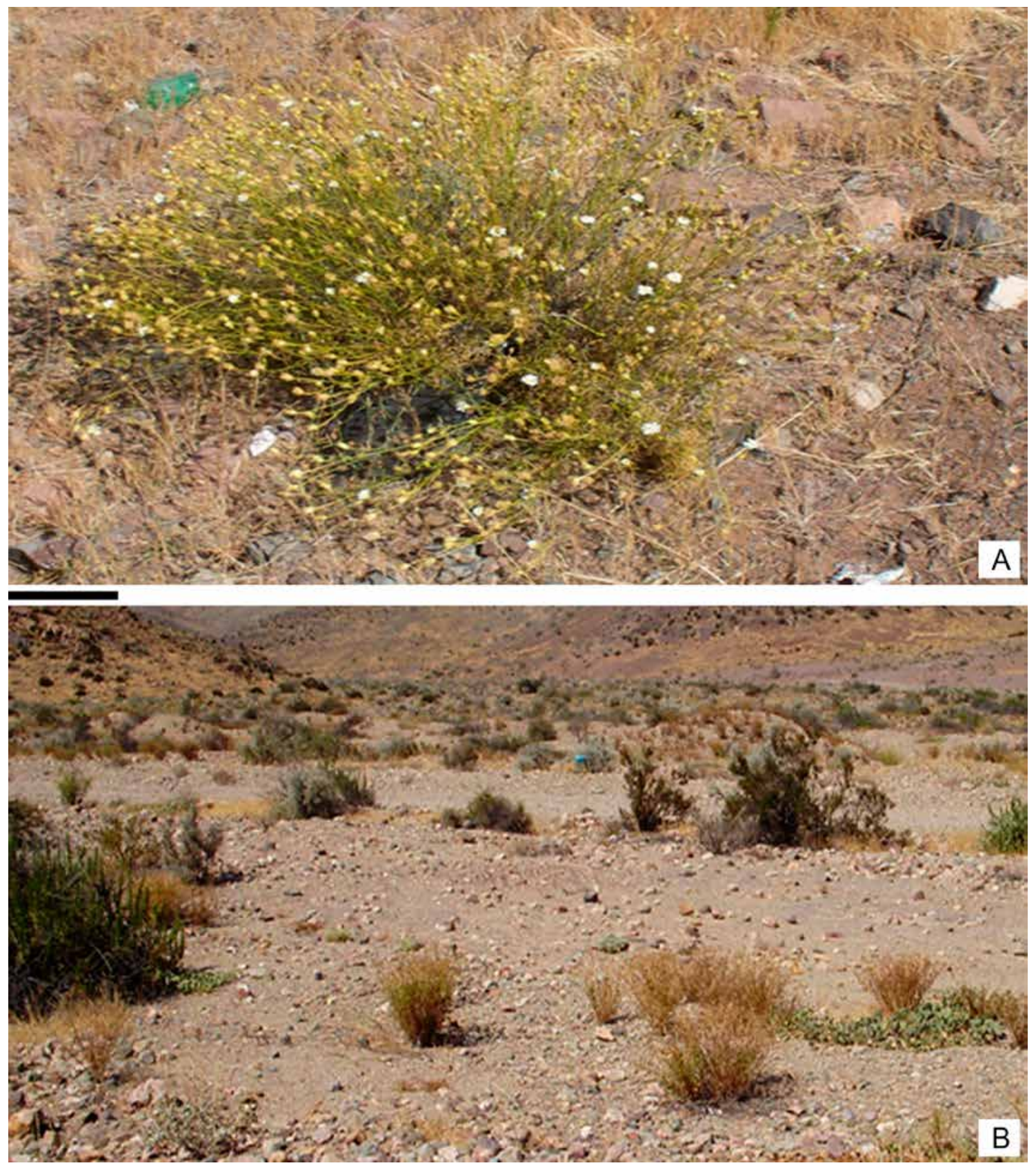

Fig. 11. Gutierrezia gayana. A: Planta. B: Hábitat. Fotografías por F. Ratto. Escalas=A: $2 \mathrm{~cm}$.

de $0,5-1 \mathrm{~mm}$ de largo en flores liguladas y de $1-1,5 \mathrm{~mm}$ de largo en las flores del disco.

Distribución geográfica y hábitat. Se la encuentra en Chile, Región III, Atacama y Coquimbo y Región
IV, Valparaíso, entre los 0 y los 1400 msnm. Habita el Dominio Fitogeográfico Chile Mediterráneo (Fig. 13).

Nombre vulgar. "monte amarillo, pichanilla, hierba delgadilla". 


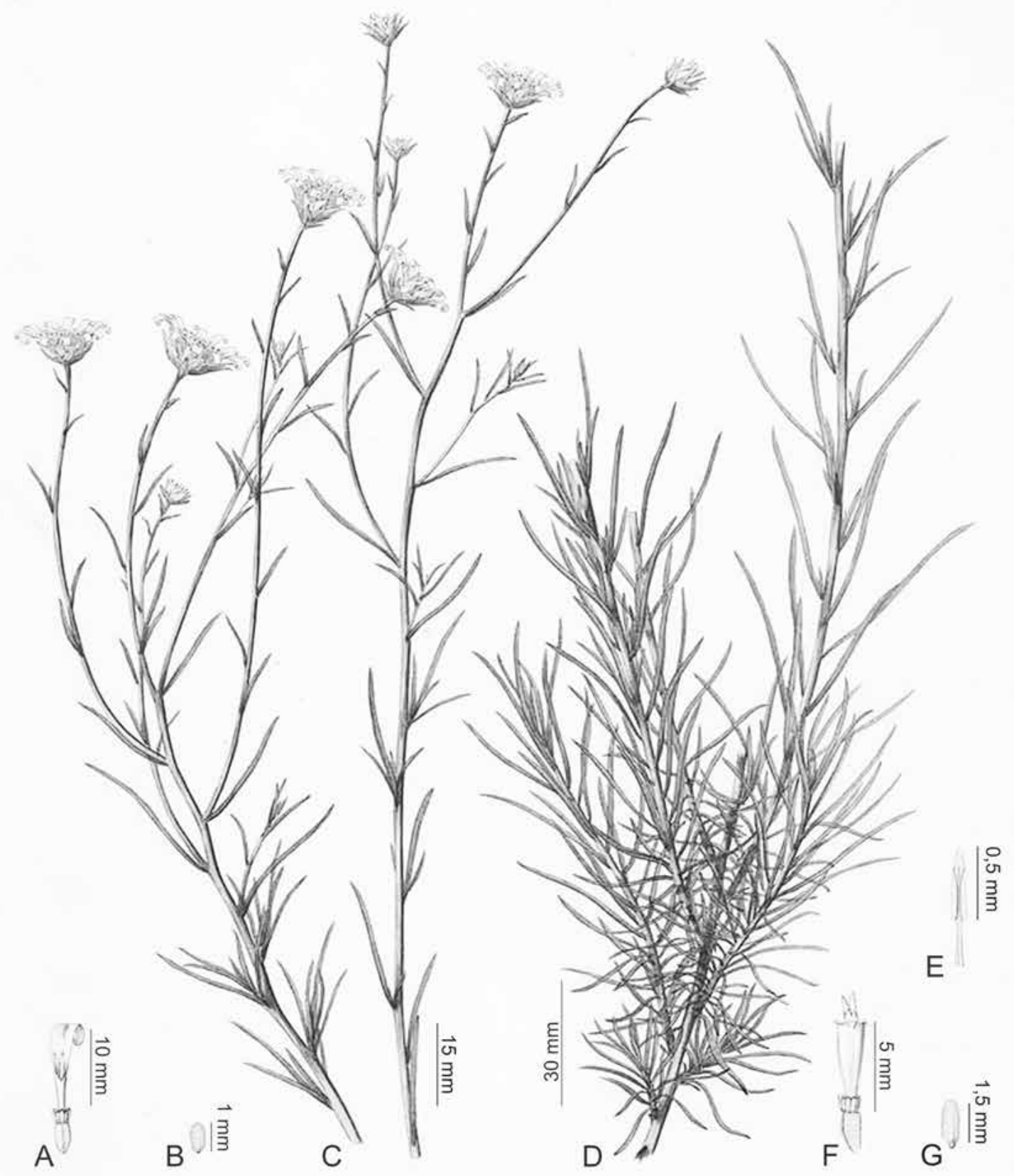

Fig. 12. Gutierrezia gayana. A: Flor ligulada. B: Pálea del papus de una flor ligulada. C-D: Planta. E: Antera. F: Flor tubulosa. G: Pálea del papus de una flor tubulosa.

Especímenes examinados. CHILE: III Región: Atacama, Prov. Copiapó, Arena, Minería Los Loros, $16 \mathrm{~km}$ al S de Tres Cruces, 3-XI-1949, W. Biese 2895 (SGO). Prov. Huasco, Camino a Domeyko, entre 30-40 km al Sur de Vallenar, 23-IX-1941, C. Muñoz P. \& G. T. Johnson 2001 (SGO); Cuesta de
La Viñita, al interior de Marquesa, 20-IX-1957, C. Muñoz P. 4198 (SGO); Cuesta Pajonales, 2-XII1987, M. O. Dillon \& J. T. S. Teillier 5007 (SGO); km 576 ruta 5, sur Cuesta Pajonales, 9-X-2004, M. T. Eyzaguirre s.n. (SGO); Norte entrada de Los Cristales, cuesta ruta 5 entre Vallenar y llanos La 


\section{F. Ratto y A. Bartoli - Revisión de Gutierrezia}

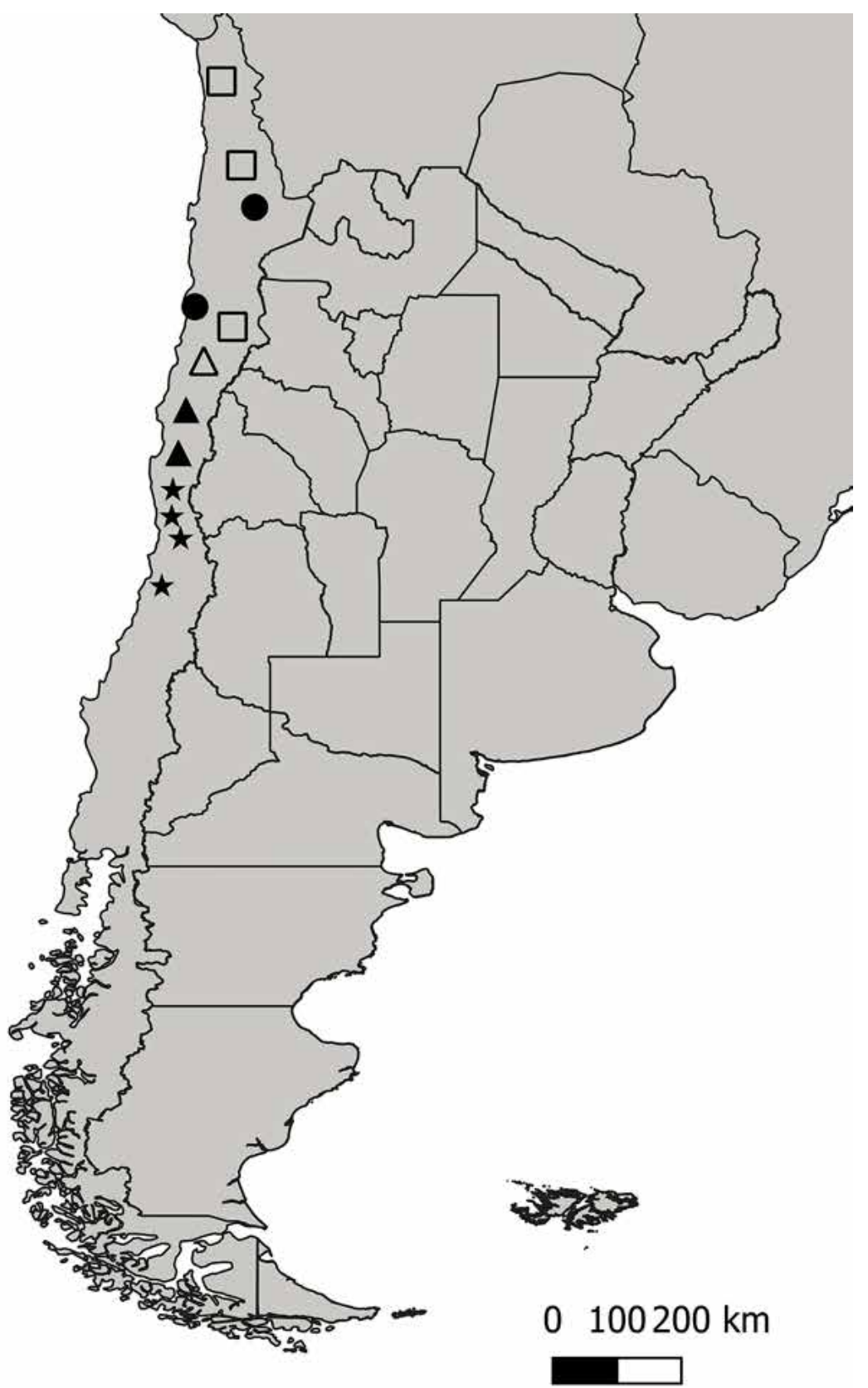

Fig. 13. Distribución geográfica de: Gutierrezia espinosae - G. gayana $\square$, G. neaeana $\boldsymbol{\Lambda}$, G. resinosa $\Delta$, G. taltalensis

Higuera, 8-X-2008, M. Muñoz S. 5047 (SGO); Carretera panamericana $30 \mathrm{~km}$ al $\mathrm{N}$ de Vallenar, 8-IX-1928, A. L. Cabrera 12621 (LP); Cuesta Pajonales, 23-IX-1941, O. Zölner 723 (LP); Inca Huasi, sur de Cuesta Pajonales, Ruta 5, 4-I-2012,
Ratto et al. 10, 11, 12, 13, 14, 15, 16 y 17 (BAA). IV Región: Coquimbo, Prov. Elqui, La Higuera, 1886, F. Fonck s.n. (SGO); Bajada cuesta Viñeta, $111 \mathrm{~km}$ from Serena on road to Condoriaco, 9-X-1959, O. T. Solbrig 3072 (LP); Desierto frente al Tofo, 9- 
II-1968, Ricardi 5466 (BAB, LP); Panamericana norte, $1 \mathrm{~km}$ al norte de la entrada a la mina El Tofo, 3-X-1991, Ch. von Bohlen 1180 (SGO).

Observaciones. 1) Remy (1846) fundó la especie $O$. gayana basado en un ejemplar de M. Claudio Gay a quien dedicó el epíteto. Posteriormente el mismo autor (1849) transfirió la especie al género Brachyris, como B. gayana y finalmente Reiche (1901) transfirió esta especie al género Gutierrezia.

2) Especie notablemente resinosa. Suele ser erróneamente determinada como G. resinosa, de la cual se diferencia por poseer flores liguladas y tubulosas siempre blancas cuando en $G$. resinosa son amarillas. También difiere en el largo y ancho de las hojas y en la arquitectura de la planta. La confusión en los botánicos se debería a que $G$. gayana es mucho más "resinosa" que G. resinosa.

6. Gutierrezia gilliesii Griseb., Abh. Königl. Ges. Wiss. Göttingen. 19: 173. 1874. (Fig. 14). Gutierrezia spathulata (Phil.) Kurtz var. gilliesii (Griseb.) Kuntze., Revis. Gen. Pl. 3 (3): 156. 1898. Gutierrezia mandonii (Sch. Bip.) Solbrig subsp. gilliesii (Griseb.) Solbrig., Contr. Gray Herb. 197: 22. 1966. Tipo: Argentina. Córdoba. Inder Sierra zwischen San Pedro und Horco, P. G. Lorentz 183, Jun 1871. (Holotipo GOET 001591!; Isotipos: B destruido [fotografía de Serie Field Museum 14815], CORD 00006301!, LP 001994!).

Iconografia. Cabrera, A. L.1971. Compositae. En M. N Correa (Ed.), Fl. Patagónica parte VII: 29, fig. 15. Colección científica del INTA.

Arbustos de 15-40 cm, ramificados en la base. Tallos erectos, costados, glandulares, frondosos en la base y ligeramente foliáceos hasta el ápice. Hojas subcoriáceas, sésiles, las basales linearelípticas, de 15-45 x 1-3 mm, agudas, las caulinares gradualmente menores. Capítulos radiados, sésiles, de 1-1,2 $\mathrm{cm}$ de diámetro, agrupados en cimas corimbiformes en el ápice de los tallos, con 1 o 2 brácteas lineares elípticas, de $3-5 \mathrm{~mm}$ de longitud. Involucro acampanado, resinoso, 5-8 x 4-7 mm. Receptáculo plano o ligeramente convexo, alveolado, piloso. Filarios en 3 series, oblongos, los externos glandulosos, acuminados, los internos triangulares, glandulosos, apiculados. Flores liguladas 6 a 8, blancas, raro blanco-amarillentas, con lígula estrechamente obovada, de $6-8 \mathrm{~mm}$ de longitud. Flores del disco 7 a 16, tubulosas, pistiladas, con la corola de color amarillento, de 3-4 mm de longitud, con garganta bruscamente ampliada. Anteras redondeadas en la base con tejido conectivo triangular de $0,5 \mathrm{~mm}$. Ramas del estilo obtusas. Aquenios grisáceos, ovoide-turbinados, costados, densamente seríceos, de $1,5 \mathrm{~mm}$. Vilano de 10-17 páleas linear-elípticas y laciniadas, de 1 $\mathrm{mm}$ de longitud en las flores liguladas y de $2 \mathrm{~mm}$ de longitud en las flores del disco.

Distribución geográfica y hábitat. Se distribuye desde Catamarca hasta el este de la Provincia de Río Negro. Habita la provincia fitogeográfica del Monte, entre los 100 y los $2600 \mathrm{msnm}$, en suelos rocosos y/o arenosos (Fig. 15).

\section{Nombre vulgar. No se conoce.}

Especimenes examinados. ARGENTINA. Prov. Córdoba: Dpto. Santa María, Alrededores de Malagueño, 9-VIII-1946, A. T. Hunziker 6658 (LP); Malagueño, 12-VIII-1949, A. M. Fuchs 17102 (SI). Dpto. Punilla, Cerro Uritorco, falda occidental, 15-I-1965, A. T. Hunziker 18816 (CORD). Dpto. Rio IV, Achiras (Monte Guazú), 8-III-2010, J. J. Cantero 6274 (CORD). Prov. Catamarca: Dpto. Andalgalá, 1915, P. Jöergensen 1506 (SI). Dpto. Belén, Granadillas, I-1883, F. Schikendantz 170 (LP); Puerta del Corral Quemado, 30-III-1929, A. L. Cabrera 977 (LP). Dpto. Capital, Río de Hualfín, I-1883, F. Schikendantz 139 (LP). Dpto. Pomán, Cuesta de Pomán, I-1883, F. Schickendantz 118 (LP); Las Ciénagas, cerros al SE, 18 km de Pomán, 27-II-1952, F. Vervoorst 3476 (LP). Prov. La Pampa: Dpto. Chicalcó, Ruta 151, loma amarilla, 19-XI-1965, E. Cano 3255 (BAB); Loma de Los Guanacos, ruta 151, XII-1960, E. Cano 1121 (BAB). Dpto. Puelén, Cruce rutas 21 y 151, XII1960, Cano 1200 (BAB); Cerro Bayo, 9-X-1981, Steibel \& Troiani 6607 (CORD). Prov. La Rioja: Dpto. Sierra Velasco, Pampa de Sigú, 29-II-1908, F. Kurtz 15312 (CORD). Dpto. Capital, Estribación oriental de la Sierra de Velazco: cerca de la Mina El Cantadero (=La Esperanza), 5-III-1944, A. T. Hunziker 5218 (CORD). Dpto. Famatina, Río Amarillo, Quebrada de Juan Díaz, 13-III-1906, F. Kurtz 13474 (CORD). Dpto. Independencia, Entre Gualo y Puesto Talampaya, 27-I-1906, F. Kurtz 


\section{F. Ratto y A. Bartoli - Revisión de Gutierrezia}
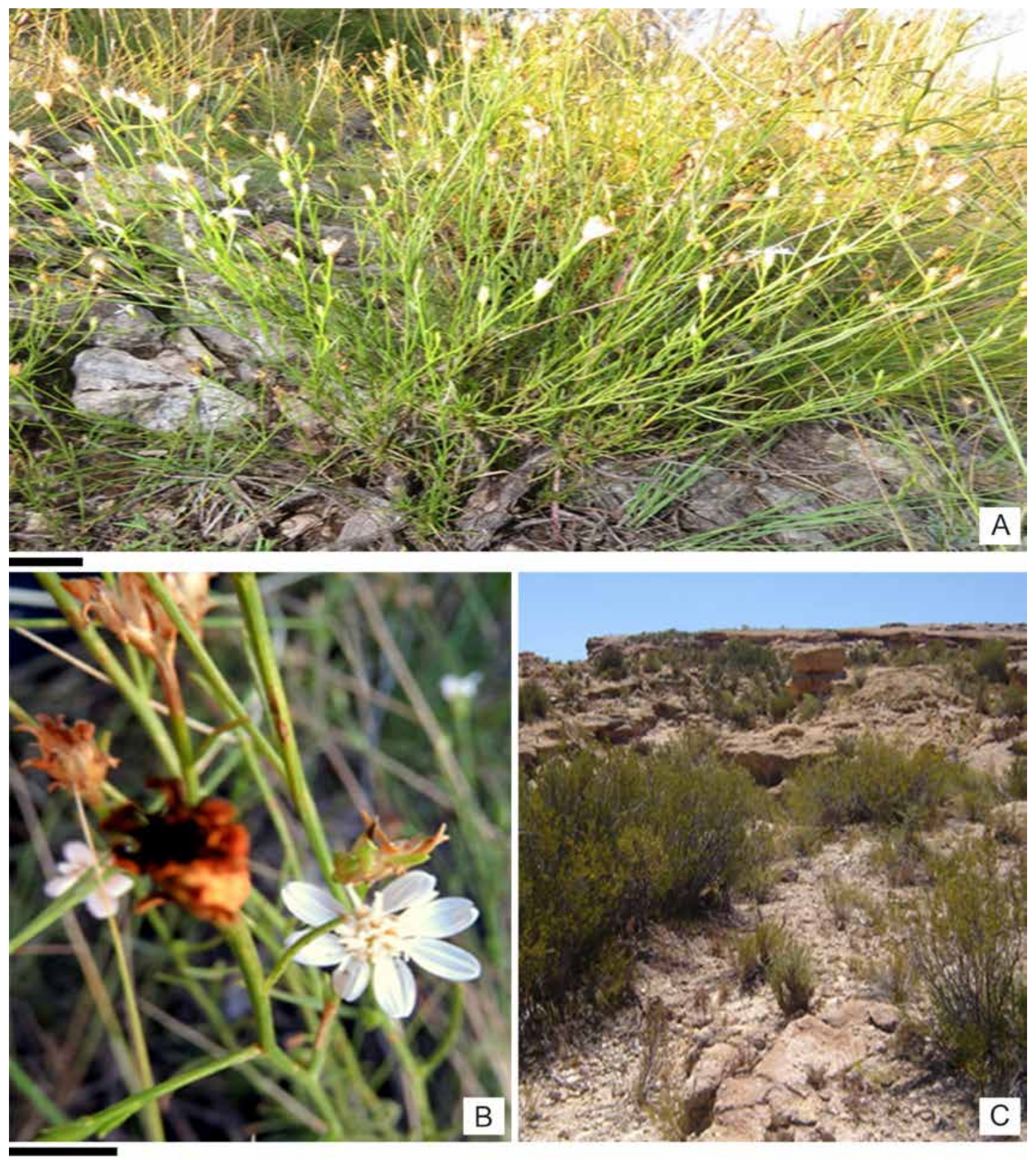

Fig. 14. Gutierrezia gilliesii. A: Planta. B: Detalle del capítulo. C: Hábitat. Fotografías por Francisco Ratto. Escalas $=A: 1 \mathrm{~cm} ; B: 0,5 \mathrm{~cm}$.

13292 (CORD); Sierra de Paganzo, 3-II-1961, A. T. Hunziker et al. 15859 (CORD); Ruta nacional 150: entre Los Baldecitos y La Torre, a +/- $3 \mathrm{~km}$ de ésta, 8-XI-1995, F. Biurrun et al. 4192 (CORD). Dpto. Lavalle, Gualo, 26-I-1906, F. Kurtz 13285
(CORD). Prov. San Luis: Dpto. Ayacucho, San Francisco, Qda. de los Carrizales, 12-II-1925, A. Castellanos s.n. (BA). Dpto. Belgrano, Nogolí, I-1922, J. W. Gez 95 (SI). Dpto. Pringles, Estancia El Rincón del Valle de R. Sorondo, Valle Pancanta, 


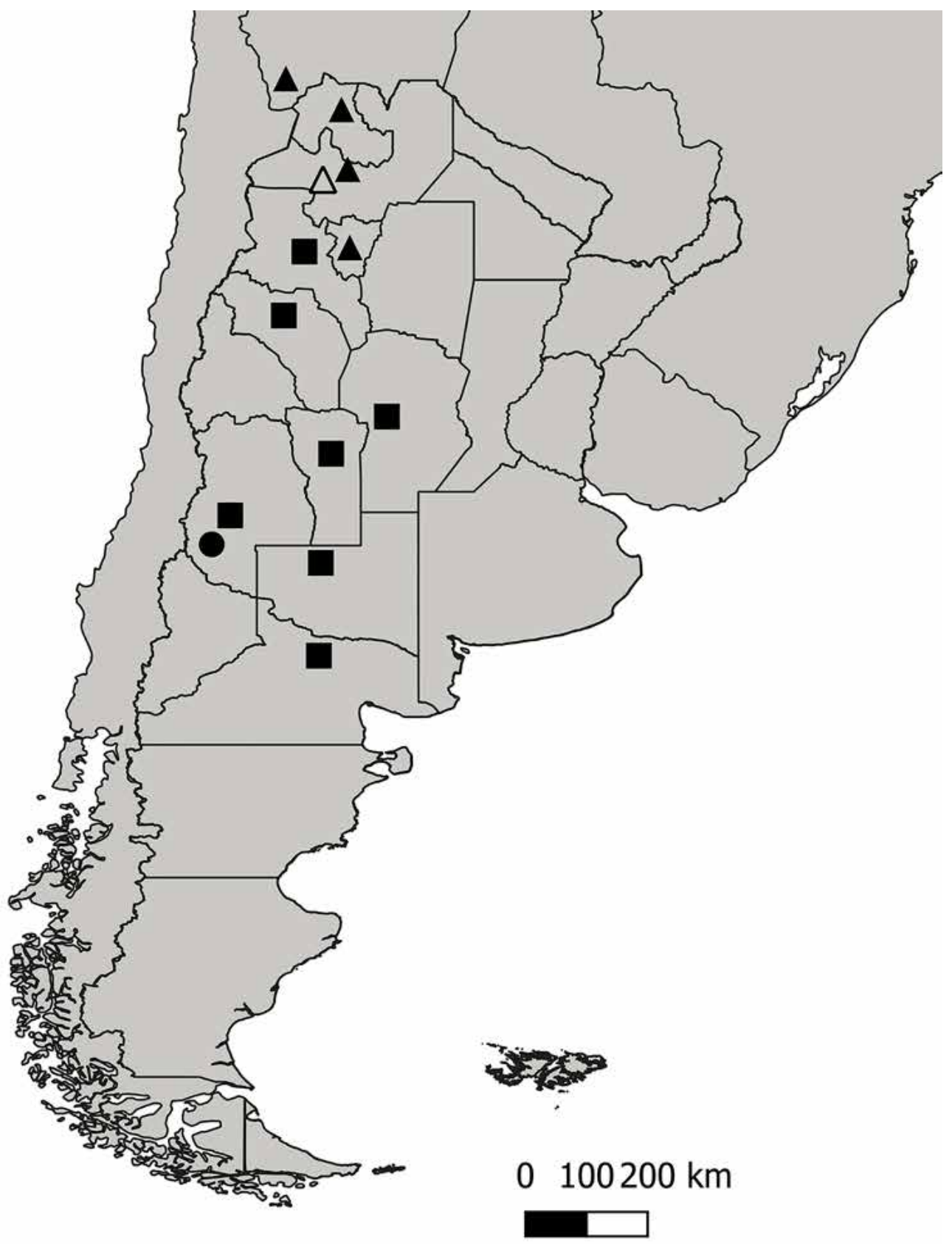

Fig. 15. Distribución geográfica de Gutierrezia gilliesii $\mathbf{\square}$, G. mandonii var. mandonii $\mathbf{\Delta}$, G. mandonii var. anomala $\Delta$, G. spathulata

29-III-1972, D. L. Anderson 2399 (CORD); Sierra de San Luis, entre Pampa del Tamboreo y dique La Florida, 15-V-1982, D. L. Anderson 3905 (CORD). Prov. Mendoza: Dpto. Las Heras, Quebrada del Toro (Cerro Pelado), 18-I-1897,
F. Kurtz 9339 (CORD); Camino de Uspallata a Villavicencio, 1-II-1939, N. Troncoso 6058 (SI). Dpto. Luján de Cuyo, Cacheuta, I- 1925, Gianetti 9066 (SI). Dpto. San Carlos, I-1925, Gianetti 5 (SI). Dpto. San Rafael, Cuesta de Los Terneros, 


\section{F. Ratto y A. Bartoli - Revisión de Gutierrezia}

28-I-2016, F. Ratto, D. Sbarra \& M. Sorondo 108/2016 (BAA); Embalse Agua del Toro, 14 II-2016, F. Ratto, D. Sbarra \& D. Schiavinato 114/2016 (BAA). Dpto. Tupungato, Tupungato, Pampa de las Aguaditas, 8-IV-1965, F. A. Roig 5365 (CORD). Prov. Río Negro: Dpto. Adolfo Alsina, A. Alsina, RN $3 \mathrm{~km} 1060(80 \mathrm{~km}$ al E de S. Antonio Oeste), 19-I-1958, F. Vervoorst 5570 (BAB). Dpto. Avellaneda, La Japonesa, costa del Colorado, 14-I-1927, A. Castellanos s.n. (BA). Dpto. San Antonio, Las Grutas, San Antonio Oeste, 14-XII-1981, S. Crespo \& P. Calieres 2509 (BAB).

Observaciones. 1) Especie fundada por Grisebach (1874) basada en un ejemplar de P. G. Lorentz. Kuntze (1898) sobre el mismo ejemplar, combinó la especie como variedad de $G$. spathulata, G. spathulata var. gilliesii. Finalmente, Solbrig (1966) la combinó como subespecie de $G$. mandonii, G. mandonii subsp. gilliesii.

2) La especie presenta hojas lineares, pero existen poblaciones con hojas linear-elípticas en la provincia de Mendoza. Se puede confundir con G. leucantha, especie recientemente rehabilitada (Ratto \& Bartoli, 2016b), de la cual difiere por ser de menor tamaño y poseer hojas lineares.

3) En la provincia de Río Negro, Departamento de San Antonio, existen ejemplares intermedios entre esta especie y $G$. solbrigii.

4) Es también afín a $G$. isernii, con la cual superpone parcialmente su área de distribución. En las provincias de Córdoba y San Luis existen ejemplares intermedios entre estas dos especies.

7. Gutierrezia isernii (Phil.) Phil., Anales Univ. Chile, 87: 427. 1894. Brachyris isernii Phil., Anales Univ. Chile 27: 337. 1865. Gutierrezia mandonii (Sch. Bip.) Solbrig subsp. isernii (Phil.) Solbrig., Cont. Gray Herb. Harvard Univ. 197: 24. 1966. Tipo: Argentina. Inter Mendoza et Santa Rosa, 1861/63, J. Isern s. n. (Holotipo SGO65115!; Isotipo LP 001997).

Iconografía. Instituto Darwinion (2013). Catálogo de plantas vasculares. Gutierrezia isernii (Phil.) Phil. var. isernii. San Isidro, Argentina. Instituto de Botánica Darwinion. Recuperado de: http://www2.darwin.edu.ar/ImagenesIris/ Gutierrezia\%20isernii_corr.jpg

\section{Clave para determinar las variedades}

A. Capítulos con todas las flores amarillas.

G. isernii var. isernii

AA. Capítulos con todas las flores blancas.

G. isernii var. nivea

7a. Gutierrezia isernii (Phil.) Phil. var. isernii. (Figs. 16, 17).

Arbustos de 20-60 cm. Tallos erectos, notablemente costados, glandulares, frondosos desde la base. Hojas subcoriáceas, sésiles, lineares o linear-elípticas, con el ápice agudo, de 10-30 x 0,5-2 mm. Capítulos radiados, solitarios, sésiles, de $8-10 \mathrm{~mm}$ de diámetro acompañados de 1-2 brácteas lineares o linear-elípticas de 1-5 $\mathrm{mm}$. Involucro cilíndrico, resinoso, 5-6 x 2-4 mm. Filarios en 3 series, oblongos, con bordes hialinos, los de la serie externa ovados, agudos, glandulares, apiculados; los de la serie interna triangulares, acuminados, glandulares. Receptáculo plano o ligeramente convexo, alveolado, piloso. Flores liguladas 6 a 9, femeninas, color amarillo, lígulas elípticas, de 5-6 mm de largo por 1-2 $\mathrm{mm}$ de ancho. Flores del disco 6 a 10, hermafroditas, con la corola amarilla, de 3-4 mm con garganta bruscamente ampliada. Anteras redondeadas en la base con tejido conectivo triangular de $0,5 \mathrm{~mm}$. Ramas del estilo agudas a subagudas. Aquenios grisáceos, cilíndricoturbinados, costados, densamente seríceos, de 1-1,5 $\mathrm{mm}$. Vilano compuesto de $10-15$ páleas lineares o linear-elípticas, laciniadas de $0,5-1 \mathrm{~mm}$ de largo en flores liguladas y de 1-2 $\mathrm{mm}$ en las flores del disco.

Distribución geográfica y hábitat. Habita las provincias de Catamarca, Córdoba, La Rioja, Mendoza, San Juan y San Luis. Se la encuentra en la provincia fitogeográfica del Monte entre los 900 y los $2700 \mathrm{msnm}$, en laderas con suelos pedregosos.

Nombre vulgar. "yerba de sapo".

Especímenes examinados. ARGENTINA. Prov. Catamarca: Dpto. Ambato, Sierra de Ambato, camino del Rodeo a Las Juntas, Bella Vista, 29-I-1957, C. E. Calderón 1455 (BAA). Dpto. Andalgalá, R 63, 17 mi N Andalgalá, 2-III-1977, SI 98620 (SI); Andalgalá, P. Jöergensen 1508 

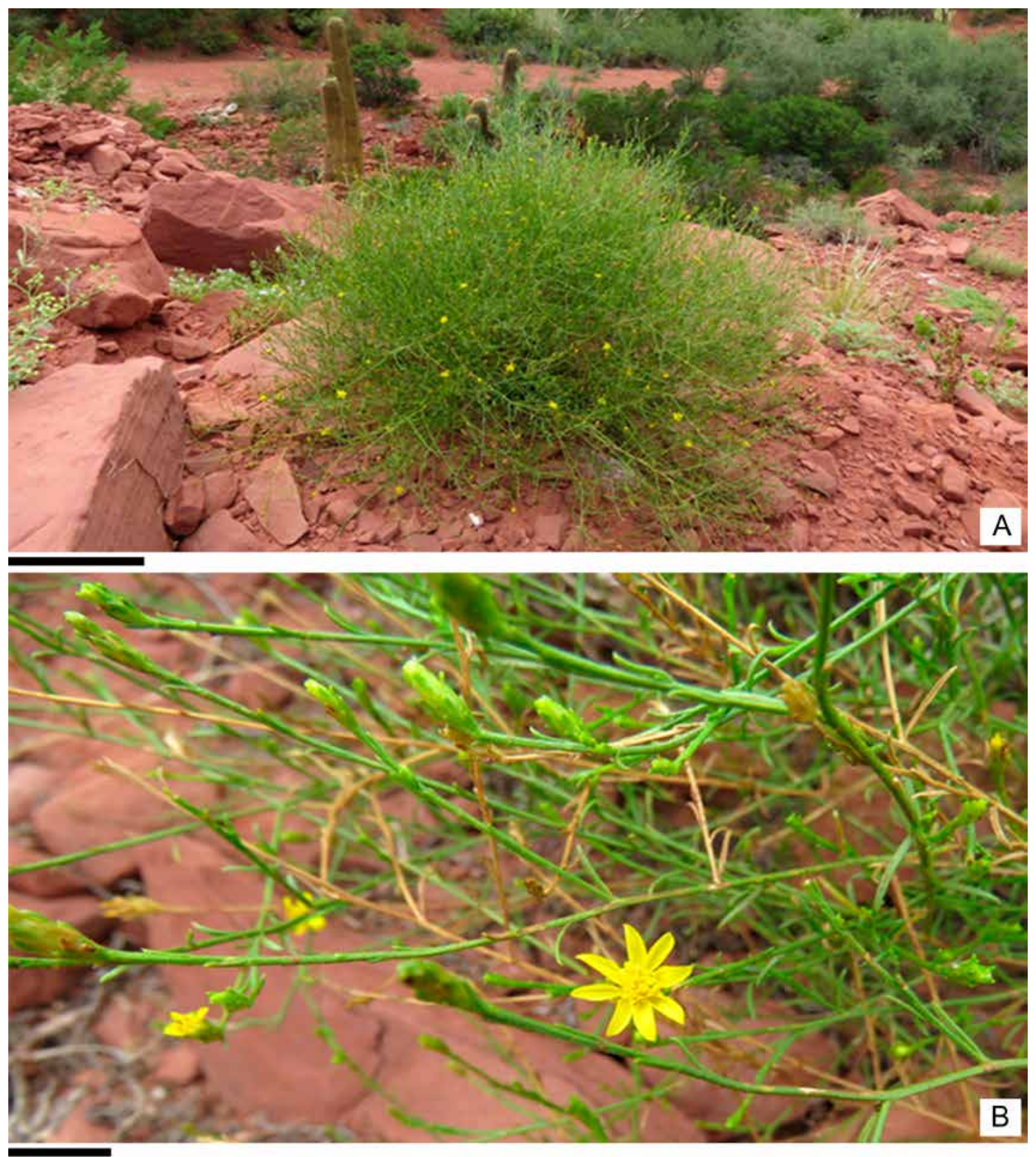

Fig. 16. Gutierrezia isernii var. isernii. A: Planta. B: Detalle de capítulos. Fotografías por Francisco Ratto. Escalas $=A: 10 \mathrm{~cm} ; B: 1 \mathrm{~cm}$.

(SI). Dpto. Belén, Cerro de Belén, 2-III-1955, M. Sayago 1977 (LP). Dpto. Bella Vista, Sa. De Ambato camino a El Rodeo de Las Juntas, 29-I-1957, C. E. Calderón 1452 (SI). Dpto. La Paz, Ruta de Salas a La Horqueta, 17-V-1975, F. A. Roig 9514 (MERL).
Dpto. Tinogasta, Cuesta de Zapata en el camino de Tinogasta a Belén, 27-II-1965, A. L. Cabrera et al. 16749 (LP), R40, 22 mi NE Tinogasta, 24-V-1977, SI 4855 (SI). Prov. Córdoba: Dpto. Ischilín, Sierra de Copacabana, faldeos del noreste, 5-II-1960, 


\section{F. Ratto y A. Bartoli - Revisión de Gutierrezia}
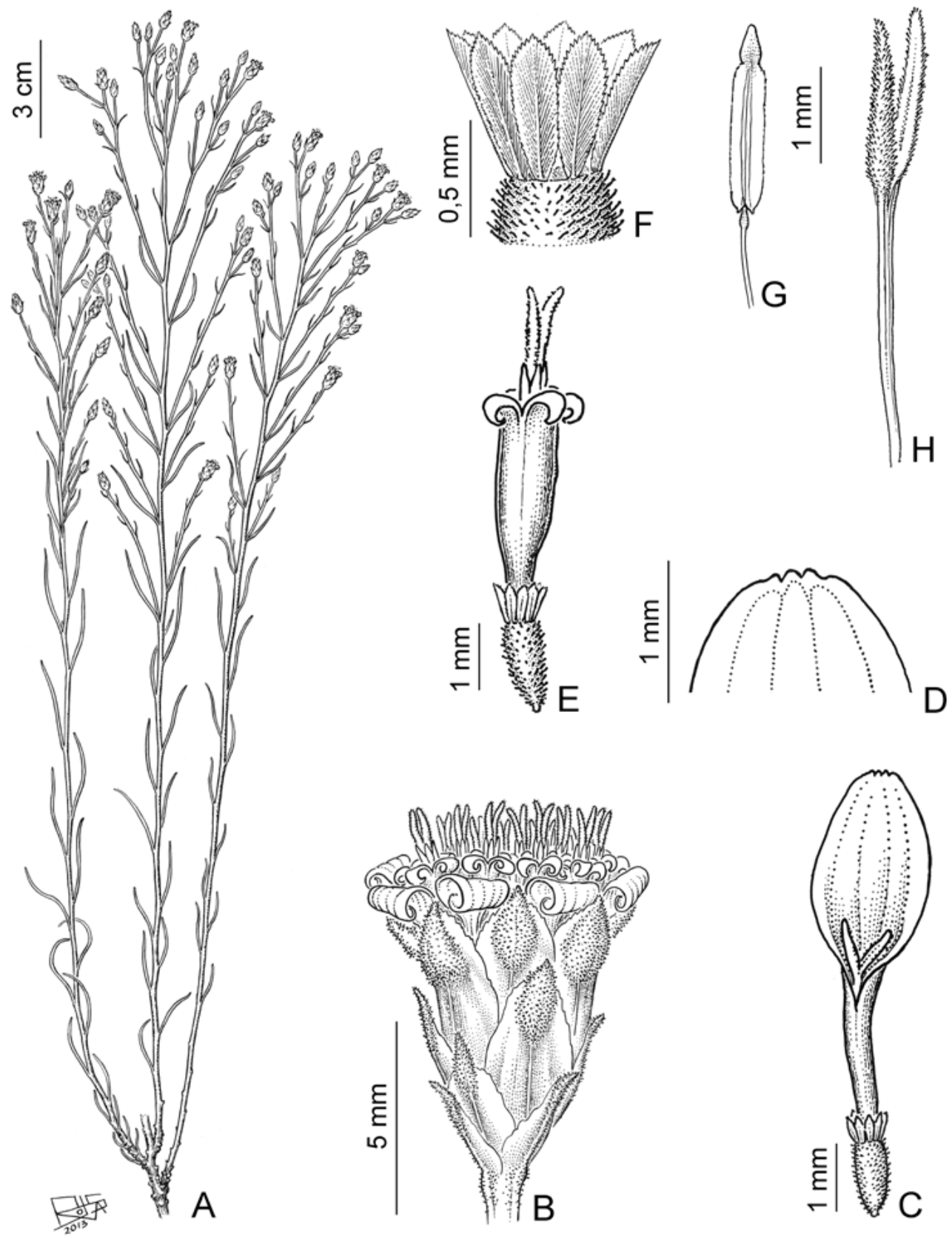

Fig. 17. Gutierrezia isernii var. isernii. A: Planta. B: Capítulo. C: Flor ligulada. D: Ápice de la lámina. E: Flor tubulosa. F: Papus. G: Antera. H: Estilo y estigma.

A. T. Hunziker 14801 (SI). Dpto. Pocho, Laguna de Pocho, 15-II-1922, A. Castellanos s.n. (BA). Dpto. Punilla, Los Cocos, II-1940, A. L. Cabrera 6390 (LP), R 156, 1 mi S. La cumbre, 26-II-1977, Sin colector 98061 (SI). Dpto. Tuluma, San Pedro
Norte, 24-I-1963, Sin colector 4147 (LP). Prov. La Rioja: Dpto. Capital, Sierra de Velazco, cerca de la mina el Cantadero (=la esperanza), 6-III-1944, A. T. Hunziker 5218 (LP); Quebrada de la Cébila, vertiente occidental de la sierra de Ambato a 25 
km del empalme con la RP $\mathrm{N}^{\circ} 46,7-\mathrm{II}-1997, \mathrm{~F}$. Biurrun \& E. Pagliari 4729 (SI). Dpto. Chilecito, Ruta 40, cuesta del Río Miranda, 10-I-2011, F. Ratto, F. Marzaro \& M. Bello 25, 26, 27, 28, 29, 30, 78, 79, 80 (BAA); Ruta 40, cuesta del Río Miranda, 10-I-2011, F.Ratto, F. Marzaro, \& M. Bello 31 (BAA); RN 40, Cuesta de Miranda, 21-II-2016, F. Ratto, D. Sbarra \& D. Schiavinato 118/2016 (BAA). Dpto. Coronel Felipe Varela, RN 40 de Guandacol a Chilecito, Cuesta de Miranda, $2050 \mathrm{~m}$, 12-II-2011, F. O. Zuloaga et al. 12830 (SI); RN 40, Piedra Pintada, 17-II-2016, F. Ratto, D. Sbarra \& D. Schiavinato 117/2016 (BAA). Dpto. Famatina, Valle Hermoso, Los Colorados, 08-III-1950, J. Hunziker \& O. Caso 4252 (LP); Sierra de Famatina, camino a La Mejicana, 6-II-1927, L. R. Parodi 8061 (BAA). Dpto. Vinchina, Juntas del Bonete y Ciénaga Grande, 9-II-1949, A. Krapovickas \& J. Hunziker 5910 (BAB). Prov. Mendoza: Dpto. La $P a z$, Ruta de Salas a La Horqueta, 17-V-1975, F. A. Roig 9514 (SI). Dpto. Las Heras, Villavicencio, 27-II-1942, A. Burkart et al. 14385 (LP); Cerca del Portezuelo (Quebrada del Toro), 4-I-1961, F. A. Roig 4299 (MERL); Quebrada de La Obligación, 15-II-1972, F. A. Roig 7305 (MERL), Dpto. Luján de Cuyo, La Crucecita, 19-II-1944, A. Burkart 14959 (SI); Potrerillos, 16-IV-1954, F. A. Roig 600 (MERL); Cacheuta, II-1962, O. T. Solbrig 22679 (LP). Dpto. San Carlos, Quebrada Alvarado, 20-III-1945, G. Covas 3424 (SI). Dpto. Rivadavia, San Isidro, 9-I-1962, A. V. Borrello (LP). Prov. San Juan: Dpto. Angaco, Sierra Pie de Palo, 28 XI-1980, A. T. Hunziker et al. 23693 (SI); Sa. De Pie de Palo, Camino a Mogote de Los Corralitos, 2500 m, 28-I-1981, R. Kiesling 3135 (SI). Dpto. Calingasta, Qda. De Santa Clara, 17-II-2000, Tombesi et al. 82 (SI). Dpto. Jáchal, de Jáchal a Gualcamayo, 15-II-2000, Tombesi et al. 28 (LP, SI). Dpto. Valle Fértil, Quebrada del Río Tumanas, 27-IV-1971, Piccinini \& Leguizamón 2014 (BAB), San Agustín del Valle Fértil, 3-IV-1982, A. Cortez 136 (LP); 5 km de Los Bretes, 9-III-1998, R. H. Fortunato et al. 5936 (SI). Dpto. Sarmiento, Sierra de Ansilta, Quebrada Santa Clara, 31-III-1999, F. Biurrun et al. 5830 (LP). Dpto. Zonda, Estancia Maradona, 7-II-1986, R. Kiesling, N. Bacigalupo \& E. V. Gómez Sosa 5965 (SI). Prov. San Luis: Dpto. Belgrano, Falda oriental de La Sierra del Gigante, G. R. Guiñazú 31 (LP); Ea. Bajo del Jume, G. R. Guiñazú 8 (LP).
Observaciones. 1) Especie fundada por Philippi (1865) como B. isernii a partir de un ejemplar coleccionado por el botánico español Juan Isern Batlló y Carrera (1821-1866) a quien homenajeó con su nombre, posteriormente transferida por el mismo autor al género Gutierrezia. Solbrig (1966) propuso la entidad como G. mandonii subsp. isernii. Finalmente, Sancho \& Ariza Espinar (2003) volvió la especie a su nombre original.

2) Es similar a $G$. gilliesii pero es de mayor tamaño y presenta capítulos con involucro cilíndrico notablemente más angostos. Existen ejemplares intermedios con $G$. gilliesii en las provincias de Córdoba y San Luis.

7b. Gutierrezia isernii (Phil.) Phil. var. nivea Ratto \& A. Bartoli., Bol. Soc. Argent. Bot. 52(4) 2017. (Fig. 18). Tipo: Argentina. Mendoza. Las Heras. Caracoles de Villavicencio, 15-II-2016, F. Ratto, D. Sbarra \& D. Schiavinato 113/2016 (Holotipo, BAA 00004810!, Isotipos BAA 00004811!, BC!, SI!).

Difiere de la variedad típica por presentar flores liguladas blancas en lugar de amarillas. A su vez, las flores tubulosas pueden ser amarillentas o blancas.

Distribución geográfica y hábitat. Habita las provincias de Córdoba, Mendoza y San Luis. Se la encuentra en la provincia fitogeográfica del Monte entre los 900 y $2700 \mathrm{msnm}$, en laderas con suelos pedregosos.

Nombre vulgar. no se conoce.

Especímenes examinados. ARGENTINA. Prov. Córdoba: Dpto. Santa María, $3 \mathrm{~km}$ al S de San Pedro, 14-II-1962, O.T. Solbrig 3402 (LP). Prov. Mendoza: Dpto. Godoy Cruz, Cerro Melocotón, 22-III-1973, F. A. Roig 7705 (MERL). Dpto. Las Heras, Ca. Del cerro Casa de Piedra, 22-VII-1975, F. A. Roig 8741 (MERL); Ruta 52, entrada al Hotel Villavicencio, 11-I-2011, F. Ratto, F. Marzaro \& M. Bello 32 (BAA); Ruta 52, entrada al Hotel Villavicencio, 11-I-2011, F. Ratto, F. Marzaro \& M. Bello 33, 34, 35, 37 y 95 (BAA). Prov. San Luis: Dpto. La Capital, Sierra Varela, 22-XII-1925, Castellanos s.n. (BA); Potrero de Los Funes, 3-III-2014, D. Sbarra 20, 21, 22, 23, 24 y 26 (BAA). Dpto. Coronel Pringles, La Carolina, 20-I-2013, R. Tortosa 27214 (BAA). 

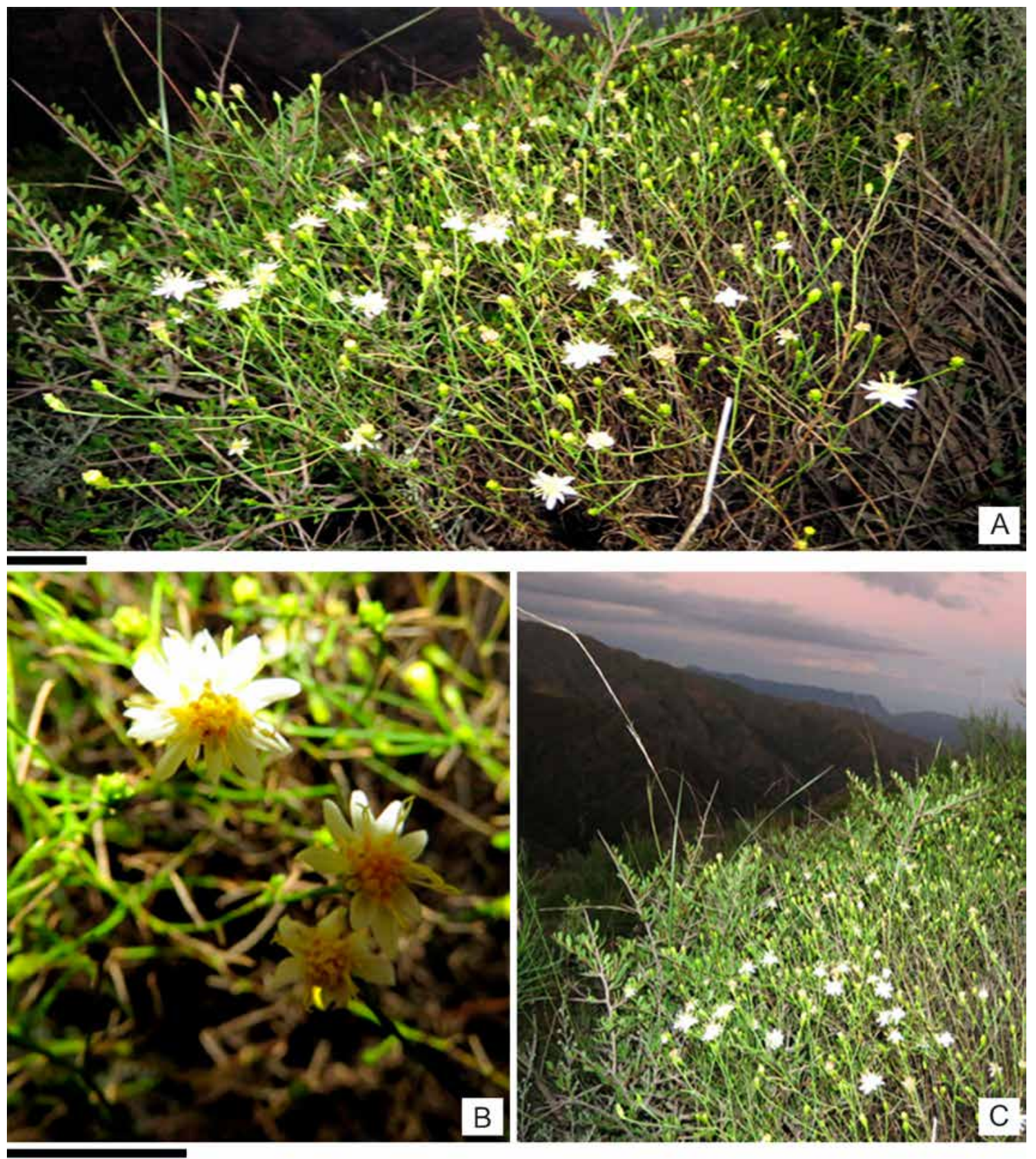

Fig. 18. Gutierrezia isernii var nivea. A: Planta. B: Detalle de capítulos. C: Hábitat. Fotografías por Francisco Ratto. Escalas $=\mathrm{A}: 1 \mathrm{~cm} ; \mathrm{B}: 5 \mathrm{~cm}$.

Observaciones.

1) Variedad recientemente fundada por Ratto \& Bartoli (2017).

2) Se distingue de la variedad típica por poseer todas sus flores blancas o bien las liguladas blancas y las tubulosas amarillentas.

3) Se encuentran poblaciones aisladas que no conviven con la variedad típica. 
8. Gutierrezia leucantha Cabrera., Revista. Mus. La Plata (Nueva Serie), Secc. Bot. 4: 61. 1941. (Fig. 19). Tipo: Argentina. Buenos Aires. Sierra de la Ventana, entre las peñas, 23 May 1938, A. L. Cabrera 4475 (Lectotipo designado por Ratto et al. 2019 LP 000269!; Isolectotipos, K 001097231 [foto]!, LP 000270!, SI!).

Iconografia. Cabrera, A. L. Revista Mus. La Plata. Secc. Bot. 4: 61 Fig. 16. 1941.

Arbustos de 30-100 cm de altura, ramificados desde la base. Tallos erectos, costados, glandulares, foliosos, hojas subcoriáceas, sésiles, irregularmente dentadas en la margen, hojas linear-elípticas de 30-50 x 3-5 mm, agudas. Capítulos radiados, solitarios, heterógamos, sésiles, de 10-16 $\mathrm{mm}$ de diámetro, dispuestos en cimas corimbiformes muy laxas, con 1 o 2 brácteas elípticas de 2-3 $\mathrm{mm}$ de largo. Involucro acampanado o acampanado-turbinado, resinoso, de 5-7 mm x 4-6 $\mathrm{mm}$. Receptáculo plano o ligeramente convexo, desnudo, alveolado, piloso. Filarios en 3 series, los exteriores oblongos, apiculados, glandulares, los interiores triangulares. Flores liguladas 6-9, pistiladas, con lámina blanca, elípticas, de 5-6 $\mathrm{mm}$ de largo x 1,5-2 mm de ancho; estilo con ramas lineal elíptica, ápice agudo, papilosas. Flores del disco 8-10, perfectas, amarillentas, de $4 \mathrm{~mm}$, tubulosas, con una garganta bruscamente ampliada. Anteras redondeadas en la base; ápice con el tejido conectivo ovado a ovado-elíptico, ramas del estilo linear elípticas, agudas, con tricomas papilosos colectores en el lado exterior. Aquenios gris claro, cilíndrico-turbinados, costados, densamente seríceos; de 2-3 mm. Pappus compuesto por a 15-20 páleas lineares de $0,5-1 \mathrm{~mm}$ de largo en las flores liguladas y $1,5-2,5 \mathrm{~mm}$ de largo en las flores del disco.

Distribución y hábitat. Argentina, en las provincias de Buenos Aires y La Pampa, en las provincias fitogeográficas Pampeana y del Espinal y del Monte (Cabrera \& Willink, 1980). Crece en sierras y llanuras, en suelos muy rocosos y arenosos desde el nivel del mar hasta los 700 msnm.

Nombre vulgar. no se conoce.
Especimenes examinados. ARGENTINA. Prov. Buenos Aires: Dpto. Bahía Blanca, San Blas, 1IX-2003, C. Ameghino s.n. (BA). Dpto. Saavedra, Sierra de Currumalán, 25-III-1918, L. Hauman s.n. (BA). Dpto.Tornquist, Sierra de la Ventana, 20-V1938, A. L. Cabrera 4475 (SI); RP 76, cerca del parque Tornquist, 15-I-2016, F. Ratto, D. Sbarra \& M. Sorondo 1/2016 (BAA). Prov. La Pampa: Dpto. Caleu Caleu, Entre Río Colorado y Anzoátegui, 20-XII-1952, A. Ragonese \& B. G. Piccinini 9007 (BAB). Dpto.Curacó, Entre Gobernador Duval y Puelches, 18-XII-1952, A. Ragonese \& B. G. Piccinini 8936 (BAB); Entre Puelches y Gobernador Duval, 18-XII-1952, A. Ragonese \& B. G. Piccinini 8971 (BAB). Dpto. Lihué Calel, Laguna La Asturiana, $35 \mathrm{~km}$ al sur de El Carancho, 29-XI-1959, O. Boelcke \& E. Nicora 8067 (BAA); Sierra de Lihué Calel, 30-XI-1959, H. Schwabe \& H. Fabris 2002 (LP); Próximo a la Estación de Servicios, sobre ruta, 08-XII-2010, Bartoli \& Tortosa 2/10 (BAA).

Observaciones. 1) Especie fundada por Cabrera (1941) a partir de un ejemplar coleccionado por el mismo autor en la localidad de Sierra de la Ventana. Luego Solbrig (1966) la incluyó en la sinonimia de G. gilliesii. Recientemente rehabilitada por Ratto \& Bartoli (2016a), anteriormente fue incluida en la sinonimia de G. gilliesii, de la cual se diferencia por ser de mayor tamaño y por poseer hojas más anchas.

2) Se amplía su distribución en este trabajo a la provincia de La Pampa (Fig. 20).

9. Gutierrezia mandonii (Sch. Bip.) Solbrig., Contrib. Gray Herb. Harvard Univ. 197: 20. 1966. Brachyris mandonii Sch. Bip., Linnaea 34(5): 534. 1866. Tipo: Bolivia. La Paz. Prov. Larecaja, Vicinis Sorata, 2650 m, Feb-Mar 1859, G. Mandon 228 (Holotipo P 00742784!, Isotipos B destruido (fotografía de Serie Field Museum 14817), COL 000004818!, F 0049093F!, F 0049092F!, G 00223900 !, GH 00004315!, GH 00004316!, GH 00004317!, GOET 001597!, GOET 001598!, K 000221361!, MPU 023716!, MPU 023717!, MPU 023718!, NY 00162730!, NY 00162731!, NY 00162732!, P 00742783!, P 00742786!, SI 014008!, US 00127684!).

$=$ Gutierrezia gilliesii Griseb. var. scabriuscula Griseb., Abh. Königl. Ges. Wiss. Göttingen. 19: 173. 


\section{F. Ratto y A. Bartoli - Revisión de Gutierrezia}
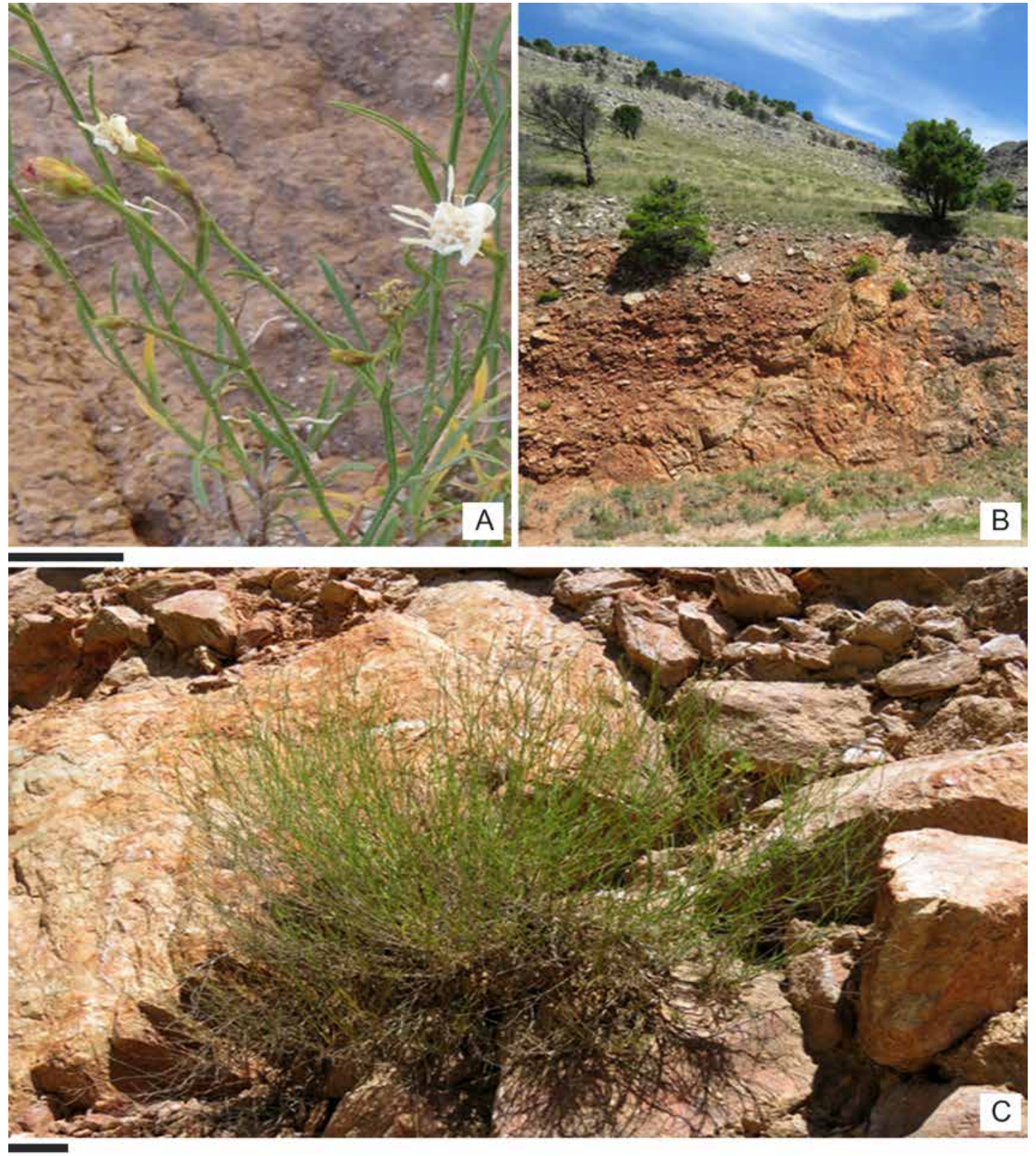

Fig. 19. Gutierrezia leucantha. A: Detalle de capítulos. B: Hábitat. C: Planta. Fotografías por Francisco Ratto. Escalas $=\mathrm{A}-\mathrm{C}: 1 \mathrm{~cm}$.

1874. Tipo: Argentina. Catamarca. Nacimientos, Sierra de Catamarca, Ene 1872, P. G. Lorentz 434 (Holotipo GOET 001593!; Isotipos, CORD 00006303!, LP 001995!, LP 001996!).
Iconografía. Cabrera, A. L. 1978. En A. L. Cabrera (Ed.). Flora de la Provincia de Jujuy. Compositae. Parte X: 161, fig. 71. Colección científica del INTA. 


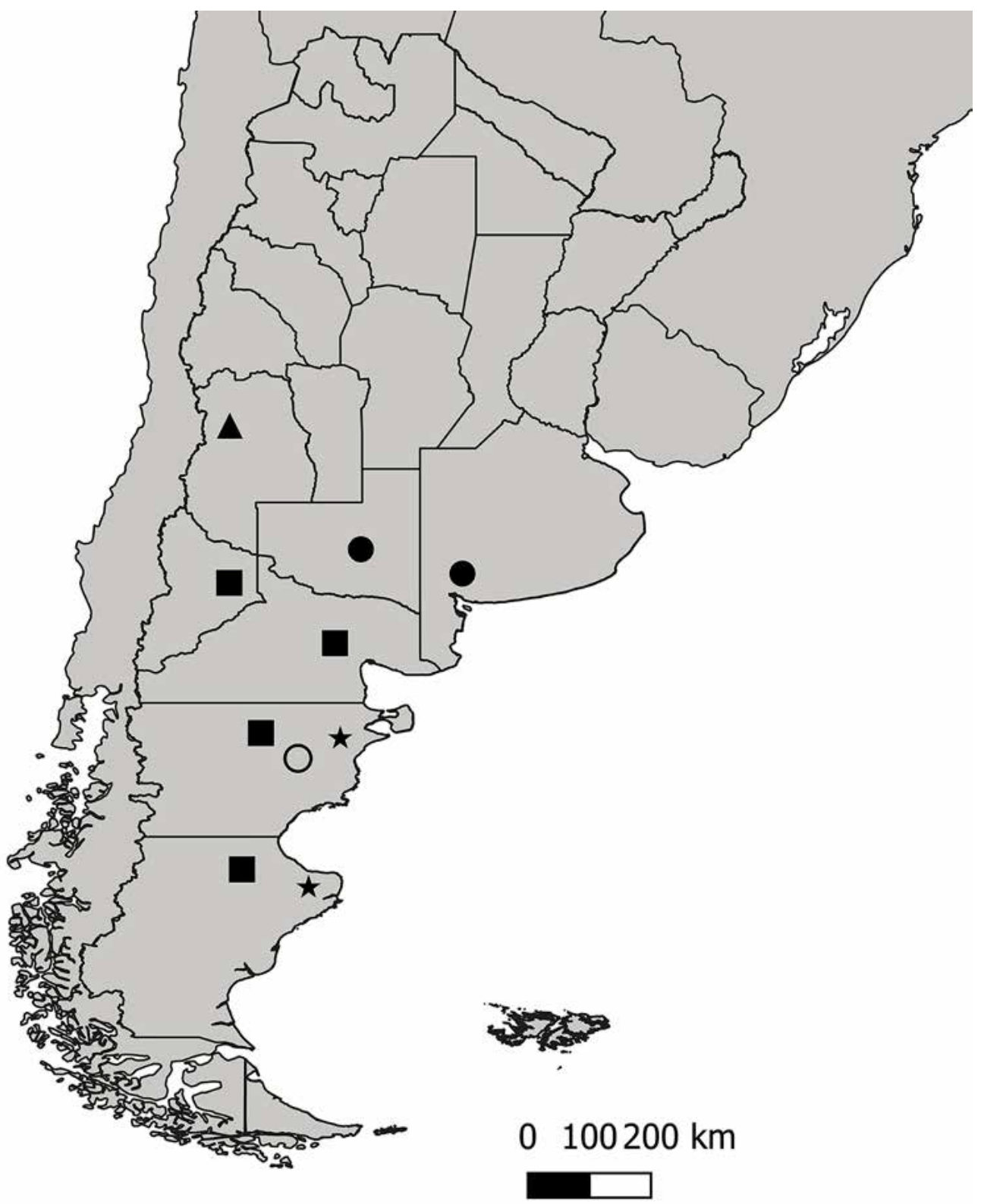

Fig. 20. Distribución geográfica de: Gutierrezia ameghinoi mendocina $\mathbf{\Lambda}$, G. solbrigii $\mathbf{m}$.

\section{Clave para determinar las variedades}

A. Capítulos con todas las flores amarillo intenso. .. G. mandonii var. mandonii

AA. Capítulos con todas las flores blancas o blancoamarillentas. G. mandonii var. anomala 9a. Gutierrezia mandonii (Sch. Bip.) Solbrig. var. mandonii. (Figs. 21, 22).

Sufrútice de 5-35 (-45) cm, ramificados en la base. Tallos decumbentes, costados, glandulares, frondosos en la base y ligeramente foliosos 


\section{F. Ratto y A. Bartoli - Revisión de Gutierrezia}

hasta el ápice. Hojas subcoriáceas, sésiles, irregularmente dentadas, linear-elípticas, de 10-25 x 1-3 mm, agudas a subobtusas, las caulinares gradualmente menores. Capítulos radiados, sésiles, de $1-1,5 \mathrm{~cm}$ de diámetro, agrupados en cimas corimbiformes en el ápice de los tallos, con 1 o 2 brácteas lineal-elípticas de 1-5 $\mathrm{mm}$ de largo. Involucro acampanado, resinoso, 4-7 $\mathrm{mm}$ x 4-10 $\mathrm{mm}$. Receptáculo plano o ligeramente convexo, alveolado, piloso. Filarios en 3 series, oblongos, la serie externa glandular, acuminados, la serie interna triangular, glandular, apiculados. Flores liguladas 8 a 15, femeninas, color amarillo, lígulas elípticas, de 6-9 $\mathrm{mm}$ de largo por 2-3,5 $\mathrm{mm}$ de ancho. Flores del disco 10 a 20, hermafroditas, con la corola de color amarillo, de 3-4 mm con garganta bruscamente ampliada. Anteras redondeadas en la base con tejido conectivo ovado-triangular de 0,5 $\mathrm{mm}$. Ramas del estilo agudas. Aquenios grisáceos, cilíndrico-ovoides, costados, densamente seríceos, de $2-2,5 \mathrm{~mm}$. Vilano compuesto de $10-18$ páleas linear-elípticas y laciniadas de $1-1,5 \mathrm{~mm}$ de largo en flores liguladas y de 1-2 $\mathrm{mm}$ en las flores del disco.

Distribución geográfica y hábitat. Se la encuentra en Argentina (Provincias de Jujuy, Salta y Tucumán) y en Bolivia (Provincia de Larecaja) en las provincias fitogeográficas de la Puna, la Prepuna y el Chaco Serrano entre los 1500 y los $3900 \mathrm{msnm}$. Vive en laderas con pendiente inclinadas al $\mathrm{W}$ y al $\mathrm{E}$ con suelos arenosopedregosos y entre pastizales serranos y también acompañada de vegetación esteparia arbustiva.

Nombre vulgar. no se conoce.

Especimenes examinados. ARGENTINA. Prov. Catamarca: Dpto. Ambato, Sierra de Ambato (Falda E): Entre El Rodeo y la quebrada del Tala, 31-III-1968, A. T. Hunziker 20103 (CORD); Sierra de Ambato, subida al Cerro Manchado, 12-I-2000, M. Negritto et al. 231 (CORD). Dpto. Andalgalá, Capillitas, F. Schickendantz s.n. (CORD); Las Minas, $3000 \mathrm{~m}, 04-\mathrm{IV}-2017$, Jöergensen 10666 (CORD). Prov. Jujuy: Dpto. Humahuaca, Cerca de Tres Cruces, Campamento Esquina Blanca, 17-IV-1987, A. E. Cocucci s.n. (CORD); Ruta provincial 12, abra camino a Iruya, 13-III-2013, F. O. Zuloaga et al. 14231 (SI). Dpto.
Santa Catalina, Santa Catalina, 24-I-2001, F. Claren 11456(CORD). Dpto. Tilcara, Maimará, borde de huerta, 10-I-1971, A. Krapovickas \& C. L. Cristóbal 17612 (BA); Tilcara, cerros $1 \mathrm{~km}$ al O de Ruta 9, 28-XII-1989, L. J. Novara \& S. Bruno 9236 (CORD); Camino del Módulo a Huairahuasi, 11-II-2010, F. O. Zuloaga et al. 11706 (SI). Dpto. Tumbaya; Volcán, Cerros al E, 20-III-1973, A. L. Cabrera et al. 23529 (LP); Camino a Abra de Lipán, 24-III-1979, A. L. Cabrera et al. 30586 (BAB); Serranías frente a El Colorado, 7-VI-2004, J. A. Tolaba et al. 3583 (SI); Volcán, Cantera, 18-II-2009, F. O. Zuloaga et al. 10950 (CORD). Dpto. Valle Grande, Caspalá, $3000 \mathrm{~m}$, 25-XII-1962, H. A. Fabris 3648 (BAB, LP); Caspalá, 1-III-1940, A. Burkart \& N. Troncoso 11742 (LP). Dpto. Capital, Entre León y Nevado de Chañi, III-1963, H. A. Fabris et al. 3923(LP); Entre León y Nevado de Chañi, III-1963, H. A. Fabris et al. 4069 (LP). Dpto Yavi, La Quiaca, 31-I-1944, A. Soriano 600 (BAB); Abra de Yavi, 10-II-2014, F. Ratto et al. 164 (BAA). Prov. La Rioja, Dpto. Famatina, Sierra Famatina: Real Viejo, 6-III-1907, F. Kurtz 14708 (CORD); Los Cajones, 18-XII-2011, G. E. Barboza et al. 3230 (CORD). Dpto. Independencia: Subiendo desde Amaná la sierra de Vilgo por la huella de la mina Las Mellizas, 28-VI-1995, Biurrun \& Molina 4163 (CORD); Ruta Nac 150 a $1 \mathrm{~km}$ al oeste de Paganzo, 27-III-1996, F. Biurrun \& A. Hunziker 4339 (CORD). Prov. Salta. Dpto. Anta, PN El Rey, 19-VII-1979, M. J. Kristensen 1003 (MCNS). Dpto. Cachi, Trayecto de aprox. $30 \mathrm{~km}$ desde el puesto de las flia. Apaza hasta Las Trancas, 08-IV1989, V. Núñez 639 (MCNS); Cuesta del Obispo, Ruta 33 km 57, 7-I-2011, F. Ratto, F. Marzaro \& M. Bello 1, 2, 3, 4, 5 y 8 (BAA); Ruta 33 km 60, 08-I-2011, F. Ratto, F. Marzaro \& M. Bello 12 y 13 (BAA). Dpto. Chicoana, Quebrada de Escoipe, $\mathrm{A}^{\circ}$ Malcanto, 10-IV-1980, A. Krapovickas \& A. Schinini 36047 (LP); Cuesta del Obispo, 29-I1999, A. A. Sulekic \& G. Cano 2272 (MCNS); Quebrada de la Sirena, entre los km 48 y 49 de rp 33 en los alrededores de la cruz, 3-IV-2003, G. E.Barboza et al. 701 (CORD). Dpto. La Viña, Potrero de Díaz, $35 \mathrm{~km}$ al $\mathrm{W}$ de Ampascachi, 21-V-1983, L. Novara 3459 (CORD, MCNS); Potrero de Castilla, $35 \mathrm{~km} 1$ O de Ampascachi, 21V-1983, L. J. Novara 3471 (CORD). Dpto. Metán, Sierras de Metán, Finca Cacharí, 12-II-2007, J. 

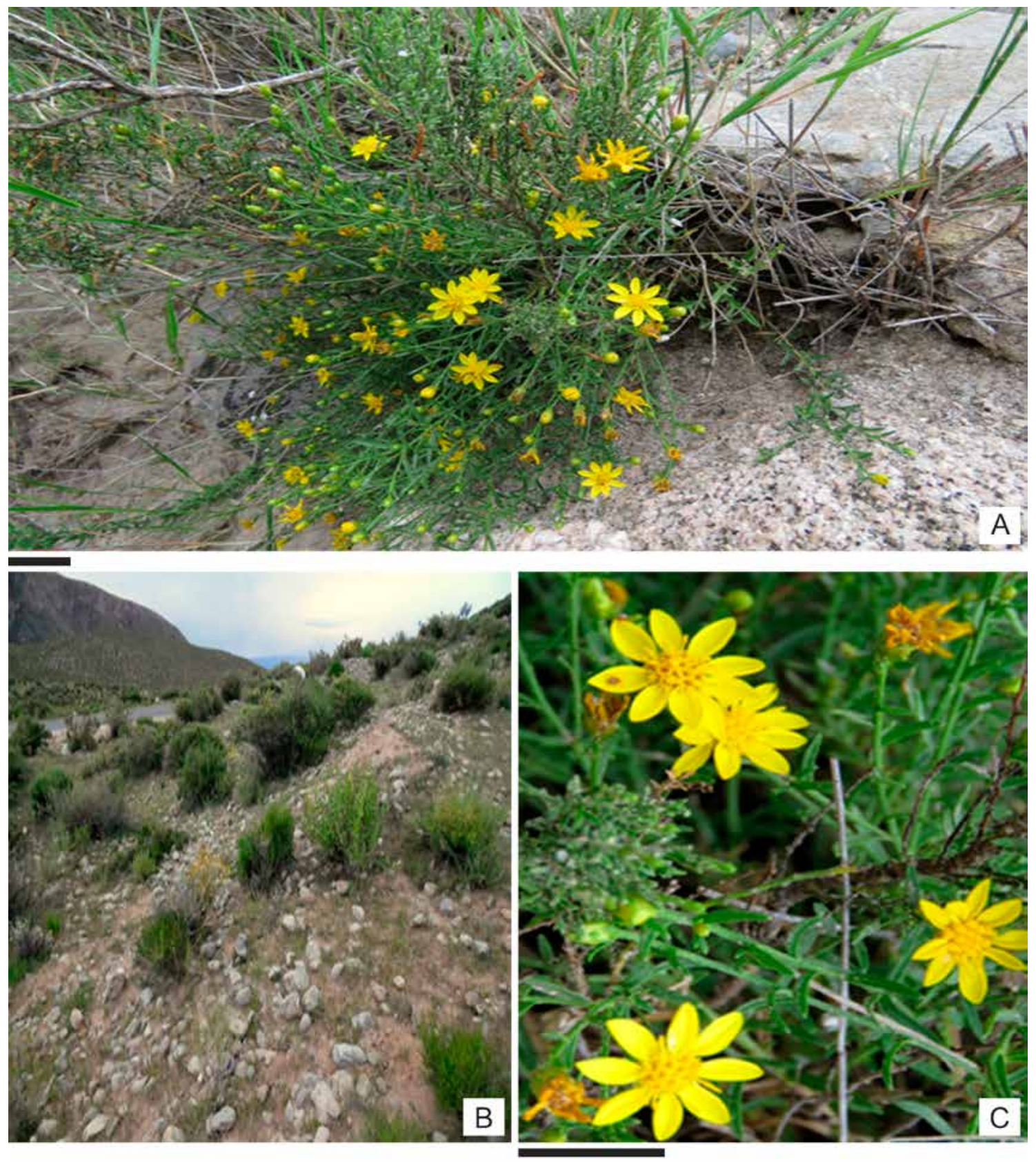

Fig. 21. Gutierrezia mandonii var mandonii. A: Planta. B: Hábitat. C: Detalle de capítulos. Fotografías por Francisco Ratto. Escalas= A: $1 \mathrm{~cm} ; \mathrm{C}: 1 \mathrm{~cm}$.

A. Tolaba \& A. Gutiérrez 4265 (MCNS). Dpto. San Carlos, Alturas de Amblayo, 25-III-1987, L. Novara 6353 (MCNS); Cuesta de Isonza, $20 \mathrm{~km}$ al sur de Piedra del Molino, 1-IV-1990, L. Novara \& R. Neumann 9776 (CORD, MCNS). Dpto.
Santa Victoria, Nazarenos, alrededores del pueblo, 23-V-1987, L. Novara 6788 (MCNS); Nazarenos, en el cementerio, 31-XII-1996, P. Adler s.n. (MCNS). Prov. Tucumán. Dpto. Burruyacu, Valle Medina: Ea Los Pinos, 23-III-1961, F. Vervoorst 


\section{F. Ratto y A. Bartoli - Revisión de Gutierrezia}

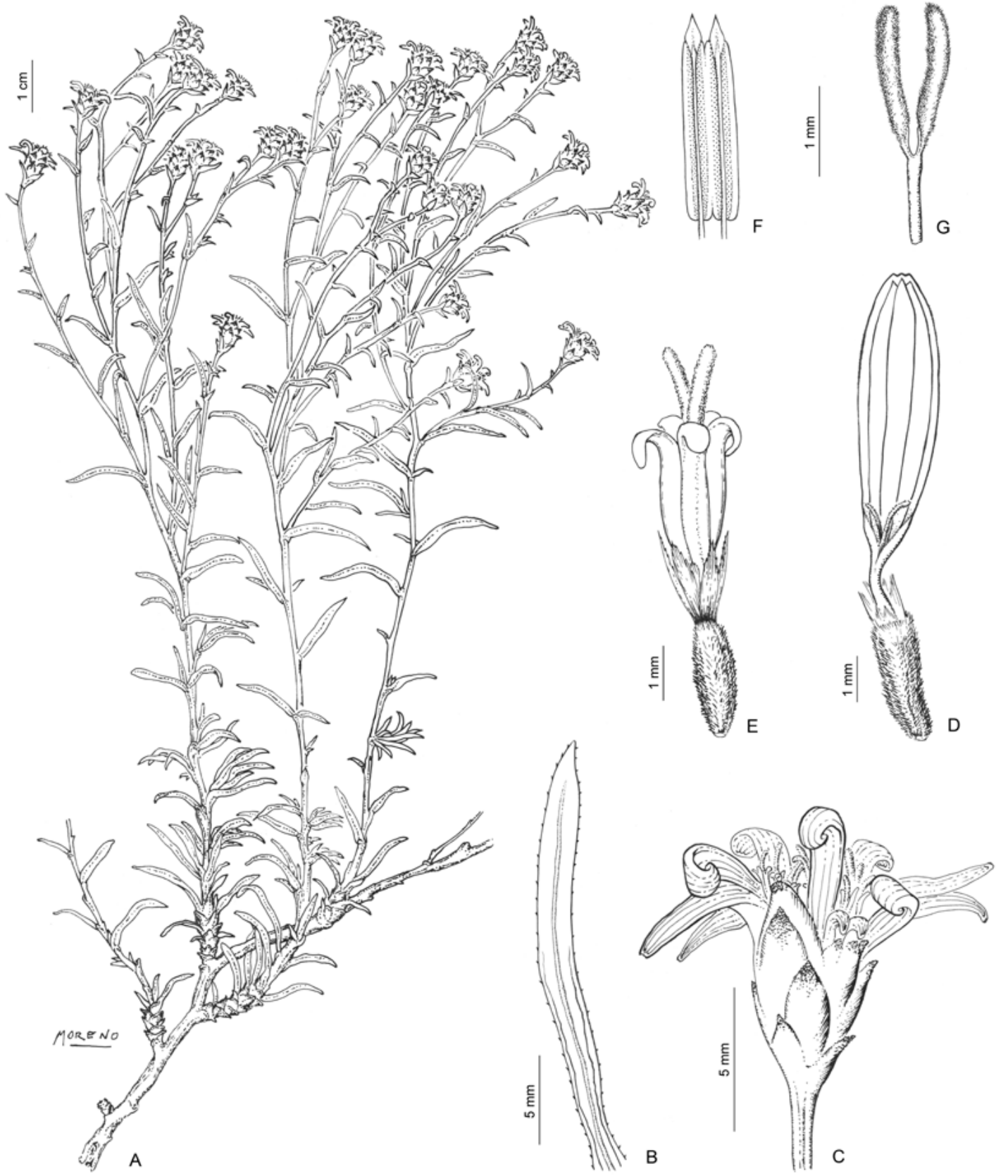

Fig. 22. Gutierrezia mandonii var mandonii. A: Planta. B: Hoja. C: Capítulo. D: Flor ligulada. E: Flores tubulosas. G: Estilo y estigma. F: Antera.

6758 (LIL). Dpto. Candelaria, Cerro del Chorrillo, 17-IV-1925, S. Venturi s.n. (BAB). Dpto. Tafi, Tafí del Valle, 11-II-1907, T. Stuckert 17877 (CORD); El Infiernillo, RP 307, 10-II-2014, F. Ratto et al. 145, 160, 161, 162, 163, 165, 166, 167,
$168,169,170,171,172,173,174,175,176,182$, 183 (BAA).

Observaciones. 1) Especie fundada bajo el nombre de B. mandonii por Schultz Bipontinus 
(1866) basado en un ejemplar coleccionado en Bolivia por G. Mandon a quien el autor dedica la especie. Luego fue transferida al género Gutierrezia por Solbrig (1966). Se incluyó en la sinonimia de esta especie a G. gilliesii Griseb. var. scabriuscula Griseb.

2) La especie presenta pocos capítulos y grandes, siempre amarillos. Las nuevas ramificaciones emergen anualmente desde una corona que crece al nivel de la superficie del suelo y son decumbentes. Es una especie afín a G. tortosae, pero se diferencia de ésta porque tiene ramas perennes siempre erectas y numerosos capítulos de menor tamaño. En los departamentos de Tilcara y Humahuaca de la provincia de Jujuy existen ejemplares intermedios entre estas dos especies.

3) También hay ejemplares intermedios con otra de las especies afines, G. repens, en algunos departamentos de las provincias de Jujuy, Salta y Tucumán donde comparten área de distribución.

9b. Gutierrezia mandonii (Sch. Bip.) Solbrig. var. anomala Ratto \& A. Bartoli., Bol. Soc. Argent. Bot. 52(4) 2017. (Fig. 23). Tipo: Argentina. Salta: Chicoana, Cuesta del Obispo, La Herradura, S25 ${ }^{\circ}$ 10,909', O65 51,040', 3091 msnm flores blancas, 19-II-2016, F. Ratto, D. Sbarra \& D. Schiavinato 121/2016 (Holotipo, BAA!; Isotipos, BAA!, BAB!, BC!, CTES!, SI!).

Difiere de la variedad típica por presentar capítulos con todas las flores de color amarillo muy claro, blancos o excepcionalmente rosados.

Distribución geográfica y hábitat. Habita la provincia de Salta, en el departamento de Chicoana, en la transición entre la Prepuna y las Yungas, en laderas empinadas con suelos muy arenosos a 3000 msnm.

\section{Nombre vulgar. No se conoce.}

Especímenes examinados. ARGENTINA. Prov. Salta: Dpto. Chicoana, Piedra del Molino, 24-I1995, F. O. Zuloaga et al. 11251 (SI). Dpto. Cachi, P. N. Los Cardones, 14-II-2002, A. M. Cialdella et al. 268 (SI); Cuesta del Obispo, entre La Herradura y La Cochera, 2-IV-2004, L. Novara et al. 12063 (MCNS); Cuesta del Obispo, 20-II-2016, F. Ratto, D. Sbarra \& D. Schiavinato 124/2016 (BAA).
Observaciones. 1) Presenta flores blancuzcas, amarillentas o excepcionalmente rosadas lo que representa una verdadera rareza dentro del género donde todas las especies tienen flores amarillas o blancas.

2) Tanto esta variedad como la típica, conviven en la provincia de Salta, en el departamento de Chicoana.

3) Ariza Espinar y Novara (2005) citaron para la Flora del Valle de Lerma a la especie G. gilliesii para la Cuesta del Obispo (Novara et al. 12063). Consideramos que se trata de un ejemplar de esta nueva variedad.

10. Gutierrezia mendocina Ratto \& A. Bartoli., Collec. Bot. 33 (1): e002. 2014. (Figs. 24, 25). Tipo: Argentina. Mendoza. Dpto. Tunuyán, Puesto de Gendarmería Alférez Portinari, ruta 94, 12 Ene 2011, F. Ratto, F. Marzaro \& M. Bello 47 (Holotipo, BAA!; Isotipos, BAA!, BC!, CTES!, SI!).

Iconografía. Ratto, F. \& A. Bartoli. 2014. Gutierrezia mendocina (Asteraceae, Astereae), a new South American species. Collec. Bot. 33 (1): 3 .

Subarbustos perennes $15-40 \mathrm{~cm}$, muy ramificados en la base. Tallos erectos, acanalados, glandulares, frondosos en la base y ligeramente foliáceos hasta el ápice, postrados en la base y con raíces nodales, hojas subcoriáceas, sésiles, 3-nervadas, las basales elípticas-espatuladas, de 15-22 x 3-4 mm, agudas o semiobtusas, las caulinares lineal elípticas de 18-22 x 2-3 mm, agudas. Capítulos radiados, pedunculados, de 1-1,2 $\mathrm{cm}$ de diámetro, agrupados en cimas corimbiformes en el ápice de los tallos. Pedúnculos 5-20 mm, con 1 o 2 brácteas lineales elípticas 3-5 $\mathrm{mm}$ de largo. Involucro turbinado, resinoso, 5-7 $\mathrm{mm}$ x 3,5 $\mathrm{mm}$. Receptáculo plano o ligeramente convexo, alveolado, piloso. Filarios en 3 series, oblongas, la serie externa glandular, acuminados, la serie interna triangular, apiculados. Flores liguladas 4 a 9, color blanco, lígulas estrechoobovadas, de 6-7 mm de largo. Flores del disco 8 a 11, con la corola de color amarillento, de 3-4 mm con garganta bruscamente ampliada. Aquenios grisáceos, turbinados, densamente seríceos. Vilano de 14-16 páleas linear lanceoladas-elípticas y laciniadas de $1 \mathrm{~mm}$ de largo en flores liguladas y de 2-2,5 mm de largo en las flores del disco. 

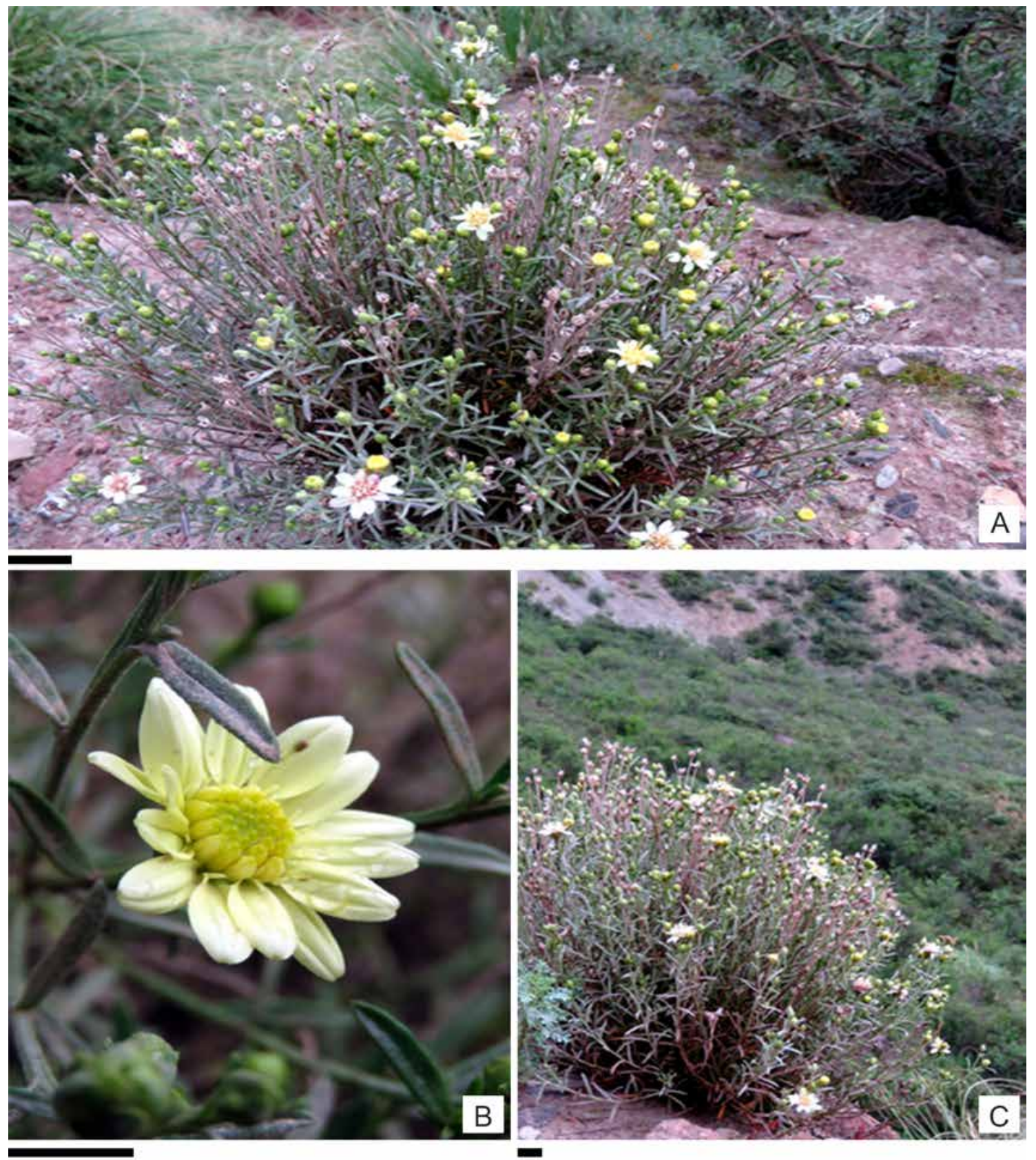

Fig. 23. Gutierrezia mandonii var anomala. A: Planta. B: Detalle del capítulo. C. Hábitat. Fotografías por Francisco Ratto. Escalas $=A: 1,5 \mathrm{~cm} ; B: 0,5 \mathrm{~cm} ; C: 1 \mathrm{~cm}$.

Distribución geográfica y hábitat. Habita en Mendoza, en la provincia fitogeográfica del Monte entre los 500 y los $3100 \mathrm{msnm}$, en laderas con suelos pedregosos de la estepa arbustiva y la precordillera.
Nombre vulgar. No se conoce.

Especimenes examinados. ARGENTINA. Prov. Mendoza: Dpto. Las Heras, Cerro Alfalfa, 16-II-1973, F. A. Roig 7676 (MERL); Pampa 

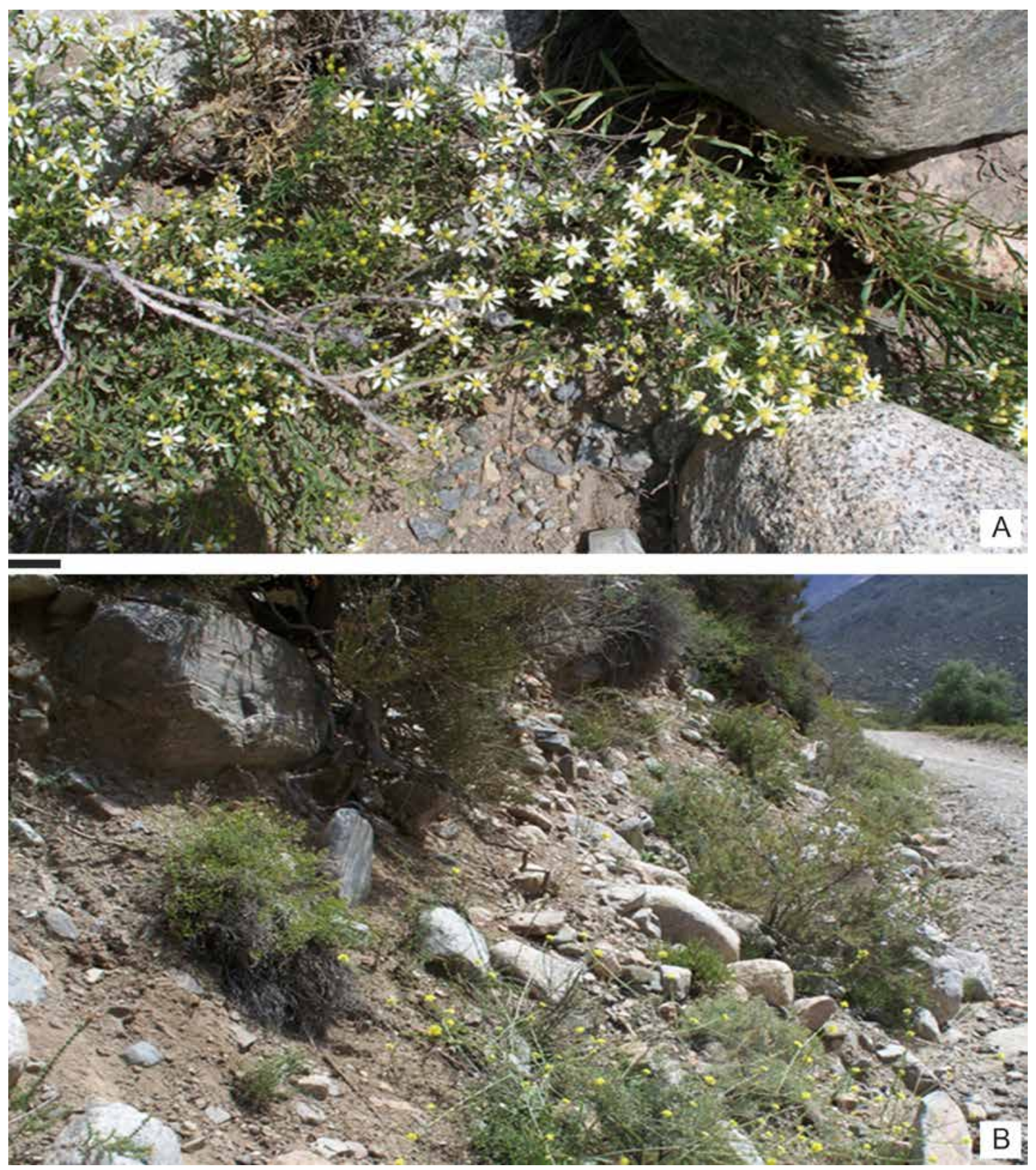

Fig. 24. Gutierrezia mendocina. A. Planta. B. Hábitat. Fotografías por Francisco Ratto. Escala= A: $1 \mathrm{~cm}$.

de Los Ñangos, 25-III-1980, A. Dalmasso \& C. Passera 31928 (MERL). Dpto. Luján de Cuyo, Pareditas, 10-XI-1985, H. A. Lagiglia 6791 (SI). Dpto. Maipú, Beltrán, 3-I-1888, F. Kurtz 5678 (CORD); Beltrán, Los Molles: Vallas
Altas, 13-I-1893, F. Kurtz 7569 (CORD). Dpto. Malargüe; Alrededores de la cueva La Bruja, +/$13 \mathrm{~km} \mathrm{~W}$ bardas blancas, 12-XII-1985, R. Ferrer \& Ferrer s.n. (SI); La Payunia, 17-XII-1989, E. Martínez Carretero 1598 (MERL). Dpto. San 


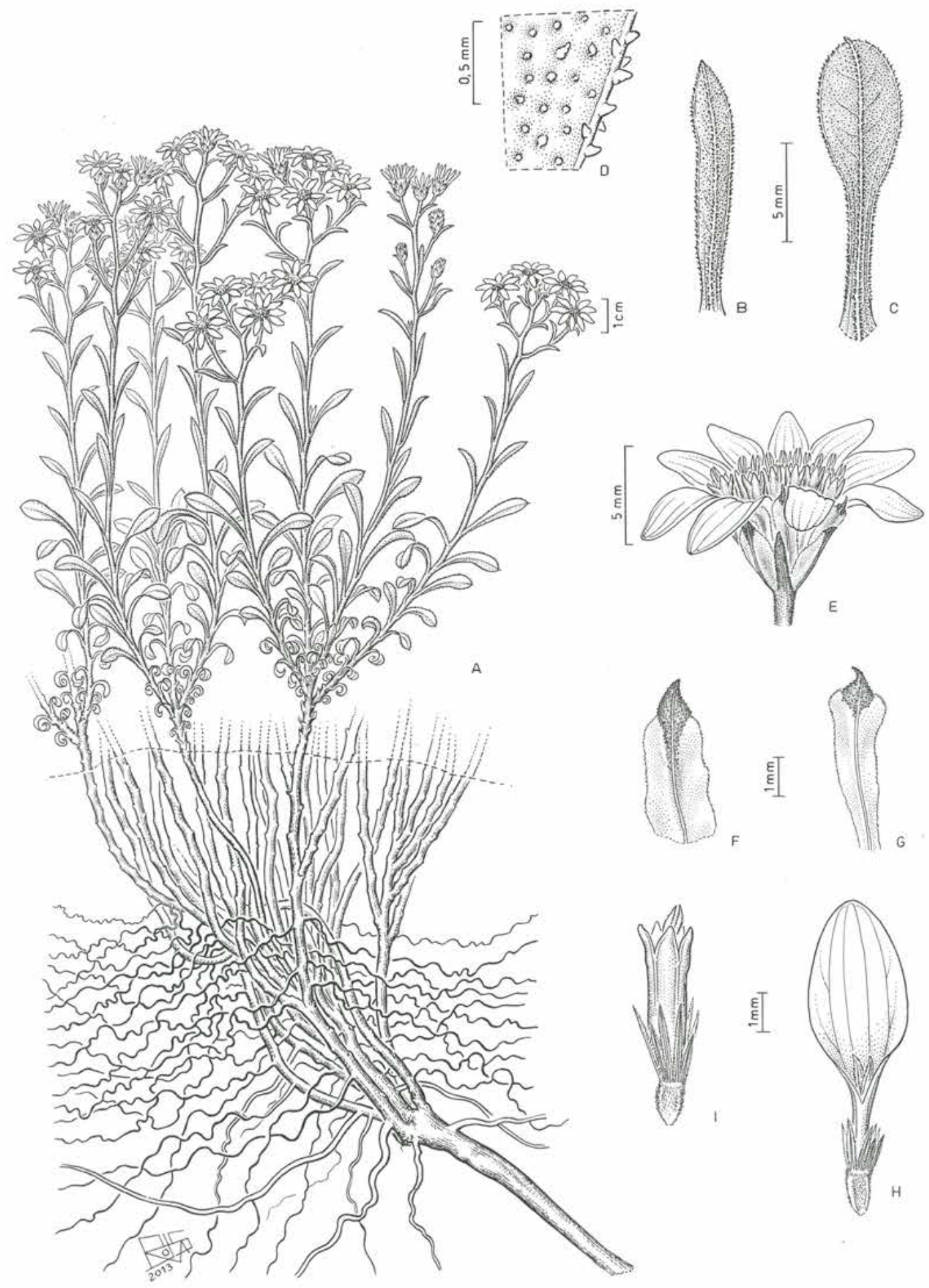

Fig. 25. Gutierrezia mendocina. A: Planta. B: Hoja caulinar. C: Hoja basal. D: Detalle de hoja. E: Capítulo. F: Filaria externa. G: Filaria intena. H: Flor ligulada. I: Flor tubulosa. 
Carlos, Qda Casa de Piedra Lag. del Diamante, 26-I-1952, L. Serra 27 (LP); Pareditas, RN 40 en proximidades de arroyo Carrizalito, 1XII-1982, J. A. Ambrosetti \& L. A. Del Vitto 34292 (MERL). Dpto. San Rafael; La Totora, 21-XII-1887, F. Kurtz 5553 (CORD); Sa. Pintada, Oeste Pto. Carrizalito, 18-VI-1973, H. A. Lagiglia 2079 (SI); El Sosneado, 13-V-1977, Sin colector 3364 (SI). Dpto. Tunuyán, $25 \mathrm{~km}$ SW de Campo de Los Andes, 15-I-1950, O. Paci 730 (BAA); Puesto Gendarmería A. Portinari, O. Boelcke et al. 10082 (BAA). Dpto. Tupungato, Ruta 94, 12-I-2011, F. Ratto, F. Marzaro \& M. Bello 52 (BAA); Cascada de la Vieja, 15II-2016, F. Ratto, D. Sbarra \& D. Schiavinato 115/2016 (BAA).

Observaciones. 1) Las flores liguladas son blanco crema, mientras que las tubulosas son amarillentas o amarillas. También existen unos pocos ejemplares con las flores liguladas amarillentas. Las hojas y tallos son pringosos. Olor dulce. Suele formar matas hemisféricas.

2) Especie afín a G. spathulata, de la cual se diferencia por poseer flores liguladas blancas y hojas basales espatuladas y caulinares elípticas.

3) No se la debe confundir con G. solbrigii, una especie anteriormente citada para la provincia de Mendoza, aunque su distribución ahora está restringida a la Patagonia. La planta presenta crecimiento decumbente, arraigante en los nudos $\mathrm{y}$ forma grandes matas.

11. Gutierrezia neaeana (DC.) Sch. Bip. ex S. F. Blake., Contr. U. S. Natl. Herb. 26: 232. 1930. (Figs. 26, 27). Brachyris neaeana DC., Prodr. 5: 313. 1836. Tipo: Chile. Sin localidad. Née s.n. (Holotipo, G 00455643!).

Iconografia. Solbrig, O. T., 1966. The South American species of Gutierrezia. Contr. Gray Herb. Pág. 197:35, Fig. 37.

Sufrútice de hasta $60 \mathrm{~cm}$, muy ramificados desde la base. Tallos erectos, costados, glandulares, frondosos en la base y ligeramente foliáceos hasta el ápice, erectos. Hojas subcoriáceas, sésiles, irregularmente dentadas, hojas oblanceoladas, subagudas hasta obtusas, de $15-50$ x 3-8 mm. Capítulos radiados, sésiles o brevísimamente pedunculados, de 12-15 $\mathrm{mm}$ de diámetro, solitarios o formando cimas corimbiformes laxas en el ápice de los tallos, con 1 o 2 brácteas lineares elípticas $2-3 \mathrm{~mm}$ de largo. Involucro acampanado-turbinado, resinoso, de 9-10 $\mathrm{mm}$ x 8-10 $\mathrm{mm}$. Receptáculo plano o ligeramente convexo, alveolado, piloso. Filarios en 3 series, oblongos, la serie externa glandular, acuminados, la serie interna triangular, glandular, apiculados. Flores liguladas 9 a 11, amarillas, lígulas estrechamente obovadas, de 5-6 mm de largo. Flores del disco 11 a 13, hermafroditas, amarillas, de 5-6 $\mathrm{mm}$ con una garganta bruscamente ampliada hacia el ápice. Anteras redondeadas en la base con tejido conectivo triangular. Aquenios grisáceos, cilíndricos, costados, densamente seríceos, de 1-2 mm. Vilano compuesto de numerosas páleas linear-elípticas y laciniadas de 1,5 $\mathrm{mm}$ de largo en flores liguladas.

Distribución geográfica y hábitat. Se la encuentra en Chile, en la Región III, Atacama y Coquimbo, creciendo entre los 2500 y los 4000 msnm, en el dominio Andino-Patagónico, provincia del Desierto.

Nombre vulgar. No se conoce.

Especimenes examinados. CHILE. III Región: Atacama, Dpto Vallenar, Quebrada Alfalfa (Q. de los Pozos), 7/8-I-1926, I. M. Johnston 6000 (GH); Huasco, E/ Portezuelo Yerba Buena y Río de Valeriano, 27-I-1983, Marticorena et al. 83606 (CONC); km 15 Río Chollay, A. S. L. et al. 94155 (CONC).

Observaciones. 1) Fundada por De Candolle con el nombre de $B$. neaeana, fue luego transferida al género Gutierrezia por Schultz Bipontinus. Blake (1930) pone de manifiesto que el material tipo coleccionado por Née, pertenece a una especie de Sudamérica y no de México.

2) Especie muy poco coleccionada.

3) Los ejemplares de hojas más angostas pueden confundirse con la especie argentina G. gilliesii, con la cual no comparte área de distribución. Se diferencian de ésta por poseer hojas siempre más anchas y capítulos de mayor tamaño con flores liguladas amarillas. 


\section{F. Ratto y A. Bartoli - Revisión de Gutierrezia}
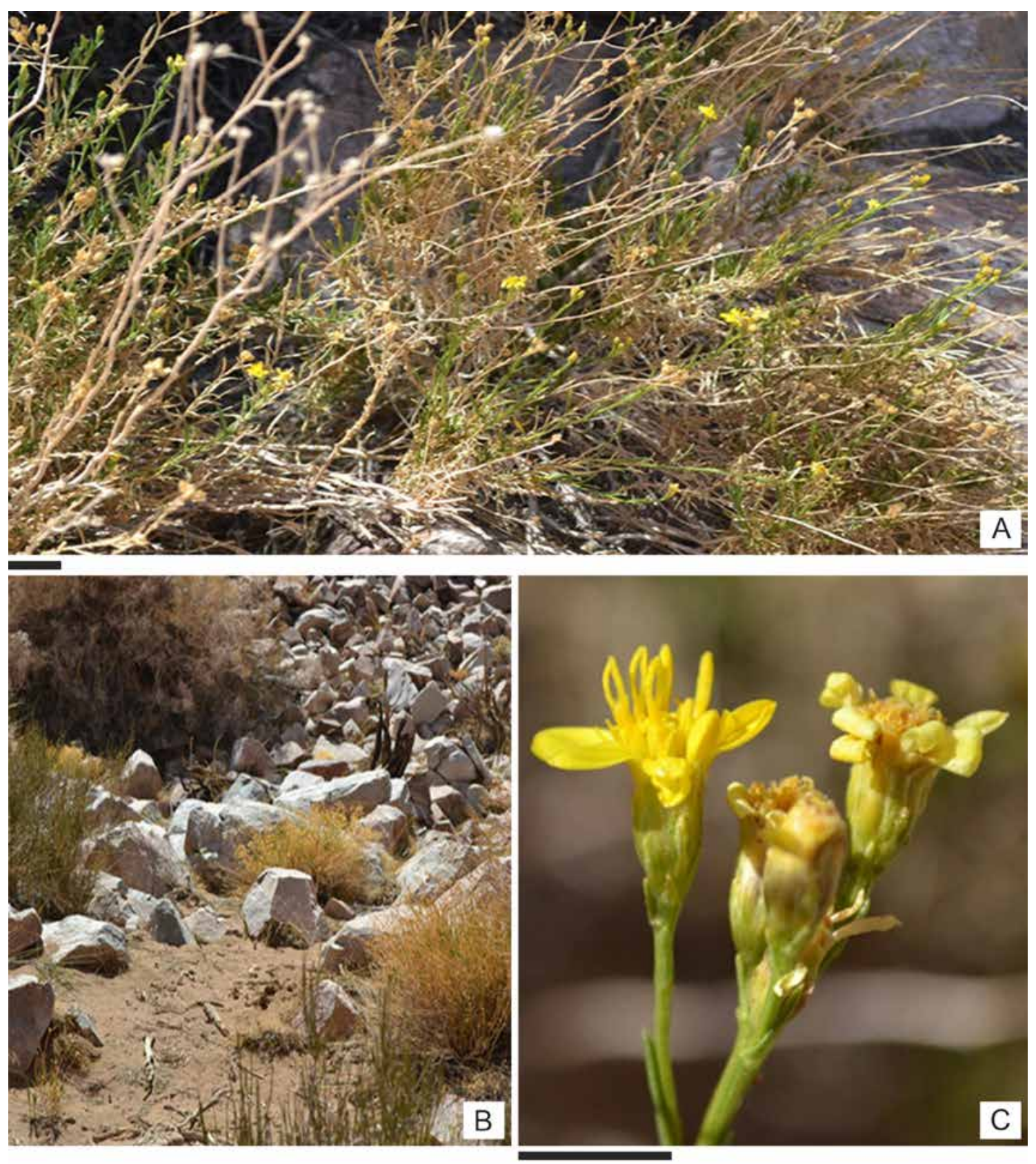

Fig. 26. Gutierrezia neaeana. A: Planta. B: Hábitat. C: Detalle de capítulos. Fotografías por Marcelo Rosas. Escalas $=A: 1,5 \mathrm{~cm} ; \mathrm{C}: 1 \mathrm{~cm}$.

12. Gutierrezia repens Griseb., Abh. Königl. Ges. Wiss. Göttingen. 19: 173-174. 1874. (Figs. 28, 29). Tipo: Argentina. Tucumán. Kriechender vielverzweigter Strauch auf der Schneide des Berges ueber ser Ciénaga, Sierra de Tucumán, 30 Mar 1872,
P. G. Lorentz 150. (Holotipo GOET 001594!; Isotipos, B destruido [fotografía de Serie Field Museum 14818], CORD 00006306!, LP 002000!, SI 025604!). $=$ Gutierrezia ruiz-lealii Solbrig., Contr. Gray Herb. 197: 26-28, f. 26, 33-34. 1966. Tipo: 


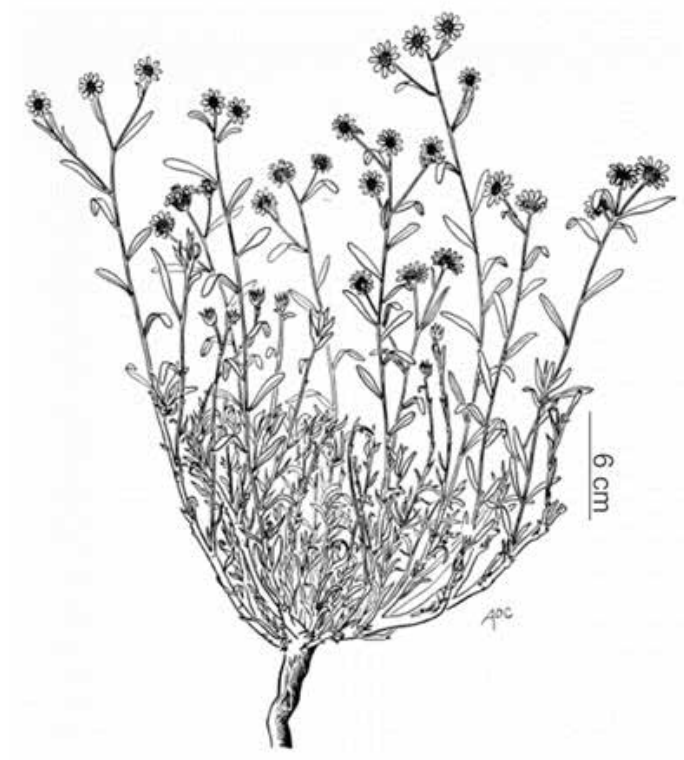

Fig. 27. Gutierrezia neaeana. Planta.

Argentina. Jujuy. Dpto. Tumbaya: Cerro Horqueta, cerca de Volcán, $3500 \mathrm{msnm}$, A. L. Cabrera \& O. Solbrig 16695 (Holotipo GH; Isotipos, LP 002001!, SI [como Cabrera 16995]!, US).

Iconografia. Cabrera, A. L.1978. En A. L. Cabrera (Ed.). Flora de la Provincia de Jujuy. Compositae. Parte X: Pág. 161 Fig. 71. Colección científica del INTA.

Subarbustos rizomatosos de $10-30 \mathrm{~cm}$. Tallos decumbentes, notablemente costados, glandulares, frondosos desde la base hasta el ápice. Hojas subcoriáceas, sésiles, elípticas o elíptico-espatuladas, con el ápice agudo, de 15-30 × 2-5 mm. Capítulos radiados, solitarios o agrupados en inflorescencias corimbiformes, sésiles, de 10-15 mm de diámetro acompañados de 1-2 brácteas lineares o linear-elípticas de 4-5 $\mathrm{mm}$. Involucro acampanado, resinoso, 5-7 $\mathrm{mm}$ x 6-10 mm. Filarios en 3 series, obovados, con bordes hialinos, los de la serie externa obovados, obtusos, glandulares; los de la serie interna angostamente obovado triangulares, levemente acuminados, glandulares. Receptáculo plano o ligeramente convexo, alveolado, piloso. Flores liguladas 8 a 12, femeninas, color amarillo o raramente blanco, lígulas elípticas, de $6-9 \mathrm{~mm}$ de largo por 2-4 $\mathrm{mm}$ de ancho. Flores del disco 1422 , hermafroditas, con la corola amarilla, de 4-5 $\mathrm{mm}$ con garganta bruscamente ampliada. Anteras redondeadas en la base con tejido conectivo triangular de $0,5 \mathrm{~mm}$. Ramas del estilo agudas a subagudas. Aquenios grisáceos, cilíndricoturbinados, costados, densamente seríceos, de 1,5-2 $\mathrm{mm}$. Vilano compuesto de 10-15 páleas lineares o linear-elípticas, laciniadas de $1 \mathrm{~mm}$ de largo en flores liguladas y de $1-2 \mathrm{~mm}$ en las flores del disco.

Distribución geográfica y hábitat. Habita las provincias de Catamarca, Jujuy, Salta y Tucumán. Se la encuentra en la provincia fitogeográfica de la Prepuna entre los 2800-4200 msnm, en laderas y pedregales.

Nombre vulgar. "topasaire".

Especímenes examinados. ARGENTINA. Prov. Catamarca: Dpto. Ambato, Subiendo desde Las Lajas hacia El Crestón del Cerro Manchado, 28-III-1968, A. T. Hunziker \& A. E. Coccuci 19967 (CORD); Sierra de Ambato (Falda E), 22-II-1971, A. T. Hunziker 20915 (CORD). Dpto. Andalgalá, 30-III-1916, P. Jöergensen 1366 (LIL, SI); Cerro medio, 31-III-1916, P. Jöergensen 366 (BA). Dpto. Pomán, Sierra de Ambato (Falda O), 19-II-1970, A. T. Hunziker \& L. Ariza Espinar 20460 (CORD). Prov. Jujuy: Dpto. Ledesma, PN Calilegua, 26-II-1986, C. A. Iudica \& E. D. Ramadori 225 (SI). Prov. Salta: Dpto. Cachi, Cuesta del Arca, LP 16826 (LP); Cuesta del Arca, LP 16824 (LP). Dpto. La Caldera, Cuesta del carancho, 13-III-1952, H. Sleumer \& F. Vervoorst 2890 (LP). Prov. Tucumán: Dpto. Chicligasta, Ea. Santa Rosa, 18-I-1927, S. Venturi 4756 (BA, BAB, LIL, LP, SI); Ea. Las Pavas, 11-III-1924, S. Venturi 3113 (BA, BAB, SI). Dpto. Tafi, Cumbre de Malamala, 03-IV-1904, M. Lillo 3471 (LIL); Cumbre del Chorro, 22-IV-1926, S. Venturi 4117 (SI); Cumbres Calchaquíes, Quebrada del Barón, 16III-1984, E. V. Gómez Sosa \& M. Múlgura 243 (SI). Dpto. Trancas, Camino a Lara, 27-III-2009, A. C. Slanis et al. 53 (SI); RP 307, cañadón entre Carapunco y La Bolsa, 18-II-2016, F. Ratto, D. Sbarra \& D. Schiavinato 119/2016 (BAA). 


\section{F. Ratto y A. Bartoli - Revisión de Gutierrezia}
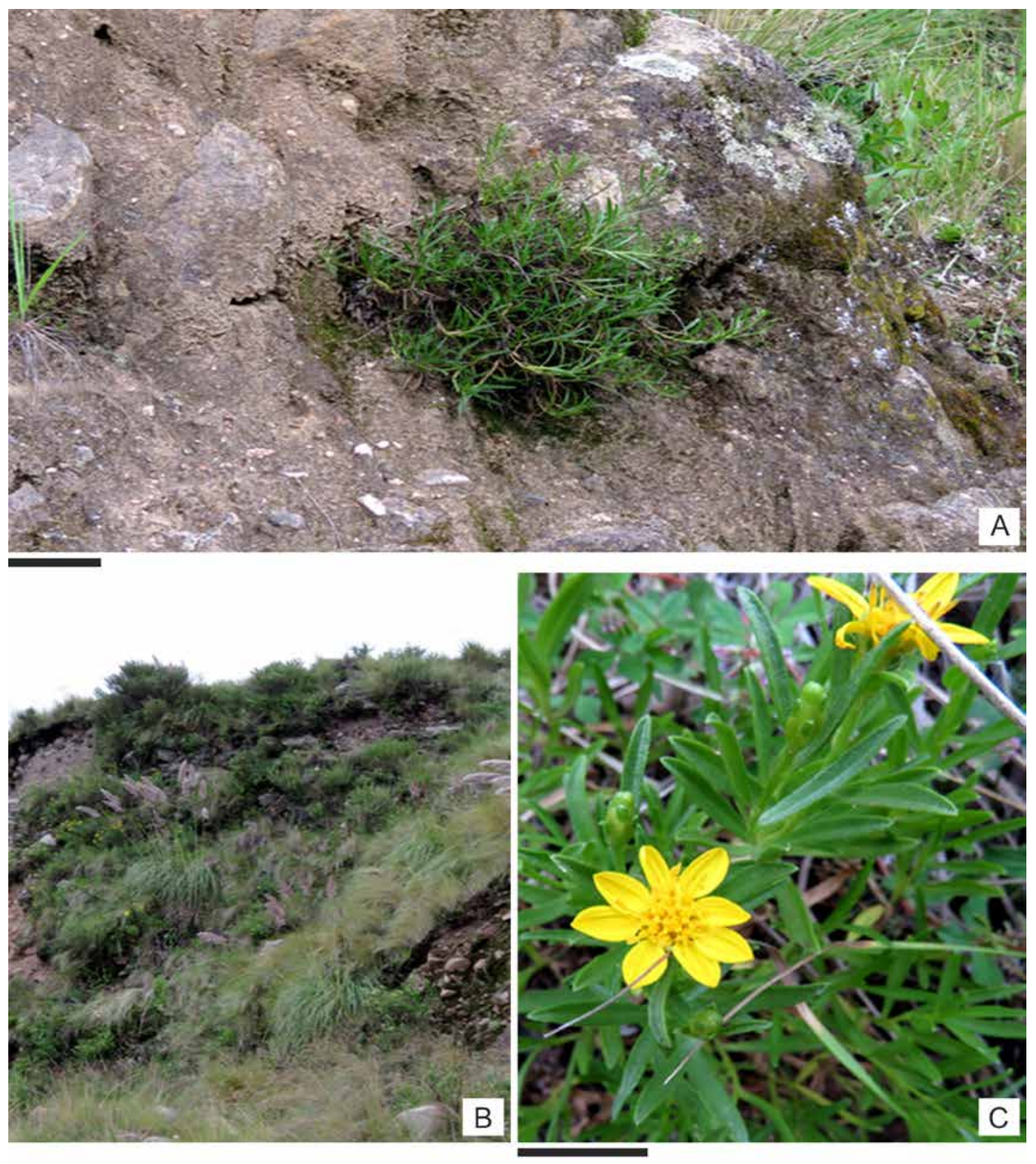

Fig. 28. Gutierrezia repens. A: Planta. B: Hábitat. C: Detalle de capítulos. Fotografías por Francisco Ratto. Escalas $=A: 3 \mathrm{~cm} ; C: 1 \mathrm{~cm}$.

Observaciones. 1) Especie fundada por Grisebach (1874). Solbrig (1966) fundó la especie G. ruiz-lealii que posteriormente fue incorporada a la lista de sinónimos de $G$. repens por Cabrera (1978), quien no encontró diferencias entre las especies.

2) Especie endémica poco coleccionada. Existen ejemplares intermedios con G. mandonii en los departamentos de Cachi y Chicoana de provincia de Salta. 
Bol. Soc. Argent. Bot. 55 (3) 2020
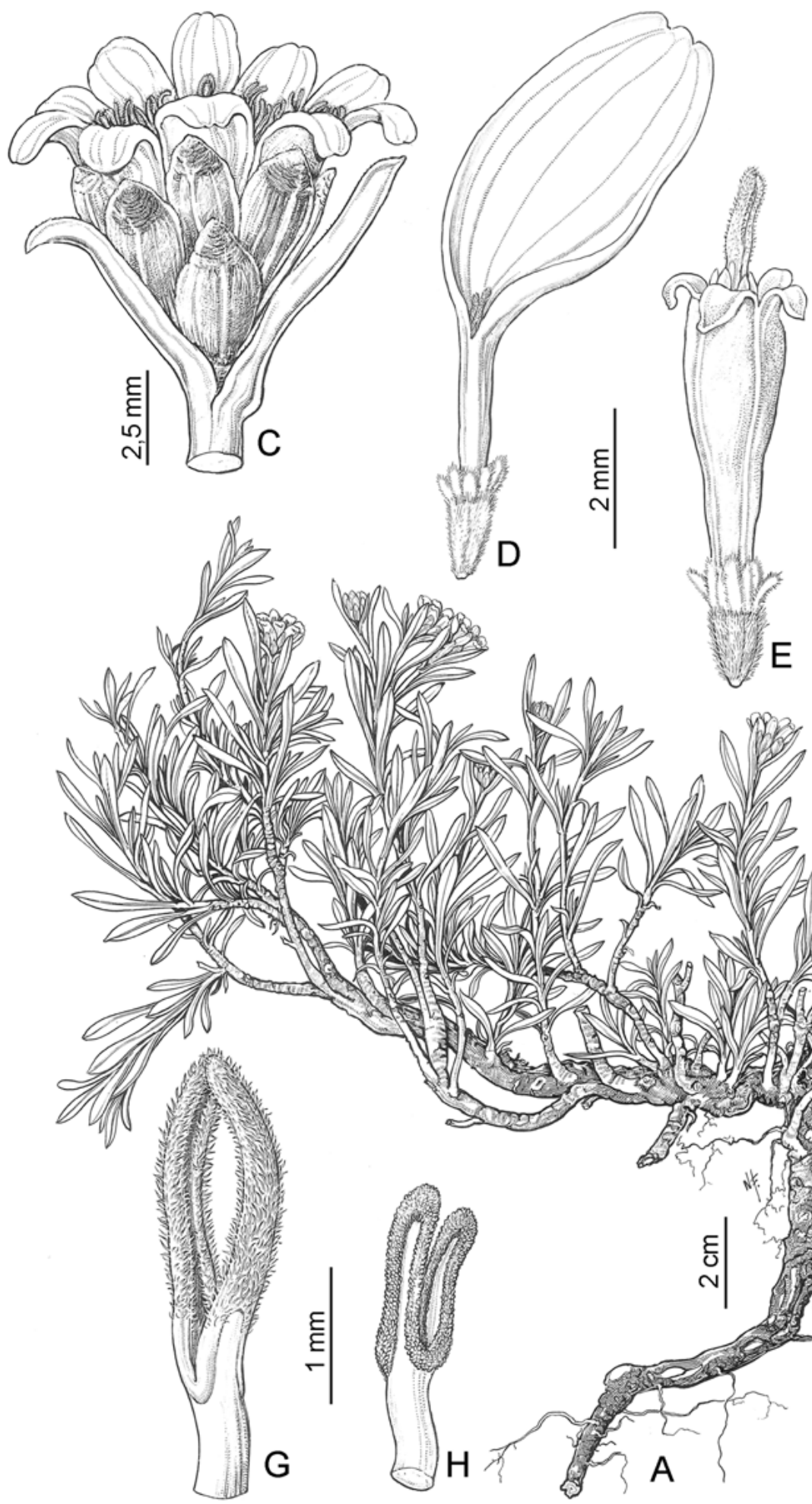


\section{F. Ratto y A. Bartoli - Revisión de Gutierrezia}

13. Gutierrezia resinosa (Hook. \& Arn.) S. F. Blake., Contr. U. S. Natl. Herb. 26(5): 232. 1930. (Figs. 30, 31). Galinsoga resinosa Hook \& Arn., Bot. Beechey Voy. 32. 1841 [1830]. Tipo: Chile. Mr. Bridges. (Lectotipo designado por Ratto et al., 2019 US 00124483 [foto]!; Isolectotipo, E 00301764 [foto]!)

$=$ Brachyris paniculata DC., Prodr. 5: 313.1836 [1-10 Oct 1836] (IK). Tipo: Chile, Coquimbo, 1834, C. Gaudichaud 105 (Lectotipo, designado por F. Ratto et al. 2019, G 00455653 [foto]!; Isolectotipos, GH 00004318 [foto]!, GH 00004319 [foto]!, P 00742785 [foto]!, P 00742787 [foto]!, P 00742788 [foto]!, P00742790 [foto]!)

= Brachyris floribunda Phil., Linnaea 33: 137. 1864. Tipo: Chile. San Felipe de Aconcagua, 1863, R. A. Philippi s.n. (Lectotipo, designado por Ratto et al. 2019, S-R-711 [foto]!; Isolectotipos, LP 000854!, NY 00162726 [foto]!, K 000221365 [foto]!, B destruido [fotografía de Serie Field Museum 14813!]).

= Gutierrezia compacta Phil., Anales Univ. Chile 87: 427. 1884. Tipo: Chile. Prope La Serena, 22 Ene 1883, F. Philippi s.n. (Holotipo SGO 65118!; Isotipos: B destruido [fotografía de Serie Field Museum 14811]; LP 001991!).

$=$ Gutierrezia laricifolia D. Don., Companion. Bot. Mag. 2: 51. 1836. Tipo: Chile, Coquimbo, Mr. Caldcleugh s.n. Tipo: Chile, IV Región de Coquimbo, Guanaqueros. F. Ratto et al. 4 (Neotipo, designado por F. Ratto et al. 2019, BAA 00004813!).

En el protólogo, Don (1836) indica que el material original proviene de Coquimbo, Chile, $\mathrm{y}$ fue coleccionado por Alexander Caldcleugh (1795-1858), botánico escocés que realizó un viaje por Sudamérica entre 1819 y 1825 , coleccionando plantas para el Jardín Botánico Real de Kew. Algunas de sus colecciones se encuentran actualmente depositadas en los herbarios $\mathrm{K}$ y G, pero no se halló ningún ejemplar que pueda haber servido como referencia para fundar G. laricifolia. Por lo tanto, se debe designar un ejemplar como neotipo, seleccionándose como tal al ejemplar BAA 00004813, que se adapta muy bien a la descripción original de la especie y fue coleccionado en la Región IV de Coquimbo, Chile.

= Odontocarpha poeppigii DC., Prod. 5: 72. 1836. Tipo: Chile, in collib. arid. inter Concon et Tavolongo E. F. Poeppig 233, 1868-Diar (Holotipo
G 00464311!; Isotipos, P 00742789!, P 00742792!).

Iconografía. se provee en el presente trabajo.

Arbustos de 50-120 cm, ramificados en la base. Tallos erectos, acanalados, glandulares, frondosos en la base hasta el ápice, hojas subcoriáceas, sésiles, irregularmente dentadas, linear-elípticas, de 30-50 × 2-4 mm, agudas, parcialmente revolutas. Capítulos radiados, sésiles, de $8-10 \mathrm{~cm}$ de diámetro, formando cimas corimbiformes en el ápice de los tallos, con 2 o 3 brácteas elípticas, obtusas de 2-4 mm de largo. Involucro cilíndrico-turbinado, resinoso de 6-8 x 3-5 mm. Receptáculo plano o ligeramente convexo, alveolado, piloso. Filarios en 3 series, oblongos, la serie externa glandular, acuminados, la serie interna triangular, glandular, apiculados. Flores liguladas 4 a 6 , femeninas, color amarillo, lígulas obovadas, de 6-8 $\mathrm{mm}$ de largo. Flores del disco 6-8 hermafroditas, con la corola amarilla, de 4-6 mm con garganta gradualmente ampliada. Anteras redondeadas en la base con tejido conectivo triangular de $0,5 \mathrm{~mm}$. Ramas del estilo agudas, notablemente pilosas en el dorso. Aquenios grisáceos, ovoide-turbinados, costados, densamente seríceos, de 1,5-2 mm. Pappus compuesto por 1216 páleas lineares, laciniadas de $1-2 \mathrm{~mm}$ en flores liguladas y de 3-3 mm en las flores del disco.

Distribución geográfica y hábitat. Se la encuentra en Chile, Regiones IV, Valparaíso; V, O'Higgins; VI, Maule y RME, Metropolitana de Santiago, entre los 0 y los $1200 \mathrm{msnm}$. Habita el dominio fitogeográfico Andino-Patagónico en la provincia Chilena.

Nombre vulgar. No se conoce.

Especimenes examinados. CHILE: IV Región: Coquimbo. Prov. Limari: Unos $3 \mathrm{~km}$ antes del PN Bosques de Fray Jorge, A. A. Cocucci 4865 (SI; CORD); Ovalle, 03-X-1940, E. Barros 1714 (LP); La Silleta, cerca de Ovalle, 10-IX-1942, C. Muñoz P. \& E. Pisano 3447 (SGO); Camino a Ovalle al sur de La Serena, 25-III-1991, C. Fernandez et al. (91) 40 (SGO); road NE of Ovalle to Samo Bajo, 26-II-1993, M. F. Gardner \& S. G. Knees 5634(SGO). Prov. Elqui, La Serena, 2-X-1953, A. L. Cabrera 11422 (LP); Vicuña, 17-IX-1926, LP 60285 (LP); Rivadavia, 17-I-1936, A. L. Cabrera 
Bol. Soc. Argent. Bot. 55 (3) 2020
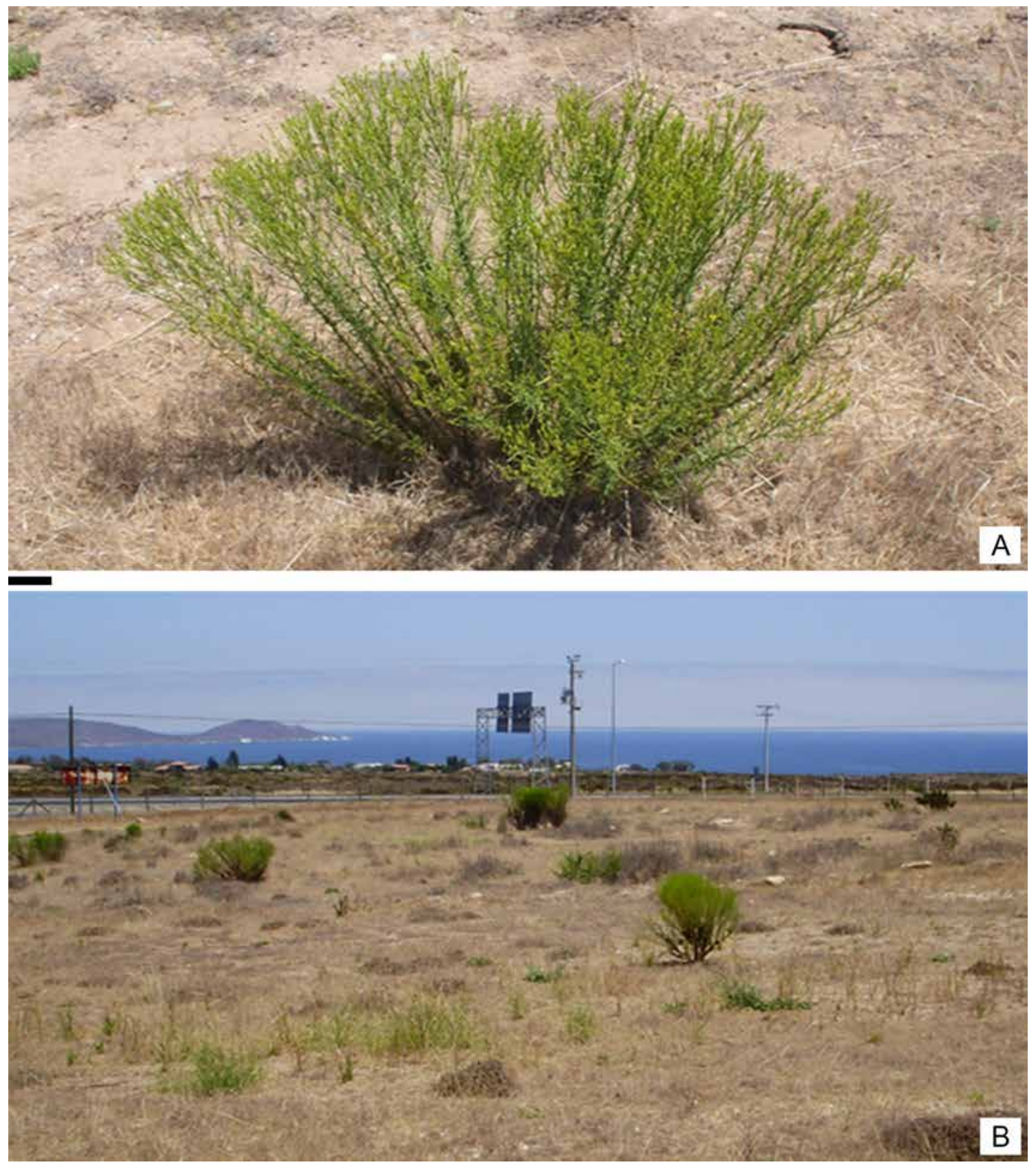

Fig. 30. Gutierrezia resinosa. A: Planta. B: Hábitat. Fotografías por Francisco Ratto. Escala= A: 4 cm.

3501 (LP); Rivadavia, 30-I-1962, O. T. Solbrig 3384 (LP); Elqui, Ca. $30 \mathrm{~km} \mathrm{~S}$ of Totoralillo \& 58 $\mathrm{km}$, S of La Serena, 29-XI-1987, M.O. Dillon \& J. T. S. Teillier 4978 (SGO, SI); Quebrada de Santa Gracia, 7-VIII-1942, SGO 134059 (SGO); Camino de Tongoy a Socos, 21-V-1970, M. Muñoz S.
300 (SGO); Entre Totoralillo y Camarones, $21-$ IX-1960, Kausel 4589 (LP); La Pampa between Lecena and Coquimbo, 31-I-1962, O. T. Solbrig 3387 (LP); frente a El Tofo, 18-II-1966, Ricardi et al. 1692 (LP) Juan Soldado, al norte de Maquhua en ladera Norte-Este, 3-IX-1974, D. Contreras \& 


\section{F. Ratto y A. Bartoli - Revisión de Gutierrezia}

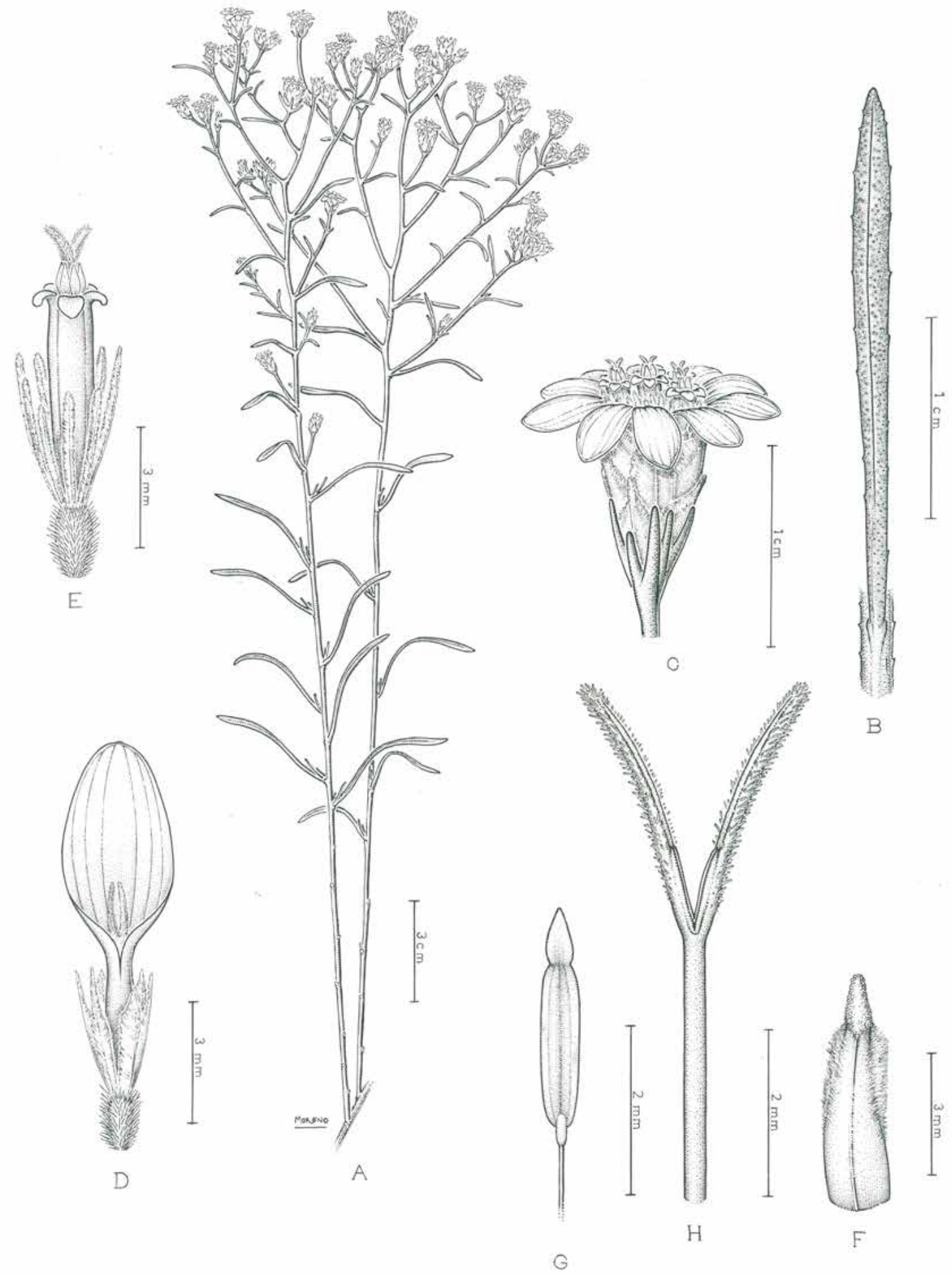

Fig. 31. Gutierrezia resinosa. A: Planta. B: Hoja. C: Detalle del capítulo. D: Flor ligulada. E: Flor tubulosa. F: Filario. G: Anteras. H: Estilo y estigma. 
E. Caviedes 310 (SGO); Tongoy, 15-I-1979, H. González V. s.n. (SGO); Entrada a Puerto Velero, 3 IV-1994, M. Muñoz S. 3383 (SGO); Guanaqueros, al borde de la autopista, 04-I-2012, F. Ratto et al. 4, 5 y 6 (BAA). Prov. Choapa, Choapa, XII-1862, Sin colector s.n. (SGO); Camino Illapel, Caimanes, km 7, 1-II-2003, S. Sepúlveda \& J. Villagrán 30 (SGO); Comunidad Mincha, Canela Baja, 2-II-1975, S. Lailhcar s.n. (SGO); Norte Puente Chigualoco, 28-XII-1993, M. Muñoz S. 3362 (SGO). V Región: Valparaíso, Prov: Marga Marga, Limache, cerro de la cruz, 05-II-1962, O. T. Solbrig 3394 (LP).

Observaciones. 1) Fundada por De Candolle bajo el nombre de B. paniculata. Blake (1930) consideró que los ejemplares tipo de Galinsoga resinosa, $O$. poeppigii y $B$. paniculata se trataban de la misma entidad. Las especies $G$. compacta Philippii (1884) y B. floribunda Philippii (1864) son consideradas sinónimos de esta especie. G. laricifolia D. Don es considerada un sinónimo ambiguo.

2) Especie de gran porte, generalmente supera el metro de altura. Su floración es poco abundante. Se la encuentra creciendo cerca de la costa, a nivel del mar.

14. Gutierrezia solbrigii Cabrera, Fl. Patagónica 8 (7): 31. 1971. (Figs. 32, 33). Tipo: Argentina. Neuquén. Dpto. Confluencia: Plaza Huincul, al E de la Barda Negra, A. L. Cabrera 11005 (Holotipo, LP 000273!; Isotipo, CORD 00005396!).

Iconografía. Cabrera, A. L. 1971. En M. N Correa (Ed.). Fl. Patagónica. Compositae. Parte VII: 29, fig. 16. Colección científica del INTA.

Arbustos de 10-40 cm, con raíces leñosas gruesas y tallos erectos ramificados, costados, glandulares, laxamente hojosos. Hojas elípticolanceoladas, agudas, de 10-35 x 1-3 mm, subcoriáceas, sésiles, con pequeñísimos dientes irregularmente distribuidos en la margen. Capítulos radiados, heterógamos, sésiles, de 12-18 mm de diámetro, agrupados en cimas corimbiformes laxas, con 1-4 brácteas linear-elípticas de $10 \mathrm{x}$ 0,5-1 mm. Involucro acampanado, resinoso, de 5-8 x 4-6 mm. Receptáculo plano o ligeramente convexo, alveolado, piloso. Filarios en 3 series, los exteriores oblongos, glandulares, acuminados, los interiores estrechamente obovados, apiculados. Flores liguladas 5-7, pistiladas, con lámina blanca, obovadas, de 6-7 $\mathrm{mm}$ de largo; estilo con ramas lineal elíptica, ápice agudo, papilosas. Flores del disco 10-14, perfectas, blanco-amarillentas, de 3-4 $\mathrm{mm}$, tubulosas, con garganta bruscamente ampliada. Anteras redondeadas en la base; ápice con el tejido conectivo ovado a ovado-elíptico, ramas del estilo lineal elípticas, agudas, con tricomas papilosos colectores en el lado exterior. Aquenios gris claro, turbinados, costados, densamente seríceos. Pappus compuesto por ca. 15 páleas desiguales con los márgenes laciniados de $2 \mathrm{~mm}$ de largo en las flores liguladas y $2,5-3 \mathrm{~mm}$ de largo en las flores del disco.

Distribución geográfica y hábitat. Se la encuentra en toda la Patagonia exceptuando Tierra del Fuego. Habita el Dominio Andino-Patagónico en las provincias Patagónica y del Monte entre los 0 y los $1200 \mathrm{msnm}$. Vive en dunas y en la meseta, en bordes de camino y entre matorrales de jarilla.

Nombre vulgar. No se conoce.

Especimenes examinados. ARGENTINA. Prov. Chubut: Dpto. Biedma, Península Valdés a 2 km Isla de Los Pájaros hacia Pto Madryn, 17-XII-1993, A. M. Molina et al. 4655 (BAB); Puerto Madryn, cruce ruta prov. 1 y Acceso Costero, 18-I-1999, G. Seijo 1468 (SI). Dpto. Escalante, Comodoro Rivadavia, C. A. Marelli 41 (SI); Dpto. Florentino Ameghino, Ea. Lochiel a Camarones, 22-I-1958, F. Vervoorst 5604 (BAB); Dique Florentino Ameghino, 17-I2016, F. Ratto, D. Sbarra \& M. Sorondo 15/2016 (BAA). Dpto. Futaleufú; Río Corcovado, N. Illin s.n. (BA). Dpto. Gaiman, Camino al dique Florentino Ameghino, A. L. Cabrera et al. 33269 (SI); Las Chapas, 27-XI-1976, S. Arroyo et al. 13 (SI); RN3 km 1493, 06-I-2013, F. Ratto et al. 1, 2, 3, 4, 5 y 6 (BAA). Dpto. Mártires; R 25 a 8 km E Las Plumas, 27-XI-1976, S. Arroyo et al. 45 (SI, BAB); R 25 a 13 km E Las Plumas, 27-XI-1976, S. Arroyo et al. 39 (SI). Dpto. Telsen, $4 \mathrm{~km} \mathrm{NO}$ de Telsen, 11-XII-1979, A. M. Beeskow 1026(BAB); Pto. Madryn a Telsen, 14-XII-2002, A. Bartoli \& R. Tortosa 6/02-2 (BAA). Dpto. Rawson, $14 \mathrm{~km} \mathrm{al}$ $\mathrm{N}$ de Trelew, 24-XI-1979, F. Roig E. Méndez 9858 (SI); Camino a Playa Isla Escondida, 17-II-1999, D. G. Gutiérrez 23 (LP); Ruta 25, estepa, 05- 

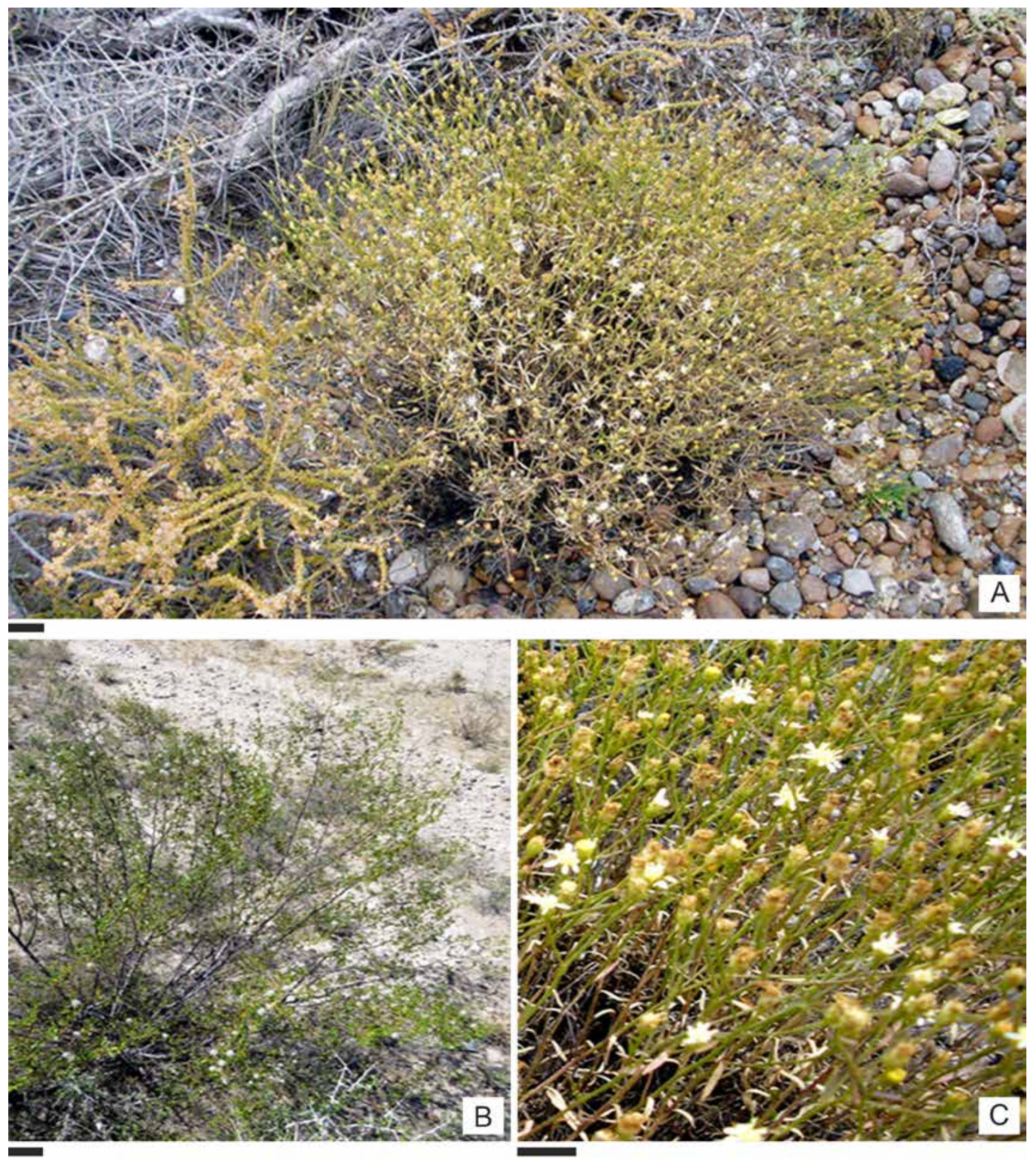

Fig. 32. Gutierrezia solbrigii. A: Planta. B: Hábitat. C: Detalle de capítulos. Fotografías por Francisco Ratto. Escalas $=A: 1,5 \mathrm{~cm} ; \mathrm{B}: 3 \mathrm{~cm} ; \mathrm{C}: 1,5 \mathrm{~cm}$.

XII-2002, M. Bonifacino \& M. Donato 803 (SI). Prov.Neuquén: Dpto. Añelo, Mina Auca Mahuida, 19-I-1961, R. L. Pérez Moreau 3013 (LP); RP 7 km 1500, Chihuido medio, 12-II-1975, D. Medán 291 (BAA). Dpto. Catán Lil, Cruce ruta Nac 40 y prov. 20, 05-XII-1980, M. N. Correa et al. 7886 (BAB). Dpto. Confluencia, Alrededores de la ciudad de Neuquén, I-1978, R. León 2224 (BAA); Neuquén R 22 y R 337, 29-XI-1978, H. Cordo \& M. Ferrer s.n. (SI); Al N de Cutralcó, 08-XII-2006, 
Bol. Soc. Argent. Bot. 55 (3) 2020

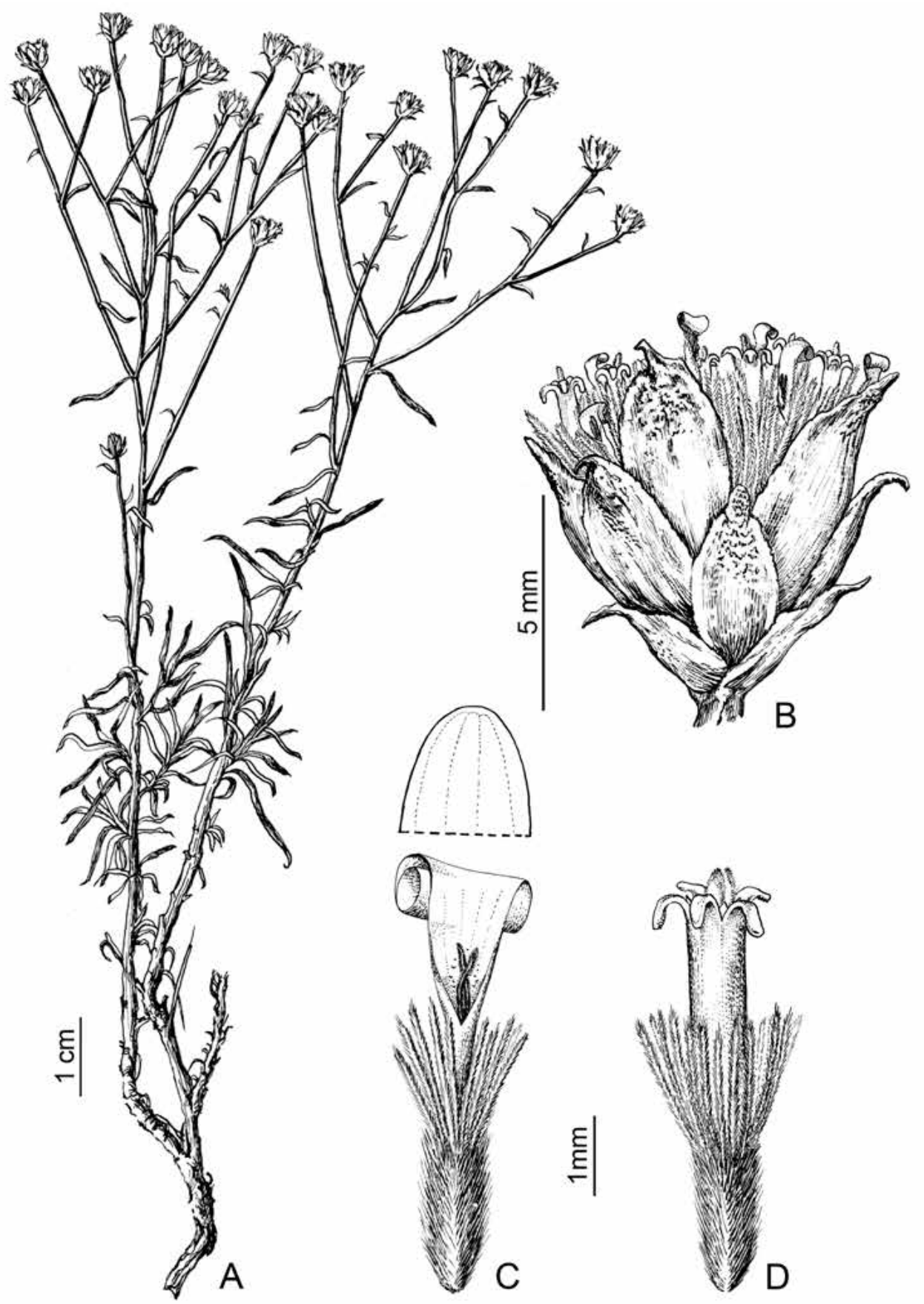

Fig. 33. Gutierrezia solbrigii. A: Planta. B: Capítulo. C: Flor ligulada. D: Flor tubulosa.

M. Bonifacino et al. 2908 (SI). Dpto. Loncopué; A pocos $\mathrm{km}$ de Río Neuquén a Río Agrico, 9II-1950, O. Boelcke 4239 (BAA). Dpto. Minas, La Negra, ruta 40, 28-XII-1963, S. Schajovoskoy
7617 (BA); De RP 43 Entre La Primavera y El Alamito, 28-XI-2010, F. O. Zuloaga et al. 12568 (SI). Dpto. Pehuenches. Costado del Río Colorado, 21-VIII-1997, R. H. Fortunato 5684 (BAB); RN 


\section{F. Ratto y A. Bartoli - Revisión de Gutierrezia}

40 km 2662, 28-I-2016, F. Ratto, D. Sbarra y M. Sorondo 112/2016 (BAA). Dpto. Zapala, Ruta 22, $10 \mathrm{~km}$ al N de P Covunco, 10-I-1964, R. L. Pérez Moreau \& S. Mazzuconi 3397(BAB); 10 km antes de Zapala desde Neuquén, 9-XII-2010, R. Tortosa \& A. Bartoli 15 (BAA). Prov. Río Negro: Dpto. Adolfo Alsina, RT $3136 \mathrm{~km}$ W Viedma, 23-XI-1978, Cordo-Ferrer s.n. (SI). Dpto. General Conesa, 15 km S de General Conesa, Ruta 257, 7 XI-1965, M. N. Correa et al. 3176 \& E. G. Nicora (BAA, BAB); R251, 15-XII-1970, S. Crespo \& N. Troncoso 1803 (SI). Dpto. El Cuy, $70 \mathrm{~km} \mathrm{~N} \mathrm{de}$ Co. Policía, ruta 242, 06-XII-1972, M. N. Correa et al. 4748 (BAB); Paso Córdoba, 6-XII-1972, N. Bacigalupo \& E. Nicora s.n. (BAA); Dpto. General Roca; Frente a Fuerte Gral. Roca, 16-II-1944, E. Nicora 4058 (SI); Along route 22, ca. $47 \mathrm{~km} \mathrm{E} \mathrm{of}$ Villa Regina, 6-I-1985, R. Merrill King \& F. E. Heinz 9361 (SI). Dpto. Avellaneda, Entre Duval y Chelforó, 6-XII-1981, A. L. Cabrera et al. 32819 (SI). Dpto. Pilcaniyeu, Ruta 237, cerca de Paso Limay, 6-I-1962, J. Vallerini s.n. (BAA). Dpto. San Antonio, Sierra Grande, 11-XII-2003, A. Bartoli \& R. Tortosa 35/3 (SI); Ruta 3 km 1050, 16-I-2016, F. Ratto, D. Sbarra \& M. Sorondo 2/2016 (BAA); Ruta 3 km 1090, 16-I-2016, F. Ratto, D. Sbarra \& M. Sorondo 5/2016 (BAA); Sierra Grande, 16I-2016, F. Ratto, D. Sbarra \& M. Sorondo 7/2016 (BAA). Dpto. Valcheta, Camino a Chanquin, 22 XI-1975, M. N. Correa et al. 6186 (BAB); Arroyo Ventana a Coná Niyeu, 9-I-2002, H. Troiani \& P. Steibel 15137 (BAA, SI). Dpto. Pichi Mahuida, Rio Colorado, 12-XI-1905, S. Renaco s.n. (SI); Juan de Garay, V-1900, L. R. Parodi 1486 (BAA). Dpto. San Antonio, Ruta 3, 16-XII-1975, M. N. Correa et al. 6802 (CORD); $35 \mathrm{~km} \mathrm{~N}$ de Sierra Grande, ruta 3, 12-XII-1981, S. Crespo \& P. Calieres 2456 (CORD). Dpto. 9 de Julio, Entre Mazza y Nahuel Niyeu, 29-XI-1965, M. N. Correa \& E. Nicora 3708 (BAB, BAA).

Observaciones. 1) Especie fundada por Cabrera (1971) cuyo material tipo fue coleccionado en Neuquén por el mismo autor, diferenciándola de las especies con las que cohabita por poseer cimas laxas y abiertas.

2) Consideramos sinónimo de esta especie a G. brachyris var. patagonica Mackloskie. Esta variedad fundada por Mackloskie (1905) fue incorporada por Cabrera (op. cit.) a la sinonimia de
G. spathulata, pero su material tipo coincide con $G$. solbrigii.

3) Especie ampliamente distribuida en las provincias de Chubut, Neuquén y Río negro. Es afín a $G$. gilliesii y $G$. mendocina, de las cuales se diferencia de por poseer inflorescencias corimbiformes amplias y hojas elípticas.

15. Gutierrezia spathulata (Phil.) Kurtz., Bol. Acad. Nac. Ciencias. Córdoba. Córdoba, Argentina 13: 194. 1893. (Figs. 34, 35). Brachyris spathulata Phil., Anales Univ. Chile. 27: 336. 1865. Tipo: Argentina, prope la Guardia in prov. Mendoza, M. Landbeck s.n. (Lectotipo, designado por Ratto et al. 2019, SGO-44787!; Isolectotipos, LP 002064!, SGO-65124!).

= Gutierrezia spathulata (Phil.) Kurtz var. ochroleuca Kurtz., Bol. Acad. Nac. Ci. 13: 186. 1893. Tipo: Argentina. Mendoza, inter arroyo Papagayos et arroyo Hondo, 27 Dic 1892, F. Kurtz 7431 (Lectotipo, designado por Ratto et al. 2019, CORD 00005398!; Isolectotipos, CORD 00005399!, LP 002065!; LP 002066!).

$=$ Gutierrezia pulviniformis Cabrera., Darwiniana 4 (1): 135. 1940. Tipo: Argentina. Mendoza. Dpto. San Rafael: Cerro Nevado, Ene 1916, E. Carette s.n. (Lectotipo, designado por Ratto et al. 2019, LP 000272!; Isolectotipo, MERL [ex Ruiz Leal 2488!]).

Iconografia. Cabrera, A. L. 1971. En M. N Correa (Ed.). Fl. Patagónica. Compositae. Parte VII: 28-33. Colección científica del INTA.

Subarbustos de 3-30 $(-40) \mathrm{cm}$, ramificados en la base. Tallos erectos, los juveniles costados, con pubescencia glandular sobre las costillas, frondosos en la base y laxamente foliosos hasta el ápice. Hojas subcoriáceas, sésiles, atenuadas en un pseudopecíolo, obtusas, irregularmente dentadas en la margen, las basales espatuladas o elípticoespatuladas, de $10-25 \times 2,5-6 \mathrm{~mm}$, obtusas, las caulinares gradualmente menores. Capítulos radiados, sésiles, de $10-12 \mathrm{~mm}$ de diámetro, agrupados en cimas corimbiformes en el ápice de los tallos, con 1 o 2 brácteas linear- elípticas de 1-3 mm de largo. Involucro ovoide, resinoso, 4-6 x 3-5 mm. Receptáculo plano o ligeramente convexo, alveolado, piloso. Filarios en 3 series, oblongos, la serie externa glandular, acuminados, la serie interna 

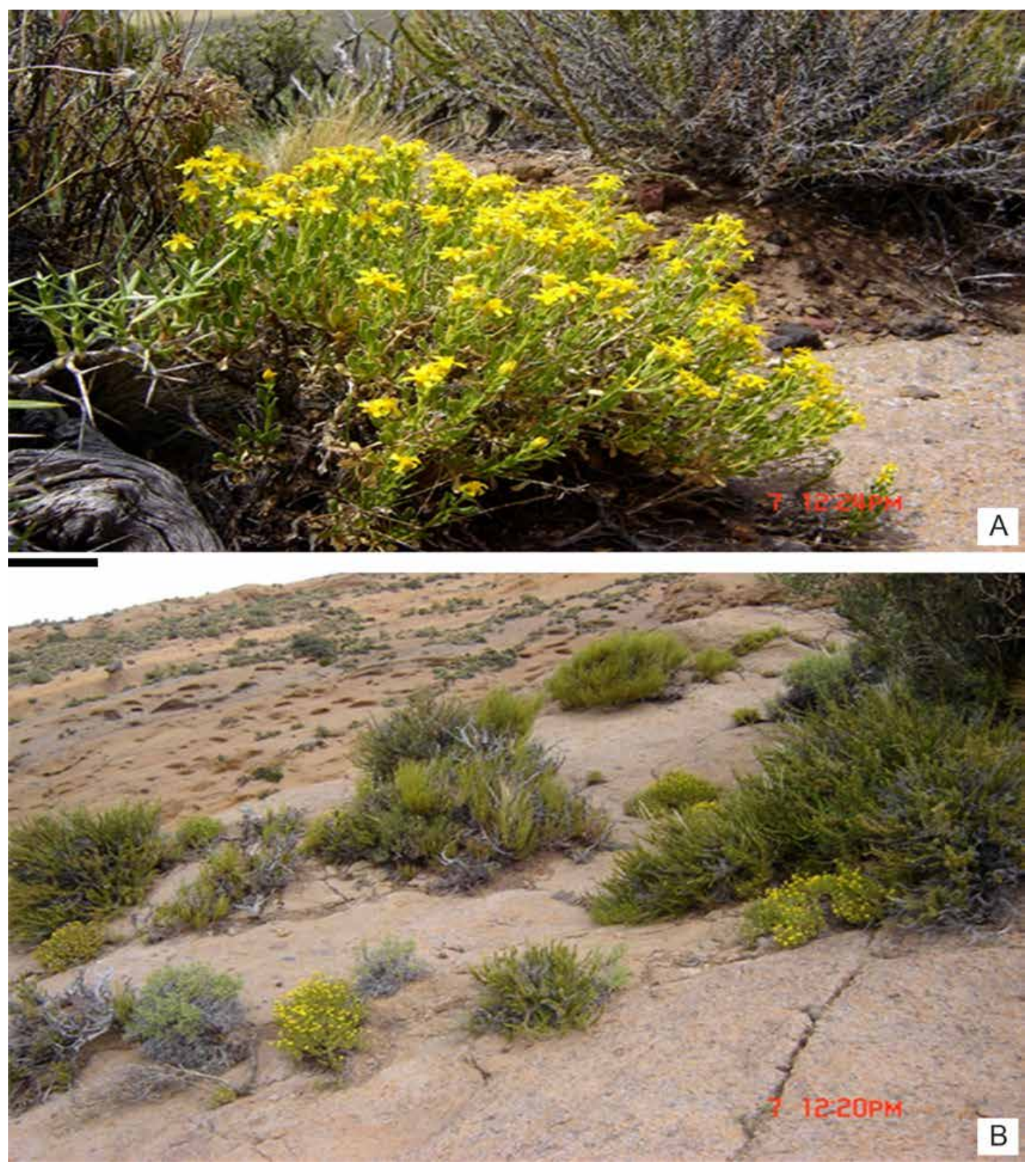

Fig. 34. Gutierrezia spathulata. A: Planta y capítulos. B: Hábitat. Fotografías por Francisco Ratto. Escala= A: $1 \mathrm{~cm}$.

triangular, glandular, apiculados. Flores liguladas 5 a 7, femeninas, color amarillo, lígulas elípticas, de 5-6 mm de largo por 1,5-2 $\mathrm{mm}$ de ancho. Flores del disco 6 a 10, hermafroditas, con la corola de color amarillo, de 3-4 mm con garganta bruscamente ampliada. Anteras redondeadas en la base con tejido conectivo triangular de $0,5 \mathrm{~mm}$. Ramas del estilo agudas. Aquenios grisáceos, cilíndricoovoides, costados, densamente seríceos, de $1 \mathrm{~mm}$. Vilano compuesto de 7-10 páleas linear-elípticas y laciniadas de $0,5-1,5 \mathrm{~mm}$ de largo en flores liguladas y de 1,5-2 $\mathrm{mm}$ en las flores del disco. 


\section{F. Ratto y A. Bartoli - Revisión de Gutierrezia}

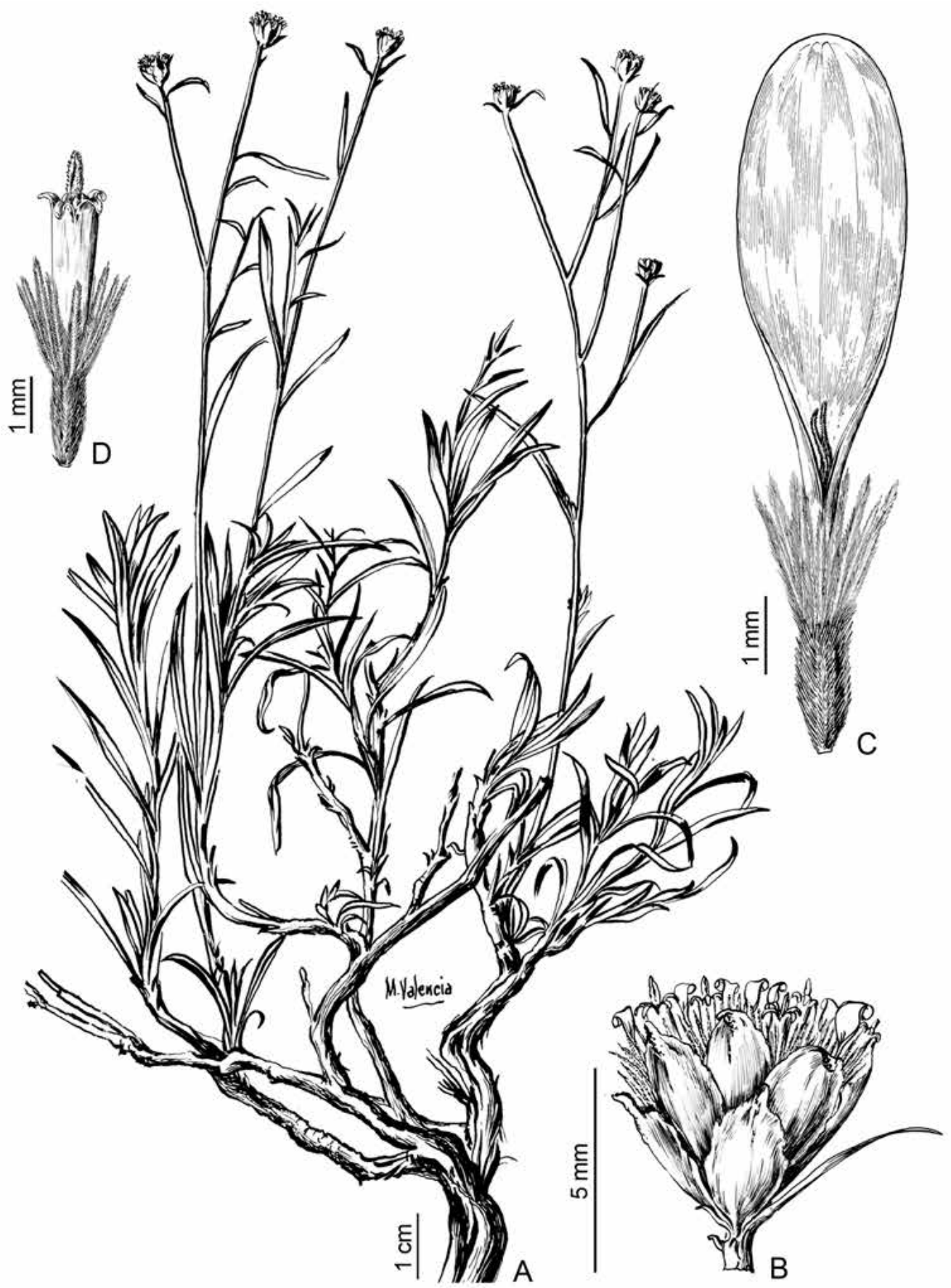

Fig. 35. Gutierrezia spathulata. A: Planta. B: Capítulo. C: Flor ligulada. D: Flor tubulosa.

Distribución geográfica y hábitat. Crece en Mendoza, habita el dominio Andino-Patagónico en la provincia Fitogeográfica Patagónica entre los 1300 y los 2400 msnm, en laderas pedregosas de los cerros, en grietas de rocas.

Nombre vulgar. "yerba de la oveja", "yerba del guanaco", "yerba del buitre". 
Especímenes examinados. ARGENTINA. Prov. Mendoza: Dpto. Maipú, Beltrán, Entre Alamito y Rodeo Viejo, 14-I-1888, F. Kurtz 5775 (CORD); Beltrán, Valle del Malargüe, 7-II-1892, F. Kurtz 7189 (CORD). Dpto. Malargüe, Ruta prov. 180 entre Pampa de los Pajaritos y Mina Ethel, 10-XII2004, A. Prina et al. 2590 (SI); Paso Pehuenche, 24-XI-2010, F. O. Zuloaga et al. 12449 (SI). Dpto. San Carlos, 26-III-1918, LP 60534 (LP). Dpto. San Rafael, RP 184, 06-I-2015, F. Ratto et al. 30 (BAA); Co. La Montura, 07-I-2015, F. Ratto et al. 52 (BAA); Co. La Montura, 07-I-2015, F. Ratto et al. 53 (BAA); El Sosneado, RP 220, 08-I-2015, F. Ratto et al. 79 (BAA); El Sosneado, RP 220, 08-I-2015, F. Ratto et al. 80 (BAA).

Observaciones. 1) Fundada por Philippi (1865) bajo el nombre de $B$. spathulata basado en material tipo de Mendoza coleccionado por Landbeck. Luego fue transferida por Kurtz (1893) al género Gutierrezia.

2) Solbrig (1966) incorporó a la lista de sinónimos de esta especie a G. spathulata (Phil.) Kurtz var. ochroleuca Kurtz cuyo material tipo también procede de Mendoza.

3) Consideramos también sinónimo de esta especie a $G$. pulviniformis Cabrera ya que no he podido encontrar diferencias entre los pocos ejemplares coleccionados bajo el nombre de la especie de Cabrera y su distribución coincide con la de G. spathulata. Muchas observaciones a campo nos permiten concluir que se trata de la misma especie que expresa variabilidad creciendo en distintas situaciones.

4) Especie endémica de la provincia de Mendoza, donde crece en laderas muy rocosas. Especie variable, desde pequeños cojines a plantas decumbentes más desarrolladas que llegan hasta los $30 \mathrm{~cm}$, es afín a $G$. mendocina pero sus flores liguladas son siempre amarillas y sus hojas notablemente espatuladas.

16. Gutierrezia taltalensis Phil., Anales Univ. Chile. 87: 426. 1894. (Fig. 36). Tipo: Chile, prope Taltal in deserto Atacama, L. Darapsky (Holotipo SGO 65123!).

$=$ Gutierrezia copiapina Phil., Anales Univ. Chile. 87: 425. 1894. Tipo: Chile, prope Chañarcillo invenit orn. G. Geisse s. n., 1885 (Holotipo SGO72368!; Isotipo LP 001992!).
Iconografía. Finger, K. \& Teillier, S. 2010. Contribución al conocimiento de la flora endémica de Taltal y Paposo, Región de Antofagasta (II), Chile. Chloris Chil. 13 (2), 1-12.

Arbustos de $20-50 \mathrm{~cm}$, ramificados desde la base. Tallos decumbentes, acanalados, glandulares, frondosos hasta el ápice, erectos, hojas subcoriáceas, sésiles, irregularmente dentadas, hojas linear-elípticas, de $20-60 \times 2-5 \mathrm{~mm}$, agudas, hojas caulinares algo menores. Capítulos radiados, sésiles, de 10-12 mm de diámetro, formando cimas corimbiformes en el ápice de los tallos, con 1 o 2 brácteas linear-elípticas 3-5 mm de largo, apiculadas. Involucro turbinado, resinoso, 5-8 mm x 3-5 mm. Receptáculo plano o ligeramente convexo, alveolado, piloso. Filarios en 3 series, elíptico-oblongos, glandulares, acuminados. Flores liguladas 8 a 10, color blanco, lígulas estrechamente obovadas, de 7-9 $\mathrm{mm}$ de largo. Flores del disco 8 a 12 , femeninas, con la corola de color amarillento, de 4-6 mm con garganta bruscamente ampliada hacia el ápice. Anteras redondeadas en la base con tejido conectivo triangular de $0,5 \mathrm{~mm}$. Ramas del estilo agudas. Aquenios grisáceos, ovoide-turbinados, costados, densamente seríceos, de 1-1,5 mm. Vilano compuesto de 15-20 páleas desiguales, lineares, laciniadas de 1-2 $\mathrm{mm}$ de largo en flores liguladas y de 2-3 mm en las flores del disco.

Distribución geográfica y hábitat. Se la encuentra en Chile, Regiones II, Antofagasta y III, Atacama y Coquimbo, entre los 0 y los $1200 \mathrm{msnm}$, en las regiones vegetales del Desierto y/o Matorral y Bosque Esclerófilo, subregiones Desierto Costero, Matorral Estepario y Matorral y Bosque Espinoso.

\section{Nombre vulgar. "pichanilla".}

Especimenes examinados. CHILE. II Región: Antofagasta. Prov. Antofagasta: Bandurrias, 1886, W. Geisse s.n. (SGO); Cerro Bandurrias, Chañarcillo, $\mathrm{X}-1886$, sin colector s.n. (SGO); Region about Aguada Cachina, 15-XII-1925, I. M. Johnston 5722 (BA); Region about Aguada Cachina, 15-XII-1925, I. M. Johnston 5723 (BA); Southwest of Agua de Los Mantos, 13-XII-1925, I. M. Johnston 5658 (BA); vecinity of Aguada Grande, near AntofagastaAtacama provincial boundary, 18-XII-1925, I. M. Johnston 5751 (BA); Aguada Panulcito, I. M. Johnston 5472 (BA); Cerro Perales, 11-XII-1925, 

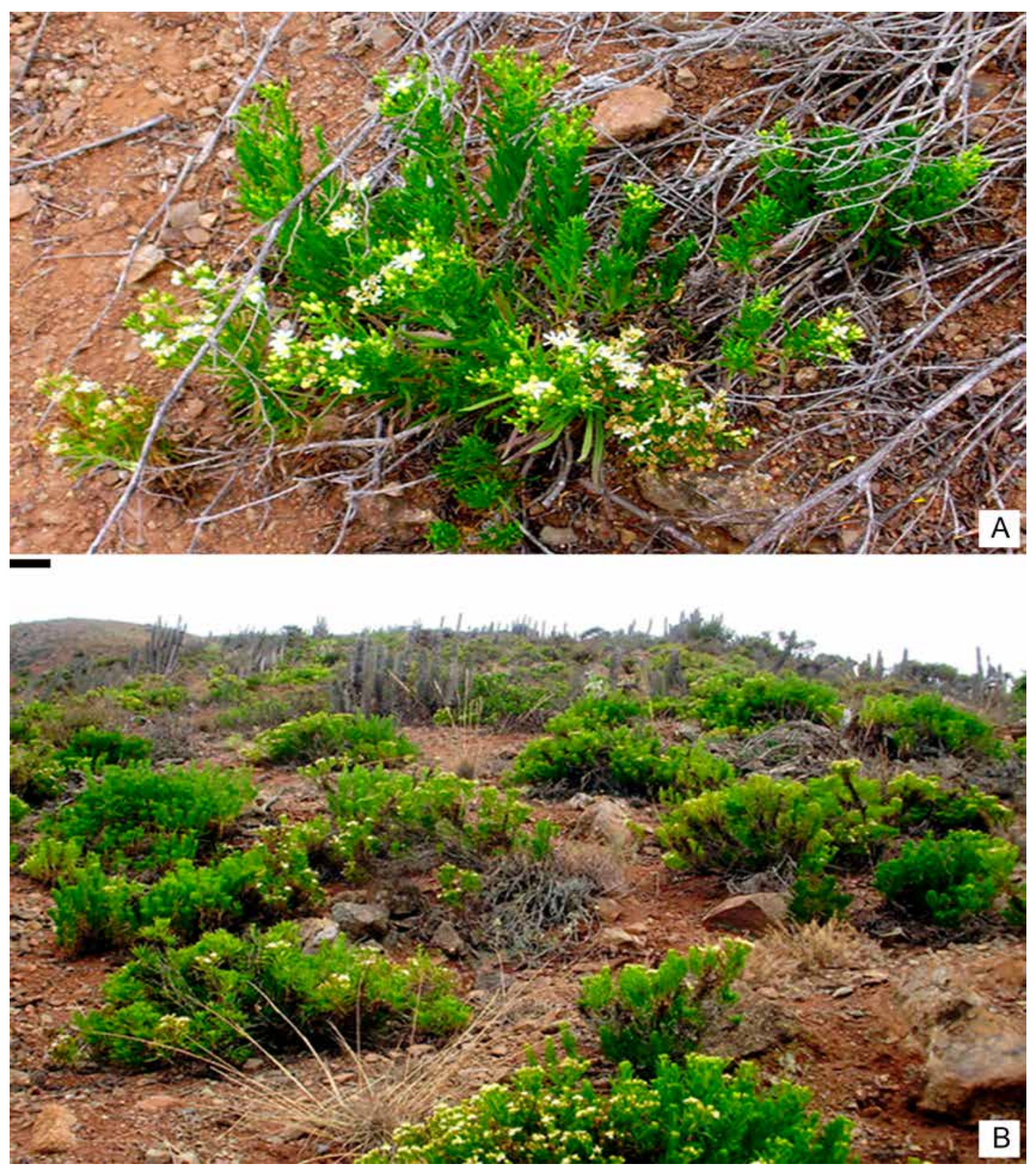

Fig. 36. Gutierrezia taltalensis. A: Planta. B: Población y hábitat. Fotografías por Francisco Ratto. Escala= A: $1 \mathrm{~cm}$.

I. M. Johnston 5625 (BA); Taltal, Quebrada El Leoncito, 4-XI-1941, Pisano V. \& R. Bravo 636 (SGO); Paposo, Quebrada Mantacilla, 9-X-1992, S. Teillier et al. 2943 (SGO); Quebrada Mantancilla, 27XI-1997, M. O. Dillon \& M. Villarroel 8117 (SGO);
Paposo, Quebrada de la Oveja, 06-I-2012, F. Ratto et al. 21, 24, 30, 31, 32 y 33 (BAA); Chañaral, 7-I-1969, O. Zöllner 3250 (LP). IV Región: Coquimbo, Prov. Limari, 30 40'Lat, IX-1935, C. Muñoz P. B-229 (SGO). 
Observaciones. 1) Especie fundada por Philippi (1894) basada en material tipo coleccionado en Taltal por Darapsky.

2) Solbrig (1966) consideró a G. copiapina, del mismo autor, como sinónimos.

3) Crece cerca del mar en laderas muy empinadas junto a la vegetación característica de la costa del pacífico. Similar a G. neaeana, de la cual se diferencia por sus flores liguladas blancas y por las hojas más largas que son siempre elípticas.

17. Gutierrezia tortosae Ratto \& A. Bartoli., Collec. Bot. 35. 2016. (Figs. 37, 38). Tipo: Argentina. Jujuy: Dpto. Susques, Angosto de las Burras, 6-2-2014, F. Ratto et al. 47 (Holotipo, BAA!; Isotipos BAA!, BC!, CTES!, SI!).

Iconografia. Ratto \& Bartoli. 2016. A new species of Gutierrezia (Asteraceae, Astereae) from Argentina. Collec. Bot. 35.

Subarbustos 5-25 $(-35) \mathrm{cm}$, con xilopodio, tallos numerosos, erectos, rígidos, costados, glandulares, más o menos ramificados, foliosos desde la base, disminuyendo hacia el ápice. Hojas subcoriáceas, erectas, sésiles, irregularmente dentadas en la margen, linear-elípticas, 5-15 x 1-1,5 mm, agudas. Capítulos radiados, heterógamos, pedunculados, de $1-1.5 \mathrm{~cm}$ diam., agrupados en cimas corimbiformes en el ápice de los tallos; pedúnculos de 5-30 mm, con 1 o 2 brácteas linear-elípticas de 2-3 mm long. Involucro acampanado, resinoso, de 4-6 $\mathrm{mm} \times 3-5 \mathrm{~mm}$. Receptáculo plano a ligeramente convexo, desnudo, alveolado, piloso. Filarios en 3 series graduales, la exterior oblongas, glandulares, acuminadas, la exterior angostamente obovadas, apiculados. Flores liguladas de 6 a 8 , pistiladas, con corola amarilla, angostamente obovada de 6-7 mm long.; estilos con ramas linear-elípticas, ápice agudo, papilosas. Flores del disco de 12 a 15 , perfectas, con corola amarilla de 3-4 mm, tubulosa, con la garganta ampliada en forma abrupta. Anteras redondeadas en la base, ápice con tejido conectivo ovado a ovado-elíptico; ramas del estilo elípticas, agudas, con tricomas colectores en su cara externa. Aquenios grises, obovado-turbinados, densamente seríceos. Pappus con 10-15 páleas linear-elípticas, laciniadas en la margen, ca. $1 \mathrm{~mm}$ en las flores liguladas y 1-1,5 mm en las flores del disco.

Distribución geográfica y hábitat. Argentina se la encuentra en las provincias de Jujuy y
Salta. Habita las provincias fitogeográficas de la Puna, Prepuna y en la transición entre Prepuna y Monte entre los 2000 y los $4400 \mathrm{msnm}$, en laderas de suelos rocosos y arenosos acompañada de vegetación esteparia arbustiva de puna seca.

Nombre vulgar. "canchalagua".

Especimenes examinados. ARGENTINA. Prov. Jujuy: Dpto. Cochinoca, 14-II-1901, F. Kurtz 11656 (CORD); Ruta Nac 9, de Tres Cruces a Abra Pampa, 13-II-09, F. O. Zuloaga et al. 10641 (SI). Dpto. Humahuaca, Puente del diablo, $5 \mathrm{~km}$ al sur de Tres Cruces, 31-IX-1970, H. A. Fabris y F. O. Zuloaga (LP); Mina Aguilar, A. L. Cabrera 9186 (LP); A casi 1 km de Río Grande, 27-II-2004, A. A. Cocucci et al. 3373 (CORD); RN 9 y RP 13, 07-II-2014, F. Ratto et al. 112 (BAA); RN 9, Tres Cruces, 07-II-2014, F. Ratto et al. 111 (BAA); El Aguilar, 11-II-2014, F. Ratto et al. 143 (BAA). Dpto. Rinconada, Abra de Queta, 9-II-1901, F. Kurtz 11626 (CORD); La Rinconada, 3-X-1901, F. Kurtz 11334 (CORD). Dpto. Santa Catalina, Ciénega, 21-II-2016, F. Ratto, D. Sbarra \& D. Schiavinato 125/2016 (BAA); RN 40, 21-II-2016, F. Ratto, D. Sbarra \& D. Schiavinato 116/2016 (BAA); RN 40, 21-II-2016, F. Ratto, D. Sbarra \&

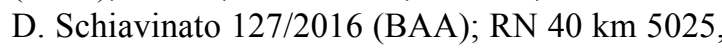
21-II-2016, F. Ratto, D. Sbarra \& D. Schiavinato 128/2016 (BAA). Dpto. Susques, RN 52, en las afueras de Susques, 07-II-2014, F. Ratto et al.64, 66, 67, 68, 69, 71, 72, 74 у 77 (BAA); RN 40, 21-II-2016, F. Ratto, D. Sbarra \& D. Schiavinato 127/2016 (BAA). Dpto. Tilcara, Garganta del Diablo, 13-II-1992, J. H. Hunziker s.n. (SI). Dpto. Tumbaya, Volcán, 18-II-2009, F. O. Zuloaga et al. 10950 (SI). RN 52, Cuesta de Lipán, 7-II-2014, F. Ratto et al. 85, 86, 87, 89, 90, 83, 94, 106 y 107 (BAA). Dpto. Yavi, Cerro Ocho hermanos, 18III-2003, A. A. Cocucci et al.2703 (CORD, SI). Prov. Salta: Dpto. Iruya. Alrededores del pueblo de Iruya, 13-III-1988, J. A. Hurrel 679 (LP); Quebrada del río San Isidro, 09-III-1998, Tolaba et al.1108 (MCNS). Dpto. La Poma, Cobres, Sierras de Rangel, 25-VII-1995, J. Tolaba 573 (MCNS); Ex RN 40, 6-II-2014, F. Ratto et al. 35, 41 y 42 (BAA). Dpto. Rosario de Lerma, Ruta 51, El Chañar, 24-I-1989, M. O. Arriaga et al.557 (BA); Finca El Toro, 19-II-1995, S. López 1570 (MCNS); Santa Rosa de Tastil, 05-II-2014, F. 


\section{F. Ratto y A. Bartoli - Revisión de Gutierrezia}
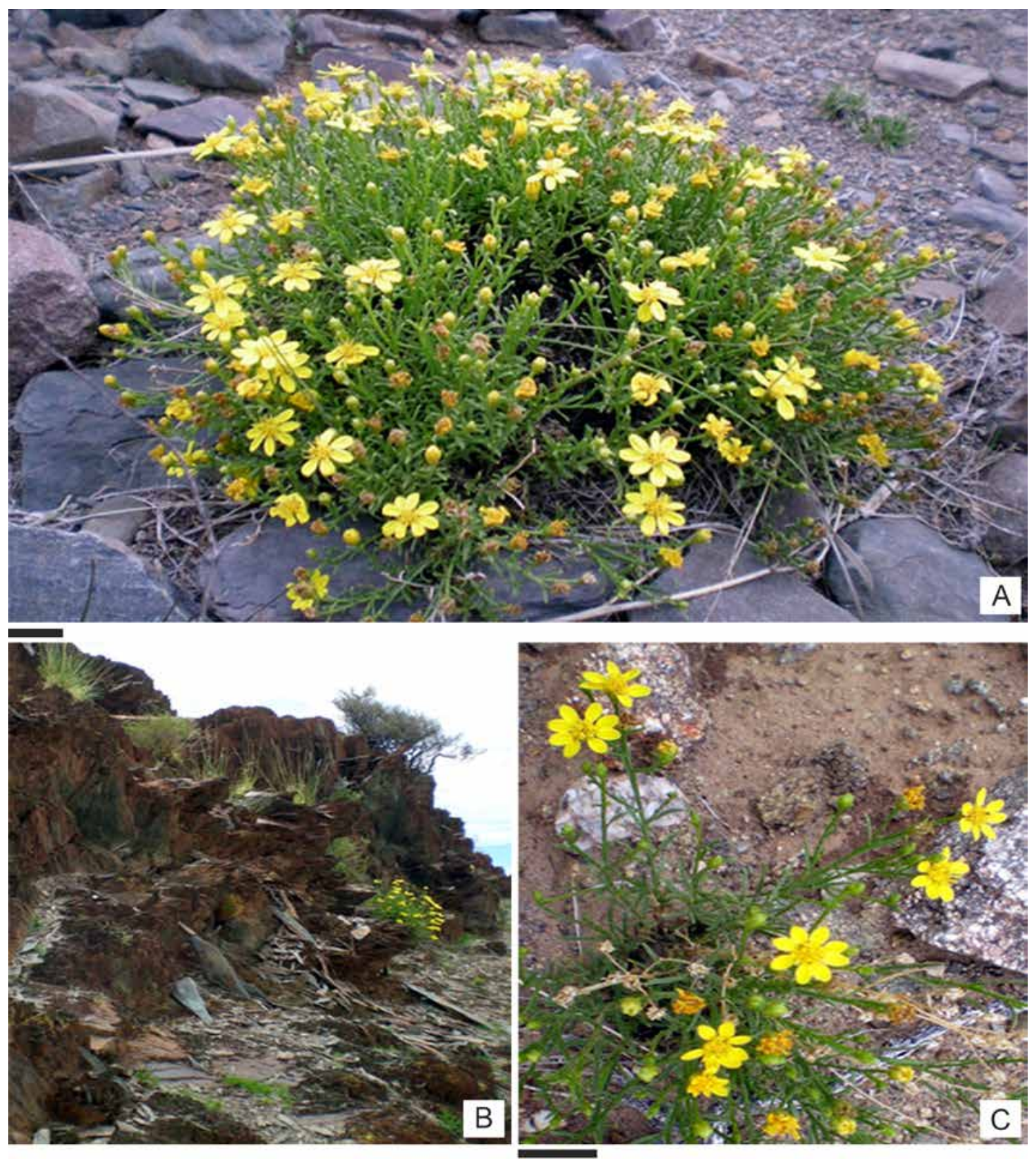

Fig. 37. Gutierrezia tortosae. A: Planta. B: Hábitat. C: Detalle de capítulos. Fotografías por Francisco Ratto. Escalas $=\mathrm{A}: 1 \mathrm{~cm} ; \mathrm{C}: 1 \mathrm{~cm}$.

Ratto et al. 11, 12, 13, 14 \& 15 (BAA). Dpto. San Antonio de Los Cobres, Quebrada de Polvorillas, 11-II-1945, A. L. Cabrera 9631 (LP); San Antonio de Los Cobres, 15-XII-1946, A. Krapovickas 3175 (LIL).
Observaciones. 1) Especie fundada recientemente por Ratto \& Bartoli (2016b) basada en material tipo coleccionado en Jujuy por el primer autor.

2) Se trata de una especie de porte variable. En general no supera los $20 \mathrm{~cm}$ de altura, pero cuando 


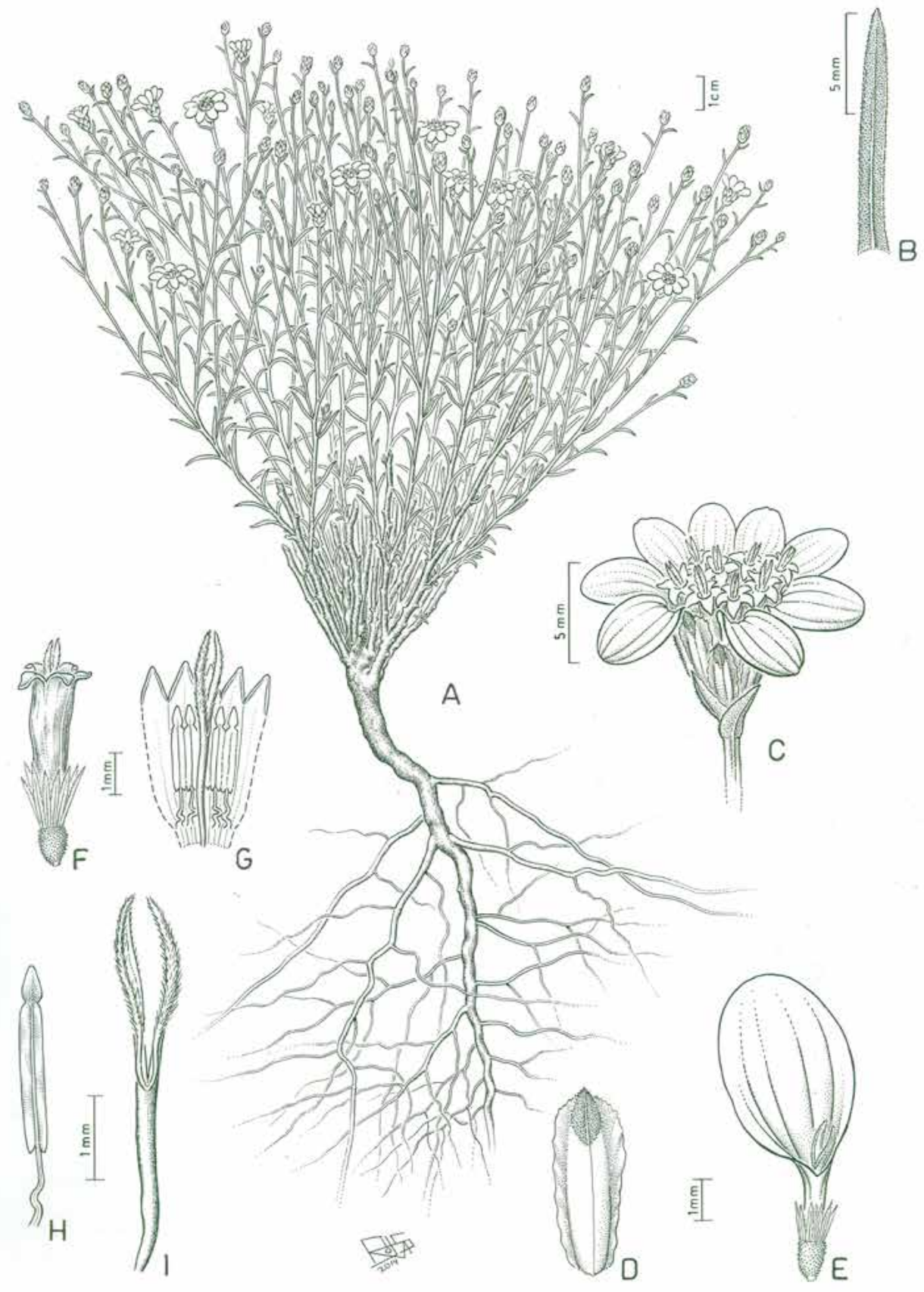

Fig. 38. Gutierrezia tortosae. A: Planta. B: Hoja. C: Capítulo. D: Filaria. E: Flor ligulada. F: Flor tubulosa. G: Detalle de antera y estilo. H: Antera. I: Estilo y estigma.

crece a alturas menores puede llegar hasta los $45-50 \mathrm{~cm}$. Esto se puede observar en los ejemplares del departamento de Rosario de Lerma en la provincia de Salta (en la localidad de Santa Rosa de Tastil). Se la suele confundir con G. mandonii, diferenciándose de esta última por el porte erecto, ramas leñosas y por poseer capítulos más pequeños, más numerosos y hojas más angostas. 


\section{F. Ratto y A. Bartoli - Revisión de Gutierrezia}

\section{Contribución DE LOS AUTORES}

FR: viajes de colección en Argentina y Chile para obtener ejemplares de herbario y realizar observaciones a campo. Definiciones taxonómicas. Redacción del manuscrito. AB: observación de material tipo y no tipo. Definiciones taxonómicas. Redacción del manuscrito.

\section{Agradecimientos}

Los autores agradecen a la Universidad de Buenos Aires por el financiamiento proporcionado para este trabajo. A los curadores de herbario que prestaron colecciones y facilitaron el acceso a las colecciones tipo y no tipo. Al ilustrador Marcelo Moreno y a Marcelo Rosas por las fotografías cedidas. A Milagros Anzuinelli por la colaboración en la edición de las imágenes digitales.

\section{Bibliografía}

ACEVEDO DE VARGAS, R. 1949. Contribución a la Flora Cordillerana del Norte de Chile, dos nuevas especies de Compuestas. Bol. Mus. Nac. Hist. Nat. Santiago de Chile. 24: 81-91.

ARIZA ESPINAR, L. \& L. J. NOVARA. 2005. Aport. Bot. Salta, Ser. Fl. 7: 9-14.

BLAKE, S. F. 1930. Contr. U. S. Natl. Herb 26: 232.

CABRERA, A. L. 1941. Compuestas bonaerenses: revisión de las compuestas de la provincia de Buenos Aires, la ciudad de Buenos Aires y la isla Martín García. Revista Mus. La Plata, Secc. Bot. 4: 1-460 pp.

CABRERA, A. L. 1971. Compositae. En CORREA, M. N. (eds.). Flora Patagónica. Parte VII. Colecc. Ci. Inst. Nac. Tecnol. Agropecu., Buenos Aires.

CABRERA, A. L. 1978. Compositae. En: CABRERA, A. L. (ed.), Flora de la Provincia de Jujuy, República Argentina. pp. 1-726. Instituto Nacional de Tecnología Agropecuaria, Buenos Aires. Tomo 13, Parte 10.

CABRERA, A. L. \& WILLINK, A. 1980. Biogeografía de América Latina. O. E. A. Serie de Biología, Monografía 13. Washington, D. C.

DE CANDOLLE, A. 1836. Prodromus systematis naturalis. Vol. 5, París.
FINGER, K. \& S. TEILLIER. 2010. Contribución al conocimiento de la flora endemica de Taltal y Paposo, Región de Antofagasta (II), Chile. Chloris Chilensis 13: 1-12.

GRISEBACH, A. 1874. Abh. Königl. Ges. Wiss. Göttingen. 19: 173.

HALL, T. A. 1999. Bioedit: a user-friendly biological sequence alignment editor and analysis program for Windows 95/98/NT. Nucl. Acids. Symp. Ser. 41: 95-98.

HAUMAN, L. 1918. La végétation des Hautes Cordilléres de Mendoza (République Argentine). Anales Soc. Ci. Argent. 86: 321.

HOOKER, W. J. \& A. W. ARNOTT. [1830-] 1841. Bot. Beechey Voy; Comprising an account of the plants collected by Messrs Lay and Collie, and other officers of the expedition, during the voyage to the Pacific and Bering's Strait, performed in His Majesty's Ship Blossom, under the Command of Captain F. W. Beechey, R.N., F.R., \& A.S., in the Years 1825, 26, 27 and 28. London, H. G. Bohn. $485 \mathrm{pp}$.

KUNTZE, O. 1898. Revis. Gen. Pl. 3: 1-576.

KURTZ, F. 1893. Dos viajes Botánicos al Río Salado Superior (Cordillera de Mendoza) ejecutados en los años 1891-1892 y 1892-1893. Bol. Acad. Nac. Ci. Republ. Argent. 13: 1-42.

LAGASCA, M. 1816. Genera et species plantarum, quae aut novae sunt, aut nondum recte cognoscuntur. Typographia regia.

LANE, M. A. 1982. Generic limits of Xanthocephalum, Gutierrezia, Amphiachyris, Gymnosperma, Greenella, and Thurovia. (Compositae: Astereae). Syst. Bot. 7: 405-416.

LANE, M. A. 1985. Taxonomy of Gutierrezia (Compositae: Astereae) in North America. Syst. Bot. 10: 7-28.

MACLOSKIE, G. 1905. Revision of Flora Patagonica. In: Reports of the Princeton University Expedition to Patagonia, 1896-1899, Vol. 8: 780. Princeton University, Princeton \& Schweizerbarth, Stuttgart.

MCNEILL1, J., F. R. BARRIE, W. R. BUCK, V. DEMOULIN, W. GREUTER, D.L. HAWKSWORTH, P. S. HERENDEEN, S. KNAPP, K. MARHOLD, J. PRADO, W.F. PRUD'HOMME VAN REINE, G.F. SMITH, J. H. WIERSEMA \& N. J. TURLAND (Eds.) 2012. International Code of Nomenclature for algae, fungi, and plants (Melbourne Code): Adopted by the Eighteenth International Botanical Congress Melbourne, 
Australia, July 2011. Regnum Vegetabile 154. Königstein: Koeltz Scientific Books. Available from: http://www.iapt-taxon.org/nomen/main. php. (accessed 26 march 2018)

NESOM, G. L. 2006. Gutierrezia. In: Flora of North America Editorial Committee (Ed.). Flora of North America \& North of Mexico, 20: 88-94. Oxford University Press, Oxford.

NUTTALL, T. 1818. The genera of North American plants and a catalogue of the species to the year 1917. Philadelphia.

PHILIPPI, R. A. 1865. Descripción de algunas plantas de la Cordillera entre Santiago y Mendoza. Anales Univ. Chille 27: 333-339.

PHILIPPI, R. A. 1894. Gutierrezia compacta. Anales Univ. Chile 87: 426.

RATTO, F. \& A. BARTOLI. 2014. Gutierrezia mendocina (Asteraceae, Astereae), a new South American species. Collec. Bot. 33: e002. http://dx.doi.org/10.3989/collectbot.2013.v33.002

RATTO, F. \& A. BARTOLI. 2015. The resurrection of Gutierrezia ameghinoi Speg. (Asteraceae, Astereae, Solidagininae), a species from Patagonia Argentina. Phytotaxa 220: 295-300. https://doi.org/10.11646/phytotaxa.220.3.8

RATTO, F. \& A. BARTOLI. 2016a. Reinstatement of Gutierrezia leucantha Cabrera (Asteraceae, Astereae). Webbia. https://doi.org/10.1080/00837792.2016.1180756

RATTO, F. \& A. BARTOLI. 2016b. A New Species of Gutierrezia (Asteraceae, Astereae) from Argentina. Collec. Bot. 35. https://doi.org/10.3989/collectbot.2016.v35.004

RATTO, F. \& A. BARTOLI. 2017a. A new species of Gutierrezia (Asteraceae, Astereae, Solidagininae) from Argentinian Patagonia. Phytotaxa 266: 157160. https://doi.org/10.11646/phytotaxa.266.2.11

RATTO, F. \& A. BARTOLI. 2017b. Taxonomic notes in Gutierrezia (Asteraceae, Astereae, Solidagininae). Bol. Soc. Argent. Bot. 52 (4): 779-785. https://doi.org/10.31055/1851.2372.v52.n4.18871

RATTO, F.; SCHIAVINATO, D. J. \& A. BARTOLI. 2019. Typification of names in South American Gutierrezia (Asteraceae, Astereae). Collec. Bot. 38: e001. https:// doi.org/10.3989/collectbot.2019.v38.001
REICHE, K. 1901. Estudios críticos sobre la flora de Chile: (continuación). Anales Univ. Chile 109: 5-80.

REMY, J. 1846. Odonthocarpa gayana. En C. GAY, Fl. Chil. IV. 36.

REMY, J. 1849. Compuesta. En GAY, Historia de Chile. Botánica Vol. IV.

RUFFIN, J. 1974. A taxonomic evaluation of the genera Anthemideae, Amphipappus, Greenella, Gutierrezia, Gymnosperma, Thurovia, and Xanthocephalum (Compositae). Sida 5: 301-333.

SANCHO, G. \& L. ARIZA ESPINAR. 2003. Asteraceae. Tribu III. Astereae, parte B. Subtribus Bellidinae, Asterinae (excepto Grindelia y Haplopappus). En: HUNZIKER, A.T. (Ed.), Flora Fanerogámica Argentina 81: 3-42, 54-58, 64-102. Consejo Nacional de Investigaciones Científicas y Técnicas, Córdoba.

SCHULTZ BIPONTINUS, C. H. 1855. Über die von Lechler an der Magellans-Strasse gesammelten Cassiniaceen. Flora 38: 113-123.

SCHULTZ BIPONTINUS, C. H. 1866. Enumeratio Cassiniacearum a cl. G. Mandon in Bolivia a. 18571861 lectarum. Linnaea 34: 527-536.

SHINNERS, L. H. 1950. Notes on Texas Compositae IV. Field \& Lab. 18: 25-42.

SHINNERS, L. H. 1951. Notes on the Texas Compositae VIII. Field \& Lab. 19: 133-136.

SOLBRIG, O. T. 1960. The status of the genera Amphiachyris, Amphipappus, Greenella, Gutierrezia, Gymnosperma, and Xanthocephalum (Compositae). Rhodora 62: 43-53.

SOLBRIG, O. T. 1965. The California species of Gutierrezia (Compositae-Astereae). Madroño 18: 75-84.

SOLBRIG, O. T. 1966. The South American species of Gutierrezia. Contr. Gray Herb. 197: 3-42.

SPEGAZZINI, C. 1897. Plantae Patagoniae Australis. Revista Fac. Agron. Univ. Nac. La Plata. 3: 485-589.

SUH, Y. \& B. B. SIMPSON. 1990. Phylogenetic analysis of chloroplast DNA in North American Gutierrezia and related genera (Asteraceae: Astereae). Syst. Bot. 660-670.

ZULOAGA, F. O, MORRONE, O. \& M. J. BELGRANO. (eds.). 2008. Catálogo de las Plantas Vasculares del Cono Sur (Argentina, Sur de Brasil, Chile, Paraguay y Uruguay. Vol.2. Monographs in Systematic Botany from the Missouri Botanical Garden, St. Louis. 